\title{
SOCIOECONOMIC STATUS AND STUDENT ACHIEVEMENT IN PRIMARY SCHOOL MATHEMATICS: A CASE STUDY OF TWO NEW ZEALAND SCHOOLS
}

\author{
Elizabeth Jennifer Harrison
}

A thesis submitted to the Victoria University of Wellington in fulfilment of the requirements for the degree of

Master of Education

Victoria University of Wellington

2016 


\section{Abstract}

Existing research consistently identifies large differences in mathematics achievement between students from high and low socioeconomic status backgrounds. The link between socioeconomic status and student achievement has been repeatedly acknowledged throughout the literature, but reasons for this link are not yet fully understood. This study builds on existing international research, which identifies a large number of potential key influences for the disparity in mathematics achievement. The aim of this study was to identify which of the potentially key influences were possibly influencing student mathematics achievement in a high and a low decile New Zealand primary school, thereby suggesting ways to improve student mathematics achievement in the low decile school.

Often, changes within education, including in many intervention programmes, are generic, made without identifying the specific needs of an individual school and its students. The tools developed during this research were designed to be used in schools, allowing evidence-based needs to be identified, and any changes made to be targeted at the specific needs of the school and its students.

This research was conceived within a qualitative paradigm, and followed a collective case study design, focusing on two case schools, a high decile school (Pīwakawaka School), and a low decile school (Whio School). Data were collected through classroom observations, archival records, interviews, questionnaires, and physical artefacts, using tools specifically designed for this study. The data were analysed using grounded theory, allowing theories to emerge from the data.

The data collected from each school were compared and two theories emerged. The first theory is that students in the high decile school appeared to be doing a greater amount of mathematics than students in the low decile school. The second theory is that students in the high decile school appeared to have more opportunities to learn new mathematics than students in the low decile school. Additionally, the findings suggested that, due to the complex nature of teaching, there was more than one key influence on student mathematics achievement contributing to each of these emergent theories.

This research suggests that teachers at Whio School may be able to improve student achievement in mathematics by increasing both the amount of mathematics students interact with and the number of opportunities to learn new mathematics their students receive. 


\section{Table of Contents}

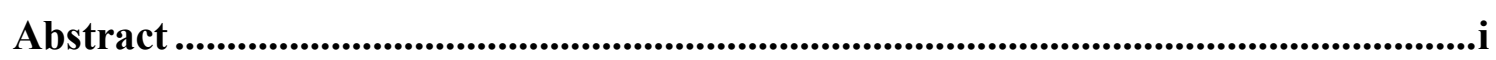

Acknowledgements ............................................................................................................................vii

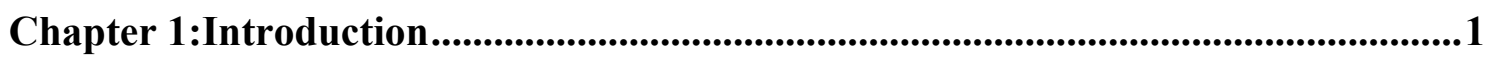

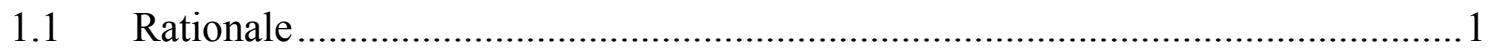

1.2 Family Socioeconomic Status and School Decile Rating ................................2

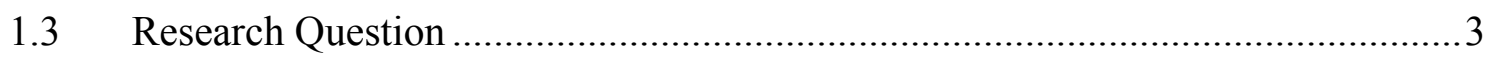

1.4 Potential Influences on Student Achievement .................................................

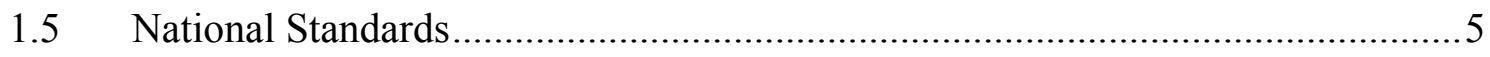

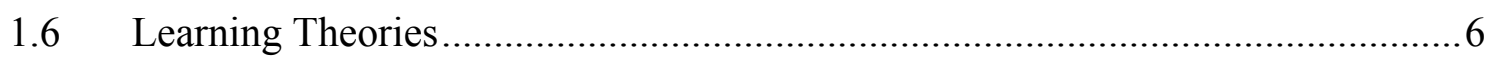

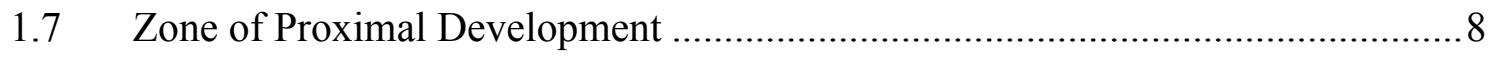

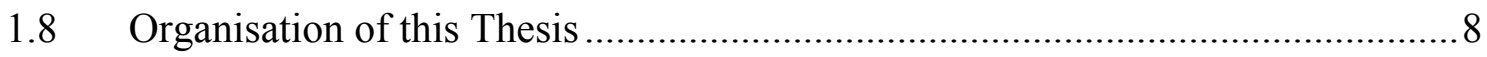

Chapter 2: Literature Review .........................................................................9

2.1 Teacher-based Influences on Mathematics Achievement …............................. 10

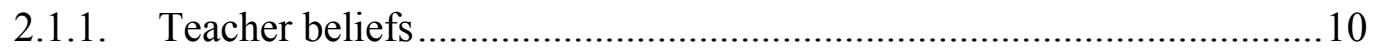

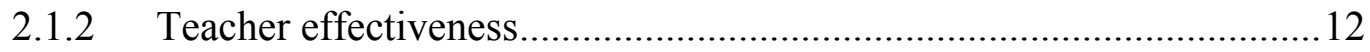

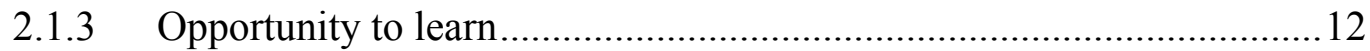

2.1.4 Level of challenge provided by mathematics tasks ............................13

2.1.5 Use of formative assessment for feedback and goal setting ................. 14

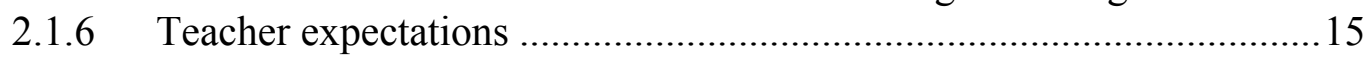

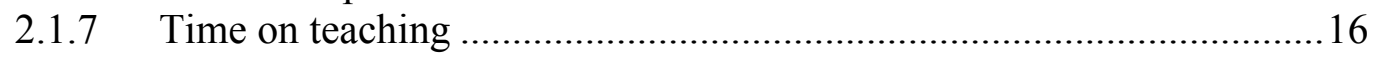

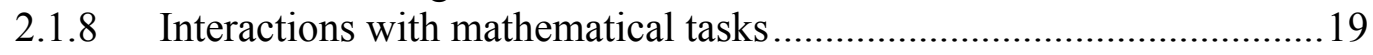

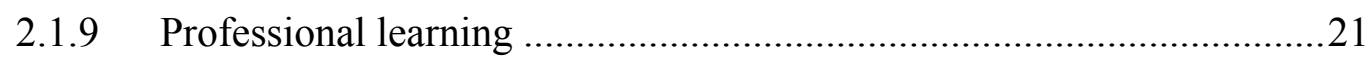

2.2 Student-based Influences on Mathematics Achievement ....................................22

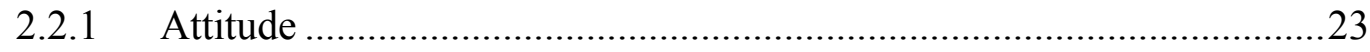

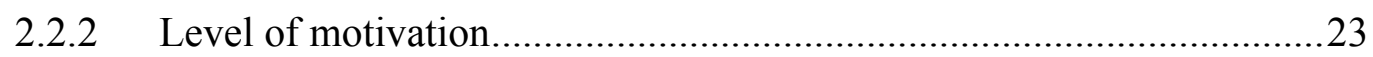

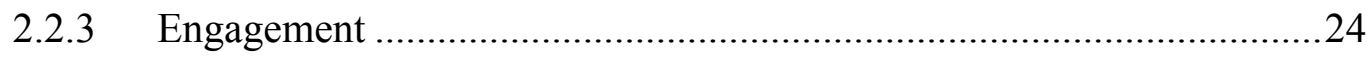

2.3 School and Home-based Influences on Mathematics Achievement ..................25

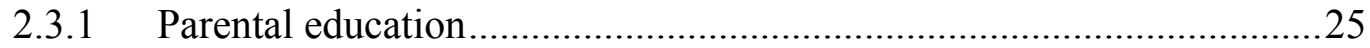

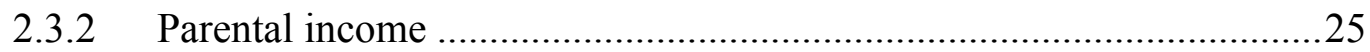

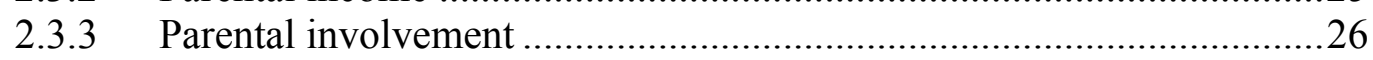

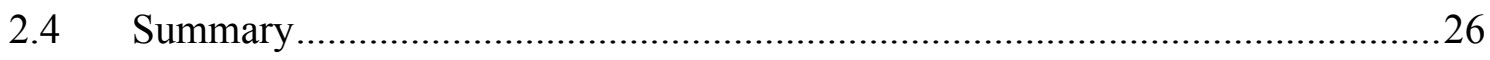

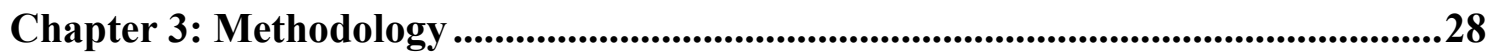

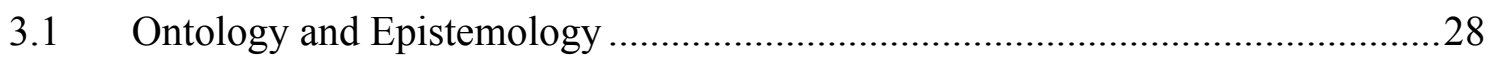

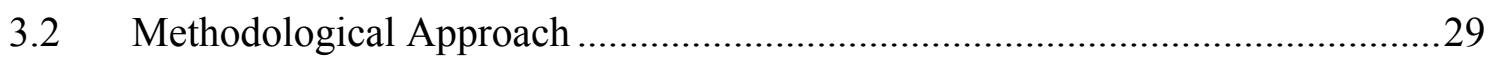

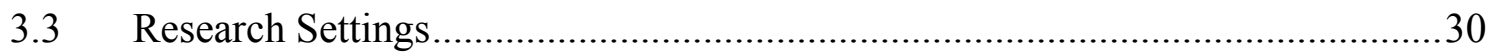

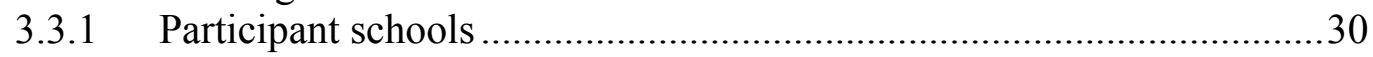

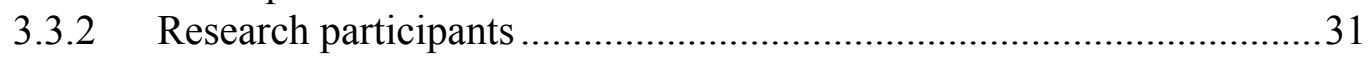

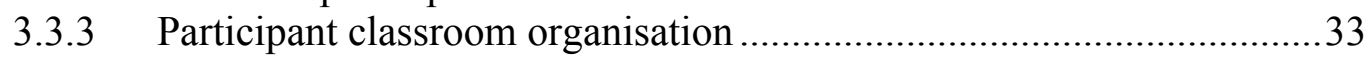




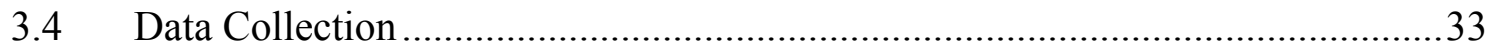

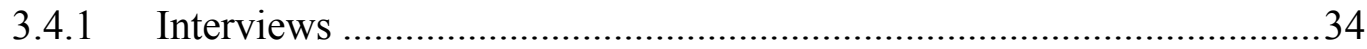

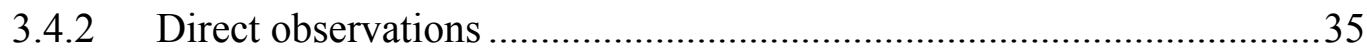

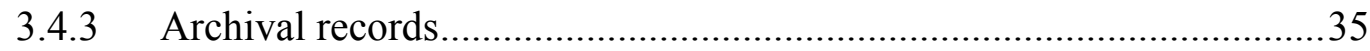

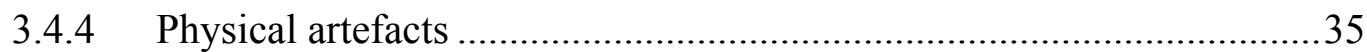

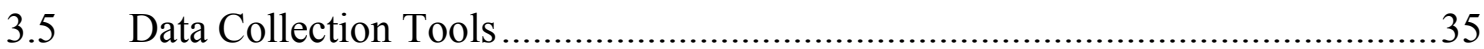

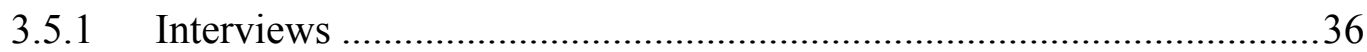

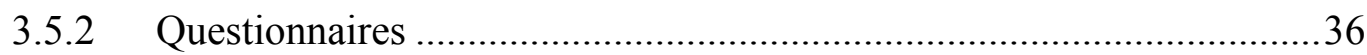

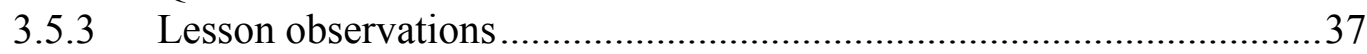

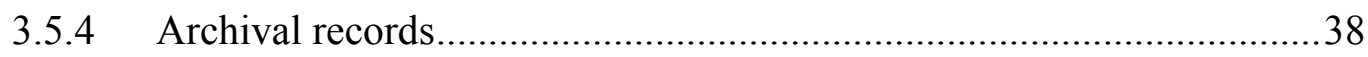

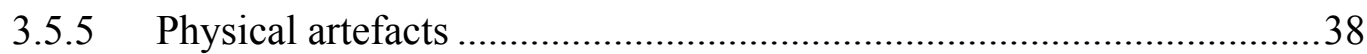

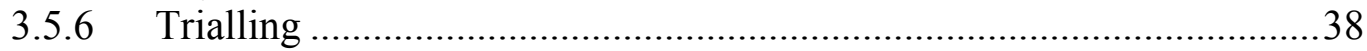

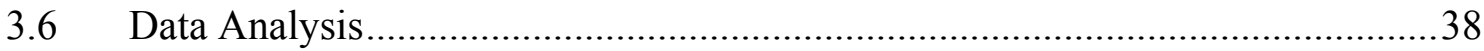

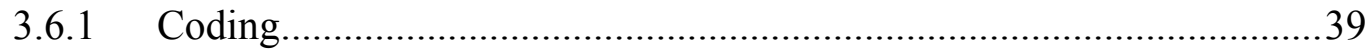

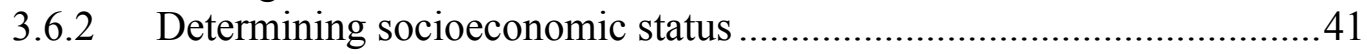

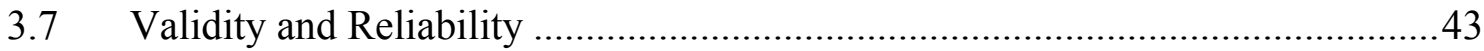

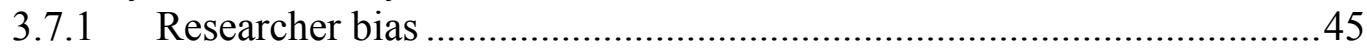

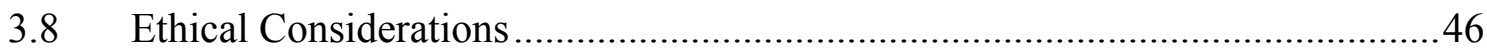

Chapter 4: The Amount of Mathematics Undertaken.............................................47

4.1 A Model for Teacher-Student-Mathematics Interactions .................................48

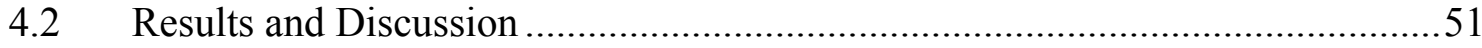

4.2.1 The use of mathematical interactions ..............................................51

4.2.2 Time on mathematics in each participant classroom ............................54

4.2.3 Time on mathematics in each school ..................................................56

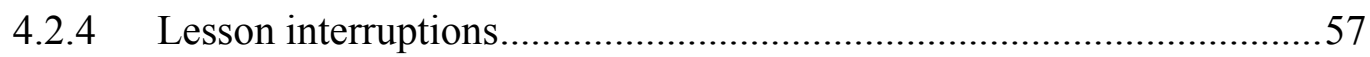

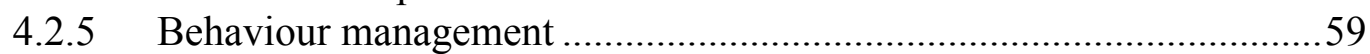

4.2.6 Classroom mathematics tasks and interactions...................................60

4.2.7 Home mathematics interactions.......................................................6 67

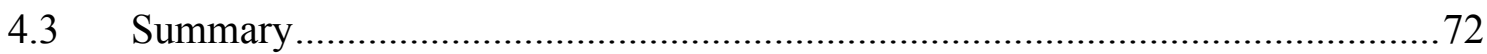

Chapter 5: Opportunity for Learning .......................................................................73

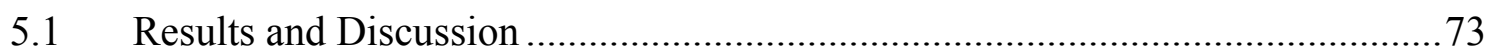

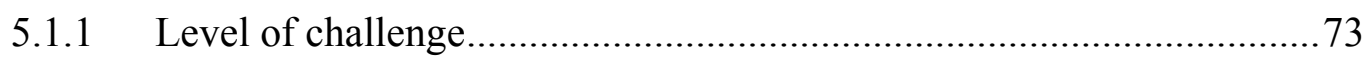

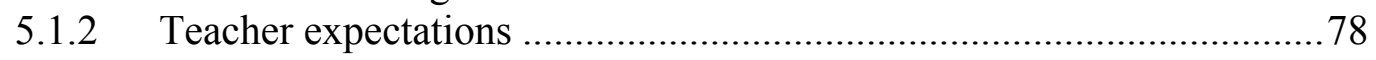

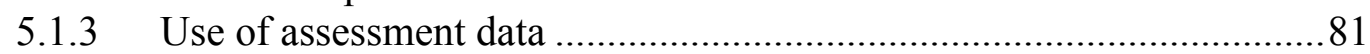

5.1.4 Opportunity to do mathematics at home..............................................8 86

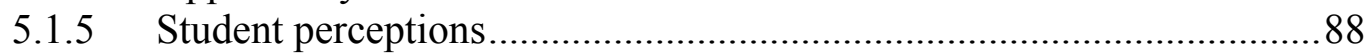

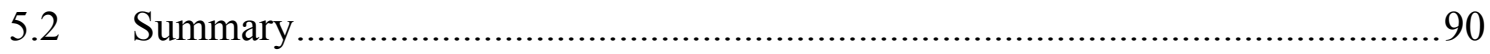

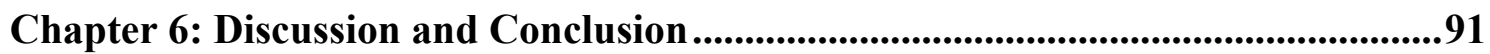

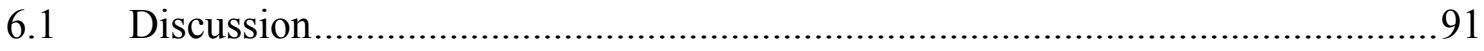

6.1.1 A model for teacher-student-mathematics interactions ........................91

6.1.2 A model for working in the accessible .............................................92

6.1.3 The amount of mathematics undertaken ........................................... 92

6.1.4 Opportunities to learn ................................................................... 93 


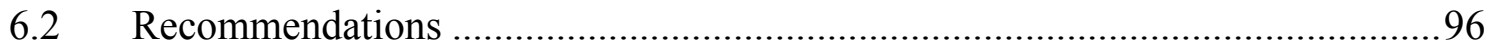

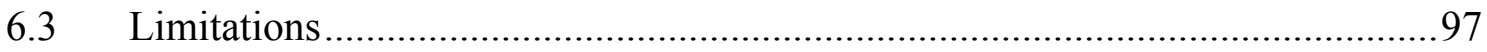

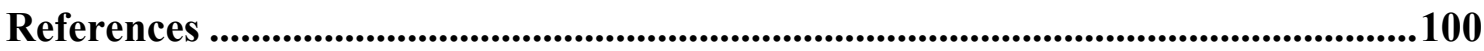

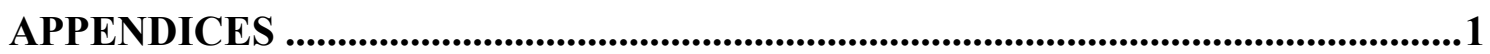

Appendix A Influences on Student Achievement / Data Gathering Tools ..................2

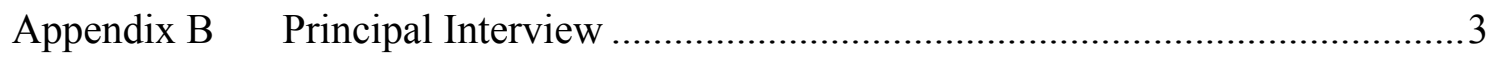

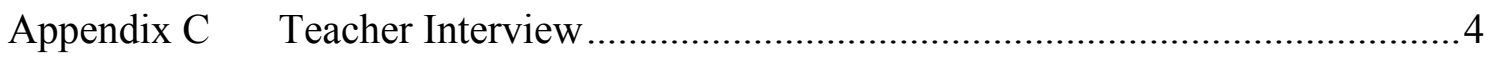

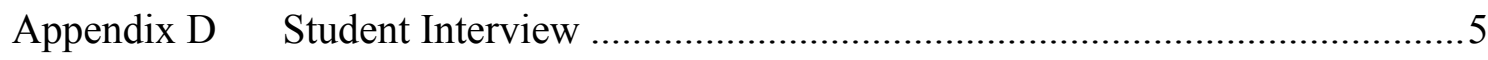

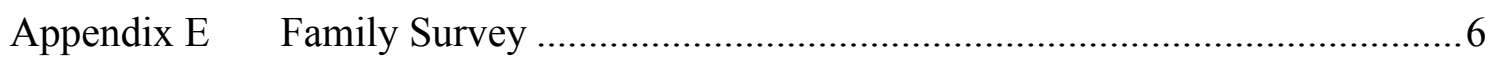

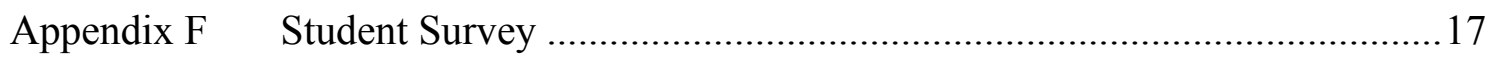

Appendix G Physical Artefacts Checklist ..........................................................21

Appendix H Master List of Codes Used Throughout the Research..........................22

Appendix I Types of Mathematics Activities and Interactions ...............................24

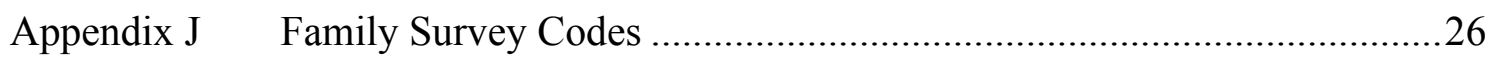

Appendix K Example of an Ethics Information Sheet.............................................27

Appendix L Example of an Ethics Consent Form .................................................29

Appendix M Stage 5 Mathematics Poster (MoE, 2008a) .......................................... 30

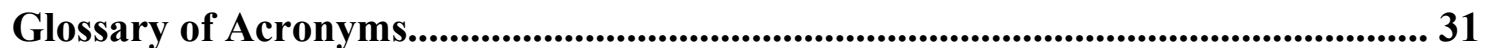




\section{List of Tables}

Table 1.1 Learning Theories, Teaching Beliefs and Teaching Styles ..........................

Table 2.1: Key Possible Influences on Student Achievement .......................................

Table 2.2: Definitions for Time on Teaching ........................................................... 17

Table 3.1: Pīwakawaka and Whio School Composition Data......................................... 31

Table 3.2 Organisation of Mathematics Lessons in Participant Classrooms ................33

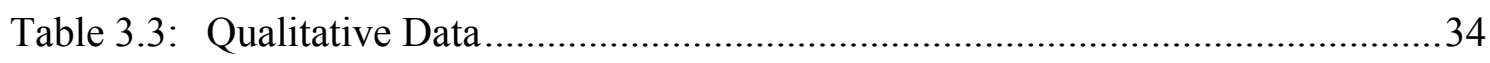

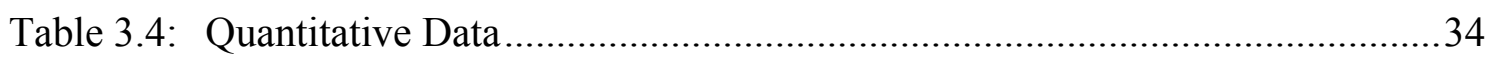

Table 3.5: Potential Influences on Student Achievement Addressed in Interviews......36

Table 3.6: Family SES of students at Pīwakawaka and Whio Schools .........................43

Table 4.1: A Comparison between Schools of the Use of Teaching Time....................54

Table 4.2: Use of Allocated Mathematics Time ........................................................57

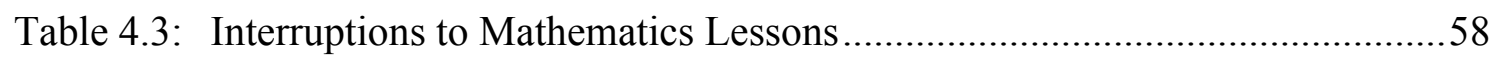

Table 4.4: Number of Behaviour Management Events ..............................................59

Table 4.5: Summary of Types of Mathematics Tasks and Interactions by School .......60

Table 4.6: Summary of Types of Mathematics Activities and Interactions by Teacher61

Table 4.7: Frequency of doing Mathematics Homework with a Parent .......................68

Table 4.8: Average Time Spent on All Homework with a Parent Each Week .............69

Table 4.9: Percentage of Students who Enjoy Mathematics at Home............................ 70

Table 4.10: Percentage of Students with Parents who Help with Mathematics at Home 71

Table 4.11: Percentage of Students who Play Mathematics Games at Home ..................71

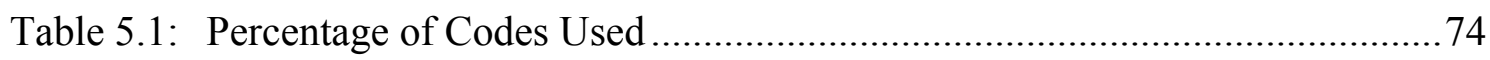

Table 5.2: Repetition Events within each Participant Classroom...................................77

Table 5.3: Percentage of Students with Materials Available at Home to Support

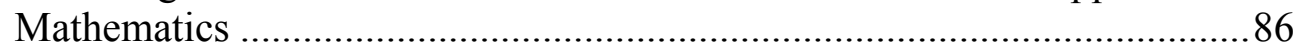

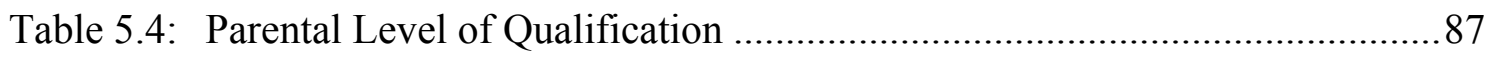

Table 5.5: Income Level Compared with National Standard Levels............................87

Table 6.1: A Summary of the Identified Possible Influences on the Amount of Mathematics Undertaken.

Table 6.2: A Summary of the Identified Possible Influences on Opportunities to Learn94 


\section{List of Figures}

Figure 1.1: Potential Influences on Student Achievement ............................................5

Figure 1.2: The ZPD in Relation to Student Knowledge ............................................. 8

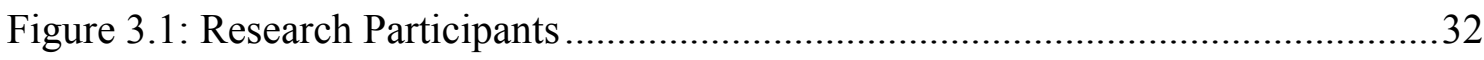

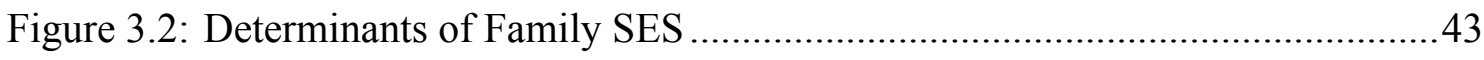

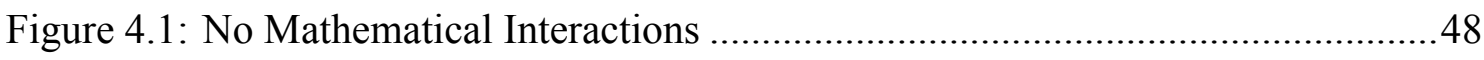

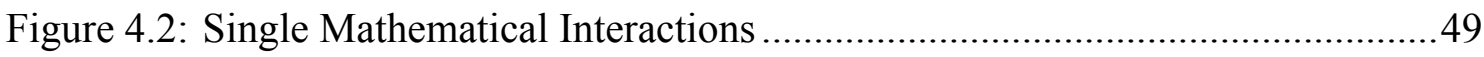

Figure 4.3: Intermittent Mathematical Interactions .................................................50

Figure 4.4: Complete Mathematical Interactions .........................................................50

Figure 4.5: Group Mathematical Interactions ............................................................. 51

Figure 6.1: Possible Influences on Student Achievement............................................ 95 


\section{Acknowledgements}

There are many people I would like to thank for the support they have given me, both personally and professionally, throughout this study.

I would like to express my greatest thanks to the two principals, along with their six teachers, students, and families, who welcomed me into their schools and classrooms. Thank you for your support, time, and enthusiasm, without you this thesis would not have been possible.

I would also like to thank my supervisors Dr. Michael Drake and Dr. Sandi McCutcheon. Thank you for asking those difficult questions, for guiding me, and for giving so much time and commitment to my study; it is appreciated beyond words.

I would like to express my gratitude to both the Ministry of Education and Victoria University of Wellington for the scholarships they provided, which allowed me to focus solely on this study.

I would like to thank Shirley and the Greenacres School Board of Trustees for encouraging my study and supporting my application for study leave.

I would also like to thank Susan Kaiser for taking the time to read through and check for any errors that I made.

Thank you to all my family. To Mum, thank you for the endless reading. To Zofia and Hugh, thank you for the use of your chair. To Lindsey and Amanda, thank you for asking questions and listening.

To all my friends, and colleagues - thank you for listening to me, for supporting me, and showing interest. To Jane, Julie, Saul, Phil, Miriam, Paul, Mary, Kristina, Stacey, Tabitha - thank you. To our Kim, without you none of this would have happened - thank you.

Simon, thank you for everything. Thank you for encouraging me, and giving me the time to do this. Thank you for believing in me, and for listening when I was struggling. Thank you for the coffee and toasties. Thank you. 


\section{Chapter 1: Introduction}

This chapter begins with the rationale for the study in Section 1.1, and is followed by a discussion of socioeconomic status, both in relation to families and New Zealand schools in Section 1.2. The research question used for this study is introduced in Section 1.3, and Section 1.4 presents the main factors identified in the literature considered to have the potential to be influencing student achievement, and discusses some potential influences that were not included. Sections 1.5 to 1.7 introduce the key concepts that thread throughout this research: national standards; learning theories; and Vygotsky's (1978) zone of proximal development. The organisation of the thesis is outlined in Section 1.8. A glossary of acronyms used throughout this research can be found on the final page.

\subsection{Rationale}

As children, our mathematical skills are key to our future job and earning potential (Fuchs et al., 2009). However, results from Trends in International Mathematics and Science Study 2010/11 (TIMSS) found that the average achievement in mathematics for New Zealand year 5 students was below that of the same cohort in the 12 countries participating in TIMSS 2003, 2007, and 2011 (Caygill, Kirkham, \& Marshall, 2013), a trend also found in earlier studies (Garden, 1997). In addition, research has also identified that socioeconomic status (SES) plays a significant role in students' mathematics achievement (Baker, Goesling, \& LeTendre, 2002; Caygill et al., 2013; Crooks, Smith, \& Flockton, 2010; Sirin, 2005; White, 1982), a finding that has important equity issues for New Zealand as the majority of our Māori and Pasifika students can be found in low decile schools. However, throughout the literature there is disagreement about how SES influences achievement in mathematics; even though a positive relationship between school SES and achievement has been repeatedly found (Boonen et al., 2014; Coleman, 1966).

One consequence of such studies has been a continual drive to improve mathematics achievement in New Zealand schools. The literature suggests many ways this can be done, for example, Accelerating Learning in Mathematics (Ministry of Education (MoE), 2010), and much research indicates that improving levels of mathematics 
achievement is an important focus (Anthony \& Walshaw, 2007). However, the lack of an evidence base from which to work could mean that much of this effort may not be targeted at the most effective of possible changes. If differences in the potential influences on student achievement can be identified within the context of an individual school, then it may be possible for teachers to use evidence specific to their context to change classroom practice, and reduce the gap in student achievement in mathematics between high and low decile schools more generally. This research seeks to use tools specifically designed for this study to identify evidence of particular factors that may be contributing to the disparity in student mathematics achievement between a high and a low decile school. It is hoped that the data gathering tools designed in this research may be useful in seeking to identify influences on student achievement at play in other schools.

\subsection{Family Socioeconomic Status and School Decile Rating}

SES is a broad term, which can be defined and measured in many different ways. According to Hackman, Farah, and Meaney (2010):

\footnotetext{
SES is a complex construct that is based on household income, material resources, education and occupation, as well as related neighbourhood and family characteristics, such as exposure to violence and toxins, parental care and provision of a cognitively stimulating environment. (Hackman, Farah, \& Meaney, p. 651)
}

Hackman et al.'s (2010) broad definition of SES presents researchers with the problem of narrowing family SES down to something that can be practically measured. For example, measures of family SES are as varied as family structure (Pong, Dronkers, \& Hampden-Thompson, 2003), receivers of regular lunch versus free or reduced price lunch (Parke \& Kanyongo, 2012), or numbers of books at home (Ismail \& Awang, 2008). White (1982) has argued that many researchers incorrectly define family SES, meaning that a strong relationship between family SES and achievement may be found, when this may not have been the case. This potential problem was kept in mind when reading the literature. There is general agreement amongst researchers that family SES can be measured using four components:

- parental income;

- parental education;

- parental occupation; and 
- home resources (Blömeke, Suhl, Kaiser, \& Döhrmann, 2012; Van Ewijk \& Sleegers, 2010).

There is also agreement that family SES should be measured using either one, three, or four of these components, but not two as this gives "unreliable approximations of SES" (Van Ewijk \& Sleegers, 2010, p. 138). Furthermore, if only one measure is used, it should not be parental income (Van Ewijk \& Sleegers, 2010). Blömeke et al. (2012) suggested measuring family SES through "the use of a composite or the use of a single indicator as...dichotomies have been regarded as unreliable" (p. 47).

In New Zealand, state and state-integrated schools are given a decile rating by the MoE. The decile rating system is the way in which SES is operationalised within the New Zealand education system. The decile rating indicates the proportion of students attending a school who come from low socioeconomic backgrounds (MoE, 2014). Decile 1 schools have the highest number of students from low SES backgrounds whilst decile 10 schools have the lowest number of these students (MoE, 2014). Additionally, the amount of government funding a school receives is determined by its decile rating, meaning that the lower the decile rating of a school, the higher the amount of government funding it receives (MoE, 2014). TIMSS 2010/2011 (Caygill et al., 2013) showed high levels of achievement by New Zealand students were more common in high decile schools than in low decile schools, while the range of achievement between students in high and low decile schools was the third highest of the 63 countries that participated. The New Zealand National Education Monitoring Project (NEMP), which provides information on educational outcomes in New Zealand, also found "statistically significant differences in the performance of students from low, medium and high decile schools ... at year 4 level" (Crooks et al., 2010, p. 4).

\subsection{Research Question}

The purpose of this study was to explore which of the potential influences on student achievement, identified within the literature, seemed to afford or constrain mathematics achievement both within, and between, two New Zealand primary schools. The guiding research question for this study was:

What factors may account for differing levels of students' mathematical achievement in a high and a low decile primary school in New Zealand? 


\subsection{Potential Influences on Student Achievement}

Student achievement is the main purpose of teaching (MoE, 2007). Throughout the extensive literature on mathematics teaching and improving student achievement, many different influences have been identified. When preparing for this research, at least 65 different potential influences were identified, including school leadership, teacher beliefs, collective teacher efficacy, parental education, student prior knowledge, and student self-efficacy. Not all the identified potential influences were considered to be of equal importance (Hattie, 2009); therefore, those influences identified in the literature as having a greater influence on student achievement became the focus of this study.

To help structure this research, a decision was made to use Hattie (2009) as a lens through which these potential key influences could be viewed. After conducting a meta-analysis of the research on factors influencing student achievement, Hattie (2009) found that the greatest effect on student achievement was the teacher with the student, the school, and the home influencing achievement to lesser extents. Figure 1.1 shows how the potential influences on student achievement identified in the literature for this study fit within Hattie's (2009) four aspects of influence on achievement (teacher, student, school, and home). Some potential influences on student achievement identified in Figure 1.1 could be at play across more than one aspect (teacher, student, school, and home), for example, family SES may be both a student-based influence and a homebased influence. As both the teacher and the student have been identified as having the largest effect on student achievement, any influences that fitted into multiple aspects were allocated to either the teacher or the student aspects. The tools used to gather data for this research were designed to specifically focus on those potential influences identified in Figure 1.1 (Section 3.5 and Appendix A).

It is important to note that some literature includes gender, ethnicity, and race as factors that potentially influence student achievement. This study did not consider these factors as influencing student achievement in mathematics. This study takes the stance that differences in levels of achievement between students of different ethnicities, genders, or races are not caused by belonging to a certain group, but are instead brought about by other factors, specifically by those identified in Figure 1.1. 


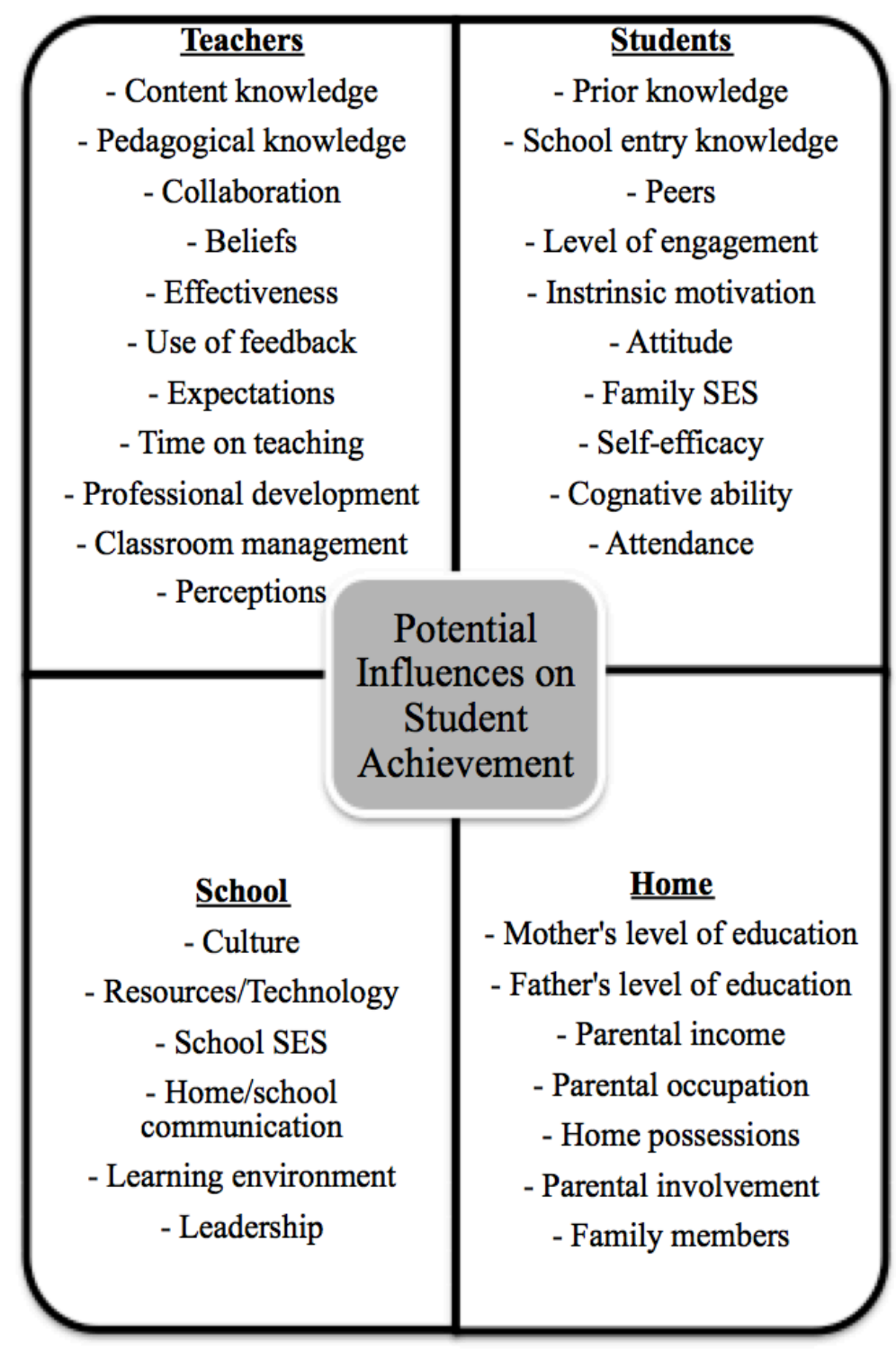

Figure 1.1: Potential Influences on Student Achievement

\subsection{National Standards}

In New Zealand primary schools, student achievement in mathematics is measured against the national standards (MoE, 2012). "The standards for mathematics are statements about what students should know and be able to do in order to meet the demands of The New Zealand Curriculum" (MoE, 2009). The level of achievement a student should reach after each school year, up to the end of year 8 (MoE, 2009), is defined by the national standards. Teachers are required to make overall teacher 
judgements (OTJs) about a student's level of achievement in relation to the standards using data gathered from a range of sources (MoE, 2011). For the purposes of an OTJ, a student is working:

- 'above' if they are working a year or more above their current year level;

- 'at' if they are working at their current year level;

- 'below' if they are working less than a year below their current year level;

- 'well below' if they are working more than a year below their current year level (MoE, 2011).

This standardisation of measures of student achievement in mathematics across New Zealand meant that it was possible to collect comparable mathematics achievement data from both participant schools, and to compare students' family SES with students' mathematics achievement.

\subsection{Learning Theories}

Within education there are many different learning theories, including social cognitive theory, constructivism, assessment for learning, social development theory, and behaviourism. Broadly speaking, learning theories can be categorised as being based in either a traditional or constructivist teaching style. Whilst the concept of constructivism is possibly the oldest of the learning theories (Barker \& Bunting, 2016), it has become the dominant learning theory in more recent times (Pelech \& Pieper, 2010), and the literature promotes a constructivist style of teaching over a traditional style. Therefore, there is little modern literature discussing the practical use of a traditional style in the classroom. Research has shown that teachers develop their beliefs about teaching through their own experience as a learner (Thompson, 1984). This would suggest that a teacher who experienced education in a traditional classroom may have formed beliefs based on a behaviourist learning theory (see Table 1.1). Likewise, teachers who experienced a constructivist teaching style as a student may believe in a social constructivist or sociocultural learning theory. However, research suggests that most teachers hold beliefs that draw from both traditional and constructivist teaching styles (Askew, Brown, Rhodes, Wiliam, \& Johnson, 1997). Table 1.1 shows three learning theories that were considered important in this study as they exemplify points on a scale which has a behaviourist style at one end and a social constructivist style at the other, and are relevant in the New Zealand context. 
Table 1.1 Learning Theories, Teaching Beliefs and Teaching Styles

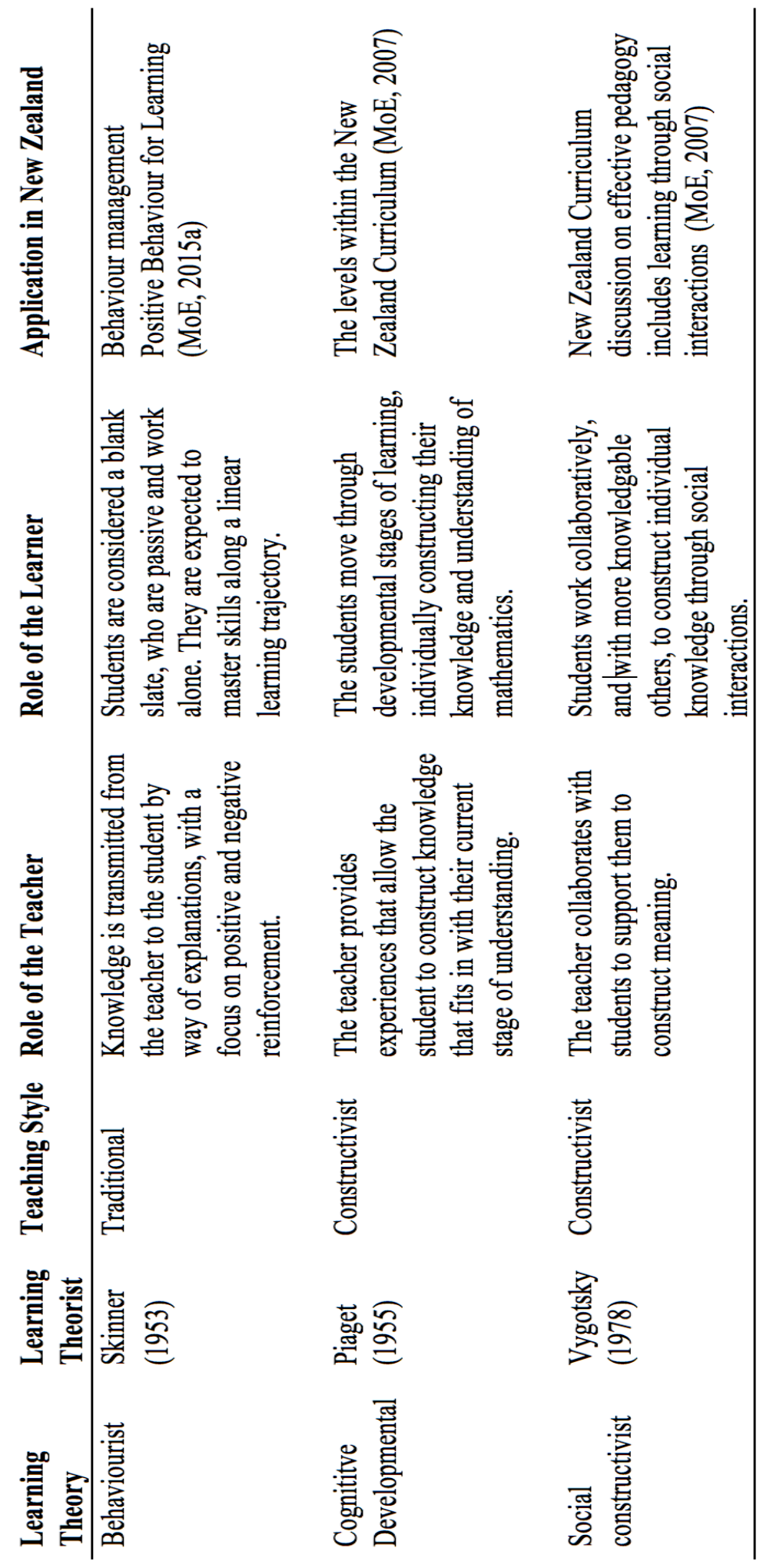




\subsection{Zone of Proximal Development}

The zone of proximal development (ZPD) derives from what is sometimes called social constructivism and at others sociocultural theory and was developed by Vygotsky. It is:

...the distance between the actual developmental level as determined by independent problem solving and the level of potential development as determined through problem solving under adult guidance, or in collaboration with more capable peers. (Vygotsky, 1978, p. 86)

Figure 1.2 shows a ladder of knowledge, with what a student already knows (existing knowledge) at the bottom. The ZPD is the area between a student's existing knowledge and inaccessible knowledge, i.e., knowledge that can be learned with support (accessible knowledge). Scaffold is the term used to describe the support needed to move through the ZPD, building the understanding needed to complete the task independently (Bruner, 1996). At the top of the ladder lies knowledge which potentially is the final goal, but is currently beyond a student's grasp, even with support (inaccessible knowledge).

\begin{tabular}{|c|}
\hline Inaccessible knowledge \\
\hline Accessible knowledge in the \\
ZPD \\
\hline Existing knowledge
\end{tabular}

Figure 1.2: The ZPD in Relation to Student Knowledge

\subsection{Organisation of this Thesis}

This chapter has introduced key potential influences (identified from the literature) on student mathematics achievement, and the main concepts used through the study. Chapter 2 discusses the relevant literature for the study, the possible influences (identified from the data analysis) on student achievement in mathematics. The methodology, including research setting, data collection tools, data collection, and analysis are in Chapter 3. Chapter 4 presents both the results and discussion around the amount of mathematics students undertake and Chapter 5 does the same for opportunities to learn. A discussion of the results, along with a summary of the results, the limitations and implications of the study, are in Chapter 6. 


\section{Chapter 2: Literature Review}

The literature on factors influencing student achievement is extensive. The literature on factors influencing student achievement in mathematics is somewhat smaller, but still sizeable. The volume of literature can be further reduced by focusing on the influence of SES on students' mathematics achievement. Due to the large volume of literature concerning the many factors potentially influencing student achievement, this chapter will focus solely on those areas that have emerged during the data analysis as having a possible influence in the schools studied as part of this research, shown in Table 2.1. As a result, the depth of literature used was shallower than would be optimal.

It should be noted that the data collection tools used in this research were designed to consider all the potential influences on student achievement identified in Figure 1.1 (Section 3.5). In Hattie's (2009) locus of influence (Section 1.4), home and school were identified as two separate aspects that may potentially influence student achievement. However, when the data were analysed, these two aspects seemed to contain only a few possible influences on student achievement, and have therefore been combined in this chapter.

Table 2.1: Key Possible Influences on Student Achievement

\begin{tabular}{lll}
\hline Teacher & Student & Home/School \\
\hline Beliefs & Attitude & Parental education \\
Effectiveness & Level of engagement & Parental income \\
Opportunity to learn & Motivation & Parental involvement \\
Level of challenge & & \\
Use of formative assessment & & \\
Expectations & & \\
Time on teaching & & \\
Interactions with mathematical tasks & & \\
Professional development & & \\
\hline
\end{tabular}

Due to the scope of this research, and the number of possible influences identified, each possible influence on student achievement identified in this study is briefly discussed independently in the following sections. Each section begins with a focus on teacher beliefs, followed by a discussion of existing literature, and finishes by considering SES in relation to the possible influence on student achievement. However, it should be remembered that in the complex environment of teaching and learning, 
these possible influences on student achievement rarely work independently, but are intertwined and influence each other.

\subsection{Teacher-based Influences on Mathematics Achievement}

Research indicates teaching quality has a large influence on student achievement (Ferguson, 1991; Wiliam, 2011). Due to the complex nature of classroom practice, teaching quality is difficult to quantify (Ball \& Rowan, 2004; Clayton, 2011). A range of teacher-based influences, briefly discussed in the following sections, are identified in the literature as contributing to teaching quality, including:

- teacher beliefs (Janosz, Chouinard, \& Archambault, 2012);

- teacher effectiveness (McDonald, Polnick, \& Robles-Pina, 2013);

- opportunity to learn provided by the teacher (Hiebert \& Grouws, 2007);

- level of challenge experienced by students (Warshauer, 2015);

- teacher use of formative assessment for feedback (Blömeke \& Klein, 2013; Hattie \& Timperley, 2007);

- teacher expectations (Bonner, 2014; Brophy, 1983; Rosenthal \& Jacobson, 1968);

- time spent teaching (Berliner, 1990; Millot \& Lane, 2002; Walberg, Niemiec, \& Frederick, 1994);

- the nature of student interactions with teacher-set mathematical tasks (NCTM, 2000); and

- teacher professional learning opportunities (Timperley, Wilson, Barrar, \& Fung, 2007).

\subsubsection{Teacher beliefs}

Teacher beliefs about the nature of mathematics and how students learn it thread through every aspect of teaching and learning, and influence all the factors contributing to teaching quality listed above. Central to student achievement as they "play a role in teachers' decisions, judgement and behaviour" (Woods, 1996, p. 192), teacher beliefs determine how students engage with learning and influence student self-efficacy (Janosz et al., 2012). However, there can be a mismatch between what a teacher says they believe and what is seen in their practice, as teacher practice may be influenced by both 
the realities of the classroom, (e.g., time, assessment requirements, resources), and their beliefs (Adam, 2012):

Our espoused theories are like the voice of an internalised coach but unless, while actually on the job, we habitually invite the coach to contribute, our theories will forever be tied to particular contexts and disembedded from our practice. (Barker \& Bunting, 2016, p. 30)

Teachers' beliefs about the nature of mathematics influence their ideas about what it is to be a mathematician (Ernest, 1989), the relationship between teaching and learning (Anthony \& Walshaw, 2007), and their teaching styles (Swan, 2005; Wilson, Cooney, \& Stinson, 2005), all of which influence student achievement. Teachers' beliefs about how students learn (Section 1.6) influence not only the type of tasks they give their students, but also the way in which they expect the student to learn from the task (Zevenbergen, Dole, \& Wright, 2004). When teachers hold traditional beliefs, they tend to teach isolated concepts (Van de Walle \& Lovin, 2006), develop instrumental understanding (Skemp, 2006), and expect their students to work alone (Adam, 2012). A traditional teaching style focuses on procedural skills, and teachers often discover that some students are consistently unable to apply a learned procedure in different contexts (Skemp, 2006). When a teacher perceives that a student cannot use the taught procedure, the teacher may lower their expectations for that student, assume that the student is not clever enough to do the mathematics asked of them, and give the student easier mathematics, thereby reducing the level of challenge experienced (Cobb, Wood, \& Yackel, 1996). Constructivist teachers focus on building students' conceptual understanding, and allow students to build knowledge together (Zevenbergen et al., 2004), develop relational understanding (Skemp, 2006), and build connections across the big ideas in mathematics (Van de Walle \& Lovin, 2006). This enables students to work collaboratively to develop mathematical understanding, and to apply their mathematical knowledge in a range of contexts (Van de Walle \& Lovin, 2006). When a teacher perceives that a student can do the mathematics asked of them, they may increase their expectations for that student, and increase the level of challenge the student experiences (Cobb et al., 1996).

Ottmar, Konold, Berry, Grissmer, and Cameron (2013) indicate that teacher beliefs about a student's SES background can influence their teaching style, with high SES students being more likely to be taught using a constructivist style, and low SES students being more likely to be taught using a traditional style. 


\subsubsection{Teacher effectiveness}

Effective teachers often have constructivist beliefs, and these beliefs are reflected in their practice (Education Review Office (ERO), 2014; McDonald et al., 2013; Woolley, Strutchens, Gilbert, \& Martin, 2010). McDonald et al. (2013) suggest that differences in teacher effectiveness may be one of the reasons for differences in student achievement in mathematics. The influence of highly effective teachers has been found to have a greater effect on student achievement in low decile schools (Nye, Konstantopoulos, \& Hedges, 2004). However, other research suggests that highly effective teachers may benefit all students equally, irrelevant of the decile of the school (Konstantopoulos \& Chung, 2011). This difference in findings could be because of the achievement gap between school deciles (Caygill et al., 2013), meaning students in low decile schools usually have more to learn (Nye et al., 2004). If levels of student achievement in low decile schools are to be increased, then teaching quality must also increase through the use of knowledge about what and how to teach most effectively (Parr \& Timperley, 2008).

\subsubsection{Opportunity to learn}

Teacher beliefs influence the types of opportunities to learn to which students have access (Van de Walle \& Lovin, 2006). The National Research Council (2001) suggested that "opportunity to learn is widely considered the single most important predictor of student achievement" (p. 334). This statement, however, raises the question of "What is an opportunity to learn?". Hiebert and Grouws (2007) identified a range of influences on opportunity to learn.

- The curriculum used. [In New Zealand this is guided by The New Zealand Curriculum (MoE, 2007)].

- Teacher emphasis on topics. Teachers may intentionally, or unintentionally, give more emphasis to a particular subject, or topic, thereby providing increased opportunities to learn that subject or topic (Schmidt, Cogan, \& Houang, 2011).

- Teacher emphasis on goals. When teachers set goals with students, opportunities to learn around those goals will increase (Parr \& Timperley, 2008) (Section 2.1.5).

- Teacher expectations (Section 2.1.6).

- Choice of tasks (Section 2.1.8). 
- Teacher questions (Section 2.1.8).

- Classroom discourse (Section 2.1.8).

Whilst exposure to content is vital in providing students with an opportunity to learn, Hiebert and Grouws (2007) suggest that other factors crucial to providing students with the opportunity to learn are prior knowledge, student engagement, and purpose of tasks. Anthony and Walshaw (2007) also write about the using tasks to provide opportunities to learn:

In the mathematics classroom, it is through tasks, more than any other way, that opportunities to learn are made available to students... The mathematical tasks with which learners engage determine not only what substance they learn, but how they come to think about, develop, use, and make sense of mathematics. (Anthony \& Walshaw, p. 94)

Students from low SES backgrounds may have less opportunity to learn when compared with students from high SES backgrounds due to having access to fewer resources (Hill \& Lubienski, 2007; White, 1982; Wylie, 2013), having parents with lower levels of qualifications (Wylie, 1999), and being taught using a traditional style (Ottmar et al., 2013). These reduced opportunities to learn may be influencing levels of student achievement.

\subsubsection{Level of challenge provided by mathematics tasks}

As Swan $(2005$, p. 3) posited, "teaching does not always result in learning". Teacher beliefs about what students can and cannot do influences the level of challenge students experience in mathematics lessons (Janosz et al., 2012; Ottmar et al., 2013) (Section 2.1.1).

Challenge, also described as productive struggle, is a key aspect in the effective teaching of mathematics (Warshauer, 2015). When teachers provide challenging tasks, along with prompts, or scaffolds that allow all students to access the task, students are being given increased opportunities to learn (Bruner, 1996; Sullivan, 2011; Sullivan, Mousley, \& Zevenbergen, 2006). When students are provided with opportunities to learn, they work in an area of accessible knowledge (Vygotsky, 1978) (Section 1.8). Hollingsworth, Lokan, and McRae (2003) suggest that students would benefit from more opportunities to learn, including being given open tasks that require high levels of thinking and discussion. 
Ottmar et al. (2013) write that it is teachers who decide the type of tasks their students work with. They go on to suggest that low SES students frequently receive closed tasks, which require low levels of challenge, and high SES students generally receive open tasks, which require high level thinking skills.

\subsubsection{Use of formative assessment for feedback and goal setting}

Teacher beliefs influence what and how mathematics is assessed (Adam, 2012). Traditional teachers tend to assess the accuracy of students' mathematical procedures, whereas constructivist teachers usually assess students' understanding and their ability to explain that understanding (Adam, 2012).

When teachers assess students' knowledge by talking and listening to their students, examining their students' work, and observing their students during teaching and learning, it is referred to as formative assessment (Alton-Lee, 2003; Finlayson, 2014; Swan, 2005). The use of formative assessment allows teachers to provide support, feedback, extension activities, and to set goals to meet individual needs (Cheeseman, Clarke, Roche, \& Wilson, 2013; Mousley, Sullivan, \& Zevenbergen, 2007; Sullivan, 2011).

Feedback has been identified by some as having a greater effect on achievement than teacher quality (Hattie, 2002a, 2009; Nguyen \& Griffin, 2010). However, for feedback to increase student achievement it should be feedback to teachers about what students can and cannot do (Hattie, 2009). Teachers can then use their knowledge about what their students can and cannot do to ensure that students are working in the area of accessible knowledge (Hattie \& Timperley, 2007). Hattie and Timperley suggest that both teachers and students should be asking three questions to support this:

1. What are my goals?

2. What progress am I making towards my goals?

3. What are my next steps?

In order to answer these questions, teachers must constantly use formative assessment to "gain as much information as possible in respect of what the student has achieved, what has not been achieved, and what the student requires to best facilitate further progress" (MoE, 2015b). When teachers address the three questions posed by Hattie and Timperley (2007), they are developing the knowledge to adapt their classroom programme to ensure that they are allowing their students to work within their individual area of accessible knowledge (Parr \& Timperley, 2008). Learning goals 
should then be developed with students based on results from formative assessment, as learning goals are more effective at increasing achievement when students are involved in constructing them (Alton-Lee, 2003; Hattie \& Timperley, 2007).

It has been suggested that students attending low decile schools are more likely to have less effective teachers (American Psychological Association, 2016; Bonner, 2014; Konstantopoulos \& Chung, 2011), and less effective teachers may not have the knowledge required to use formative assessment in the most effective way (Parr \& Timperley, 2008). This suggests that students in low decile schools may not benefit from the use of formative assessment to inform feedback and goals as much as students in high decile schools.

\subsubsection{Teacher expectations}

Teachers' beliefs influence their expectations of students (Janosz et al., 2012). In 1968, Rosenthal and Jacobson conducted an experiment which found a self-fulfilling prophecy regarding teacher expectations. Students whom teachers believed would make the most progress, did make the most progress, and those who were believed to be less capable, had lower levels of achievement.

Teachers have two different sets of expectations: those for the whole class and those for individuals (Fraser, 2016). Whole class expectations include behaving in an acceptable manner, and respecting people and the school environment, whilst a constructivist teacher will base individual expectations on their use of formative assessment to know what a student is currently capable of, and the next learning step for that student (Fraser, 2016). Rubie-Davies, Peterson, Sibley, and Rosenthal (2015) suggest that when teachers use formative assessment to set goals for students they are indicating that they have high expectations for their students. When teachers have high expectations, students perceive this (Anthony \& Walshaw, 2007; Woolley et al., 2010), and are more likely to have higher levels of engagement (Janosz et al., 2012; Sullivan, 2011), and achievement (Megowan-Romanowicz, Middleton, Ganesh, \& Joanou, 2013; Petty, Wang, \& Harbaugh, 2013; Robinson, 2013). One of the ways teachers indicate their expectations is through the amount of wait time they give (Rubie-Davies et al., 2015; Swan, 2005). Another way teachers may indicate their expectations is through the use of challenging tasks that require high level thinking skills and persistence (Blatchford, Hallam, Kutnick, \& Creech, 2008; Clarke, Roche, Cheeseman, \& Sullivan, 2014; Doyle, 1988; Warshauer, 2015; Williams, 2002). 
Teachers in high decile schools have been shown to have higher expectations than teachers in low decile schools (Janosz et al., 2012), with some teachers assuming that students from low SES backgrounds will have lower levels of prior knowledge and lower levels of achievement (Torres \& Moran, 2014). Sorhagen (2013) suggests the negative impact of low teacher expectations on low SES students has been found to have a greater impact on student achievement than the positive impact of high teacher expectations on high SES students. She adds that whilst research has not yet suggested why this may be, one explanation could be that the different ways in which teachers treat students from different SES backgrounds influence student self-efficacy and motivation.

\subsubsection{Time on teaching}

Teacher beliefs influence both how much time is allocated to mathematics, and how that time is used (Leonard, 2001a; Phelps, Corey, DeMonte, Harrison, \& Ball, 2012). Abadzi (2009) suggested that "precious class time may be spent on handing out textbooks, doing small chores, or copying from the blackboard [and] teachers may interact with only a few students who perform and neglect the rest" (p. 2).

In the past, there has been a large amount of research into the relationship between the time spent on teaching and student achievement. However, the majority of it is dated between 1970 and 1990 and, to a lesser degree, to 2000. Berliner (1990) suggested one of the reasons for this may be that "the concept of instructional time [is] intellectually unexciting, so commonsensical, and of such obvious importance that it only leads to trivial findings and findings that have the status of truisms" (p. 1). However, without time being allocated to teaching, learning cannot take place (Berliner, 1990; Fontes, Kellaghan, \& O'Brien, 1981).

Throughout the literature, various terms describe the ways in which time is used in teaching (Table 2.2). Terms relevant to this study are found in Table 2.2 and are defined as follows: 
Table 2.2: Definitions for Time on Teaching

\begin{tabular}{|c|c|c|}
\hline Concept & Literature & Definition \\
\hline $\begin{array}{l}\text { Allocated } \\
\text { time }\end{array}$ & $\begin{array}{l}\text { (Berliner, 1990; Cotton, 1990; Moore } \\
\text { \& Funkhouser, 1990; Phelps et al., } \\
\text { 2012; Walberg, 1988; Walberg et al., } \\
\text { 1994) }\end{array}$ & $\begin{array}{l}\text { The time given to teaching } \\
\text { mathematics within a school }\end{array}$ \\
\hline $\begin{array}{l}\text { Instructional } \\
\text { time }\end{array}$ & (Berliner, 1990) & $\begin{array}{l}\text { An overarching term used for the total } \\
\text { time spent on teaching mathematics }\end{array}$ \\
\hline Engaged time & $\begin{array}{l}\text { (Abadzi, 2009; Berliner, 1990; } \\
\text { Cotton, 1990; Moore \& Funkhouser, } \\
\text { 1990; Walberg, 1988; Walberg et al., } \\
\text { 1994) }\end{array}$ & $\begin{array}{l}\text { The time during which students appear } \\
\text { to be involved in general learning of } \\
\text { mathematics }\end{array}$ \\
\hline Time-on-task & $\begin{array}{l}\text { (Berliner, 1990; Cotton, 1990; Moore } \\
\text { \& Funkhouser, 1990; Rossmiller, } \\
\text { 1983) }\end{array}$ & $\begin{array}{l}\text { The time during which students are } \\
\text { engaged in learning mathematics from } \\
\text { the task that has been set for them }\end{array}$ \\
\hline $\begin{array}{l}\text { Productive } \\
\text { time }\end{array}$ & $\begin{array}{l}\text { (Walberg, 1988; Walberg et al., } \\
\text { 1994) }\end{array}$ & $\begin{array}{l}\text { The time within engaged time where } \\
\text { mathematics teaching is specific to } \\
\text { individual needs, rather than general } \\
\text { for the class or group }\end{array}$ \\
\hline $\begin{array}{l}\text { Transition } \\
\text { time }\end{array}$ & (Berliner, 1990) & $\begin{array}{l}\text { The time needed to move between } \\
\text { mathematics teaching activities }\end{array}$ \\
\hline Waiting time & (Berliner, 1990) & $\begin{array}{l}\text { The time students spend waiting for } \\
\text { instruction from the teacher (Not to be } \\
\text { confused with the Chapin and } \\
\text { O'Connor (2007) concept of wait time) }\end{array}$ \\
\hline Dead time & (Cotton, 1990) & The time when there is nothing planned \\
\hline
\end{tabular}

Research suggests that the length of mathematics lessons influences student achievement, with a small daily increase in time adding up to a much larger amount of time on mathematics over a year (Chiu, 2010; Hill, Rowan, \& Ball, 2005). Simply increasing the time allocated to mathematics lessons has little or no influence on student achievement (Hess, 2009; Rossmiller, 1983). However, changing how allocated time is used may influence student achievement (Corey, Phelps, Ball, Demonte, \& Harrison, 2012; Leonard, 2001a; Nelson, 1990). The way in which teachers use allocated time is predominantly based on their classroom management practice (Mackay, 2006). Classroom management is "necessary for learning to occur... teachers need to maintain control, guide the learning flow...guide classroom interactions and maintain an environment that enables and enhances learning" (Mackay, 2006, p. xv). Levels of student achievement can be improved if the time-on-task is increased, and these levels of achievement can be further increased if time-on-task is also productive time (Walberg, 1988; Walberg et al., 1994). 
One way in which instructional time is reduced is when interruptions occur (Leonard, 2001a). Interruptions to allocated time can be divided into two categories: those which originate outside the classroom (external interruptions), and those which originate inside the classroom (internal interruptions) (Leonard, 2001b). External interruptions are outside the teacher's control (Leonard, 2001a), and consist of planned interruptions such as assemblies, and unplanned interruptions such as students bringing messages (Lysiak, 1980). Most internal interruptions, including behaviour management, are considered to be within the control of the teacher, through their use of classroom management (Leonard, 2001b). Off-task student behaviour is an example of an internal disruption, and Hofer (2007) defines off-task behaviour as "all activities not directed towards learning” (p. 28). Off-task behaviours can be passive, for example, daydreaming, or active, for example, calling out (Hofer, 2007). Internal interruptions can be managed through the use of engaging tasks (Anthony \& Walshaw, 2007), providing work that is challenging (Mousley et al., 2007), setting high expectations (Rosenthal \& Jacobson, 1968), setting goals with students (Rubie-Davies et al., 2015), and planning extension activities for early finishers (Alton-Lee, 2003).

The way in which time on teaching is measured varies throughout the literature (Abadzi, 2009), with most research focusing on allocated time as it is considered easier to measure than engaged time or time-on-task (Moore \& Funkhouser, 1990). More indepth research measures minutes of allocated time, and time-on-task (Phelps et al., 2012). In this research a range of different measures of time were used, including allocated time, instructional time, engaged time, time-on-task, transition time, and dead time (Cotton, 1990). Despite the concept of time varying across the research, the measure of time (i.e., hours, minutes, and seconds) is consistent, allowing for comparison across the concepts (Berliner, 1990).

TIMSS 2010/2011 (Caygill et al., 2013) reported that New Zealand teachers allocate, on average, 168 hours per year to mathematics instruction, positioning them $17^{\text {th }}$ out of the 63 participant countries. Greenwood (1991) found that high SES students spent a higher proportion of instructional time engaged in learning than low SES students did. However, very little research has been done on the link between allocated time, SES, and levels of student achievement (Abadzi, 2009). 


\subsubsection{Interactions with mathematical tasks}

A teacher's classroom practice is based on their beliefs, and comprises many aspects including the types of interactions students have with the subject matter (Midcontinent Research for Education Learning, 2010), and the tools and tasks they use for learning (Protheroe, 2007). Students learn mathematics through the use of discussion, calculation, experimentation, and justification while collaborating on rich tasks (NCTM, 2000). It is during challenging, high level thinking mathematical tasks that students are working with accessible knowledge and developing the skills to persist with learning (Clarke et al., 2014; Warshauer, 2015).

\section{Written mathematics}

One of the ways students interact with mathematics is through writing (NCTM, 2000). Writing in mathematics includes the use of symbols and diagrams (NCTM, 2000), drawing pictures (Protheroe, 2007), providing visual representations (Bobis, Mulligan, \& Lowrie, 2004), recording ideas (Van de Walle \& Lovin, 2006), problem solving (Zevenbergen et al., 2004), and expressing reasoning (Chappell, Schielack, \& Zagorski, 2004). Students develop their understanding of mathematics by watching others more skilled than themselves using mathematics, which in a primary school would usually be the teacher (Munn, 1998).

Over the years there has been ongoing debate about the use of worksheets in mathematics with arguments both for (Wyels, 2015), and against (Bottle \& Canterbury Christ Church University College Primary Mathematics Team, 2005; Hansen, 2012). Whilst Susi (2011) argues that “math worksheets don't teach, teachers teach” (para. 19), she also points out that "math worksheets can provide extended practice and support development in fluency" (para. 20). This suggests that it is the way in which the worksheet is used which is the important consideration, not whether a worksheet is used or not. In this study, worksheets are grouped with written mathematics as students could be clearly identified as engaging with written mathematics when completing a worksheet.

\section{Oral mathematics}

The use of oral language, or mathematical discourse, to interact with mathematics has long been considered important in increasing student achievement (Chapin \& O'Connor, 2007; NCTM, 2000; Protheroe, 2007; Van de Walle \& Lovin, 
2006). However, the type of mathematical talk that takes place is vital, and the most beneficial type of discourse allows students to construct mathematical knowledge, and make sense of the mathematics being done (Chapin \& O'Connor, 2007; Van de Walle \& Lovin, 2006). When teachers ask questions in a constructivist classroom they are designed to provoke thinking, and support students to construct new understanding (Van de Walle \& Lovin, 2006). Van Lier (2001) tells us that the IRF (Initiation-ResponseFeedback) exchange is the most common type of talk in classrooms, and is used for rote learning, to challenge thinking, or to clarify students' understanding. Additionally, in a traditional classroom teacher questions are presented in the format of the IRF exchange to check if a student knows an answer or the next step in a procedure. When teachers use the IRF exchange it means that they are doing two-thirds of the talking as they are in control of the initiation and feedback stages, and opportunities for student talk are limited to the response stage (Dalton-Puffer, 2007). This would suggest that when traditional teachers use the IRF exchange they are not giving students the opportunity to construct knowledge and make sense of mathematics, through their own social interactions; instead, they are transmitting knowledge to students, expecting them to learn a procedure to be used and applied in a range of contexts (Van de Walle \& Lovin, 2006).

\section{Information communication technology (ICT) and mathematics}

ICT is considered essential in the teaching of mathematics (NCTM, 2000; Valtonen et al., 2015). However, research has shown that the use of ICT may only have a small influence on student achievement (Hattie, 2002a; Higgins, 2003). One of the possible causes of this may be that "generally speaking, ICT use is characterized by patchy and uncoordinated use" (Thorvaldsen, Vavik, \& Salomon, 2012, p. 214). This may suggest that it is the way in which ICT is used in mathematics teaching that influences the level of student achievement (Townsend, 2012).

\section{Mathematics games}

In this study, a mathematics game was considered a repeatable activity that proceeds "according to a set of rules and [relies] on some degree of chance, skill, strategy or endurance" (Bobis et al., 2004, p. 324). When students use mathematical games to interact with mathematics it is important that they are given the opportunity to reflect on the concept being learned or practised (Bobis et al., 2004; Van de Walle \& 
Lovin, 2006). Sherer (2012) suggests that the use of mathematics games should be planned in order to ensure that they meet the purpose of teaching, and involve multiple players to encourage collaboration and the use of mathematical discourse.

In summary, effective teachers have been shown to provide students with a range of written and oral mathematical tasks, and to have constructivist beliefs (McDonald et al., 2013). This would suggest that teachers in low decile schools may tend to have more traditional beliefs than teachers in high decile schools, and may provide their students with a narrower range of mathematical tasks with which to interact.

\subsubsection{Professional learning}

The New Zealand Curriculum is based on the concept of lifelong learning for both teachers and students (MoE, 2007). Professional learning can be used to help change teacher beliefs (Schifter, 2005). When traditional teachers are exposed to a constructivist teaching style as a student taking part in professional learning and development (PLD), they can experience learning that comes from constructing knowledge through collaboration and problem solving for themselves (Schifter, 2005):

Through mathematics lessons that challenge teachers at their own levels of mathematics competence, they can both increase their mathematical knowledge and experience a depth of learning that is, for many of them, unprecedented. ( $\mathrm{p}$. 88)

PLD can take many forms including collaboration, building professional networks, professional development sessions, or working towards further qualifications. There is little doubt about the benefits that PLD can have on student achievement as the effect has been shown to potentially result in students making two years' gain in just one year (Timperley et al., 2007). However, changing well developed classroom practice is difficult as teachers are busy, and believe what they are doing is successful (Wiliam, 2007). The complexity of effective teaching may go some way to explaining why it can be difficult for teachers to enact the learning they gain from PLD (Gomez Zwiep, \& Benken, 2013; Timperley et al. 2007; Wiliam, 2011). Timperley et al. (2007) also identify that the sustainability of PLD is dependent on teachers understanding the theory behind pedagogical practices, being able to use formative assessment to measure the rate of student learning, and identifying next teaching steps. 
Askew (2012) wrote that having high levels of mathematics qualifications did not always result in highly effective mathematics teaching. He adds teacher effectiveness could be increased by undertaking ongoing PLD in mathematics. Morris and Patterson (2013) found that New Zealand teachers were highly qualified, but their qualifications were not always in an area relevant to their teaching. Hill and Lubienski (2007) indicated that in the United States of America (USA) there was not much variation in the overall level of teachers' qualifications across schools in different SES areas. However, their research found that the level of mathematics qualifications was much lower in low SES schools.

Battey (2013) suggests that in the USA it was common for the quality of teaching for low SES students to be poorer than for high SES students. This would suggest that levels of teacher effectiveness in low decile schools could be increased through ongoing PLD in mathematics, especially when learning is experienced from the student's perspective.

\section{Summary}

Teacher-based influences on students' mathematical achievement are varied and complex, with each influence potentially affecting the others. Important considerations when planning for students' learning include the time spent teaching and learning mathematics, the opportunities students have to learn mathematics, and the level of challenge within the mathematics tasks. Additionally, teachers need to reflect on their beliefs, and how their beliefs are influencing their expectations for student achievement in mathematics, as well as how mathematics is taught within the classroom.

\subsection{Student-based Influences on Mathematics Achievement}

There are numerous potential student-based influences on student achievement (Section 1.4). From the analysed data, only three of these influences emerged as possibly influencing achievement: attitude towards mathematics (Zhao et al., 2012); level of motivation (Blömeke, Kaiser, \& Suhl, 2011); and engagement (Newmann, 1992). Each possible influence is individually discussed below, and finishes by considering SES in relation to student achievement. 


\subsubsection{Attitude}

Students' attitudes toward mathematics have been shown to influence levels of achievement (Zhao et al., 2012). Research suggests a link between a positive view of mathematics, high levels of mathematics self-esteem, and high levels of mathematics achievement (Anthony \& Walshaw, 2007; Bonner, 2014; Chang \& Choi, 2011; Hemmings, Grootenboer, \& Kay, 2011). Boucher, Bramoullé, Djebbari, and Fortin (2014) also suggested a link between mathematics achievement and peer group attitudes towards mathematics.

A student's attitude towards mathematics in the early years may be linked to later achievement as children develop their learning behaviours at a young age (Bodovski \& Youn, 2011; Chiu \& Klassen, 2010). Bodovski and Youn identified student behaviours that may indicate low levels of achievement include disrupting lessons and not paying attention. Behaviours linked to high levels of achievement include persistence, engagement, and participation in lessons (Appleton \& Lawrenz, 2011; Bodovski \& Youn, 2011; Fredricks, Blumenfeld, \& Paris, 2004; Moller, Stearns, Mickelson, Bottia, \& Banerjee, 2014; Suárez-Álvarez, Fernández-Alonso, \& Muñiz, 2014).

It has been suggested that students from high SES backgrounds tend to have more positive attitudes towards mathematics than students from low SES backgrounds (Bonner, 2014). Additionally, low SES students have been found to start school with low levels of achievement and high levels of behaviours leading to low achievement (Bodovski \& Youn, 2011).

\subsubsection{Level of motivation}

It is desirable for students to have both intrinsic and extrinsic motivation. However, it is intrinsic motivation which has the greatest impact on student engagement "as it engenders persistence, efficient cognitive processing, and positive affect" (Megowan-Romanowicz et al., 2013, p. 52). Megowan-Romanowicz et al. add that a student's motivation influences their decision to either interact with the mathematics learning, or not. When a student sees themselves as a successful mathematician, and they perceive the task to be important, levels of intrinsic motivation tend to be increased, which potentially leads to increased levels of achievement (Megowan-Romanowicz et al., 2013; Murayama, Pekrun, Lichtenfeld, \& Vom Hofe, 2013; Stephanou, 2012). 
Teachers can also influence levels of student motivation through the expectations they convey (Section 2.1.6).

Teachers in low decile schools have been found to have lower expectations for their students (Section 2.1.1), which may lead to lower levels of intrinsic motivation (Megowan-Romanowicz et al., 2013). When teachers assume students from low SES backgrounds will have lower levels of achievement, this may lead to low SES students experiencing low levels of success (Stephanou, 2012; Torres \& Moran, 2014). When students are repeatedly unsuccessful, their levels of intrinsic motivation are reduced, and their self-belief is further eroded (Stephanou, 2012). It is this cycle which may contribute to Rosenthal and Jacobson's (1968) self-fulfilling prophecy (Section 2.4.6).

\subsubsection{Engagement}

Student engagement can be defined as "the student's psychological investment in and effort directed toward learning, understanding, or mastering the knowledge, skills, or crafts that academic work is intended to promote" (Newmann, 1992, p. 12). The tasks teachers give to their students are key in engaging students in learning mathematics (Anthony \& Walshaw, 2007). Levels of student engagement have been found to be strong predicators of students' mathematics achievement (Janosz et al., 2012; Moller et al., 2014; Weiss, Carolan, \& Baker-Smith, 2010). Research has shown that low levels of engagement are common in low achievers in mathematics, and when levels of engagement increase, so do levels of achievement (Bodovski \& Farkas, 2007).

Robinson (2013) writes that students from low SES backgrounds have lower levels of engagement than students from high SES backgrounds. He suggests possible reasons for these differences in levels of engagement include "higher incidences of food insecurity, less access to health care, and greater parental stress" (p. 24), although empirical evidence is lacking as little research has been conducted in this area.

In summary, when students arrive at school, they bring with them prior mathematical experiences and knowledge which possibly influence their attitude towards mathematics, their level of motivation in mathematics, and their engagement with mathematics. Each of these possible influences works both independently, and in conjunction, to contribute to levels of achievement in mathematics. 


\subsection{School and Home-based Influences on Mathematics Achievement}

It is the role of school leaders to ensure that the necessary resources are identified, and funded, in line with student needs (Robinson, Hohepa, \& Lloyd, 2009). When students have increased levels of resources, including effective teachers, achievement levels increase (Bonner, 2014; Wiliam, 2011).

When students come from high SES families, they are more likely to have access to higher levels of resources, both at home and in school (Martins \& Veiga, 2010). However, Bottia, Moller, Mickelson, and Stearns (2014) found that students from low SES families were more likely to be taught mathematics in school using manipulatives than students from high SES families.

\subsubsection{Parental education}

Both parental qualifications and parental income can be used as measures of family SES. Therefore the lower the levels of these two factors, the lower the family SES (Marks, 2014; Zhao et al., 2012). Levels of parental education, particularly maternal education, have repeatedly been shown to influence student achievement (Nguyen \& Griffin, 2010; Petty et al., 2013; Wylie, 1999, 2001b):

\footnotetext{
Maternal education levels have more bearing on children's competency levels than family income, particularly for mathematics...Children whose mothers have no qualifications are noticeably disadvantaged; conversely, children whose mother has a university qualification are noticeably advantaged. (Wylie, 2001b, p. 9)
}

Parents with low levels of qualifications are less likely to be involved in their child(ren)'s education (Wylie, 2001a). Additionally, children of parents with low levels of qualifications have limited exposure to a range of experiences, tend to watch more hours of television, spend less time playing sport, and are less likely to have conversations about attending university (Stylianides \& Stylianides, 2010; Wylie, 2001b). This potentially reduced level of parental involvement has been shown to have a negative influence on student achievement (Stylianides \& Stylianides, 2010).

\subsubsection{Parental income}

Wylie (2001b) found that students living in low income homes before they are five years old will have lower levels of mathematics achievement, and the rate of 
achievement usually does not change, even if family income increases. The reason for this appeared to be that students from low income households were not exposed to real life experiences that required mathematics skills (Martin \& Veiga, 2010; Wylie 2001b, 2013). However, it is important to recognise that whilst such factors originating from students' homes can influence their achievement, some contend that there is little that schools and teachers can do to change those (Petty et al., 2013).

\subsubsection{Parental involvement}

Family SES has been shown to influence student achievement in mathematics (Sirin, 2005; Wylie \& Thompson, 1998). Students from high SES families usually have greater opportunities to practise skills, build knowledge, and have a range of experiences that put them in a more advantageous position in the classroom (Wylie, 2001b, 2013; Wylie \& Thompson, 1998). Research suggests this is because high SES families generally have two parents, high levels of educational resources at home, and high levels of parental involvement (Chiu, 2010). Conversely, low SES families have been shown to be more likely to have disrupted parenting, lower parental expectations, lower levels of cognitive stimulation, and poorer home environments (Pong et al., 2003; Sastry \& Pebley, 2010).

\section{Summary}

Levels of parental education and parental income are possible influences on student achievement as parents with higher income levels may be more able to afford resources that support the learning of mathematics at home. Additionally, parents with higher levels of education are more likely to know how to use those resources to support the learning of mathematics, and be involved in their child(ren)'s education, contributing to higher levels of student achievement in mathematics.

\subsection{Summary}

Several possible influences on student mathematical achievement appear to be at play simultaneously, originating across all four aspects (teacher, student, school, and home) identified in Section 1.3. Working as both an independent influence on student achievement, and also weaving through each identified teacher-based, and studentbased, possible influence, teacher beliefs may be an important influence on student 
achievement in mathematics. Teacher beliefs may influence expectations for students from different SES backgrounds, in turn influencing the opportunities to learn and the level of challenge that students experience. When teachers hold high expectations, providing lots of opportunities for learning with tasks which have high levels of challenge, students appear to have higher levels of achievement in mathematics. 


\section{Chapter 3: Methodology}

This chapter begins with a discussion of the ontology and epistemology underpinning this research in Section 3.1, and then discusses the methodological approach in Section 3.2. Section 3.3 introduces the research setting, Section 3.4 outlines the data collection methods, while Section 3.5 discusses data collection tools. Section 3.6 details the data analysis, and Section 3.7 considers validity and reliability, followed by ethical considerations in Section 3.8.

\subsection{Ontology and Epistemology}

Ontology and epistemology are important considerations within research because assumptions made about the nature of reality, and what is known about reality, influence both the methodological approach and findings (Cohen, Manion, \& Morrison, 2007). A social constructivist position was taken within this research (Crotty, 1998; Opie, 2004), prompted by the New Zealand Curriculum (MoE, 2007) which encourages teachers to use social constructivism to build a classroom culture where learning is constructed through collaboration, and conversations:

Students learn as they engage in shared activities and conversations with other people, including family members and people in the wider community... In such a community...learning conversations and learning partnerships are encouraged; and challenge, support, and feedback are always available. As they engage in reflective discourse with others, students build the language that they need to take their learning further. (MoE, 2007, p. 34)

Ontology in this research refers to "assumptions which concern the very nature or essence of the social phenomena being investigated" (Cohen et al., 2007, p. 7). In social constructivist research, ontology assumes that reality is constructed socially, and therefore reality is determined by a group of individuals (Andrews, 2012). The ontology for this research was constructed through the use of conversations and observations to find out how the participants experience their world of teaching and learning (Crotty, 1998; Opie, 2004). By taking a social constructivist approach, it was possible to explore the data gathered for theories that may suggest answers to the overarching research question.

Epistemology in this research refers to "the study of knowledge, including its nature, how it is gained or generated, how it is warranted, and the standards that are used 
to judge its adequacy" (Johnson \& Christensen, 2012, p. 12). Epistemology is about how we come to know what we know (O'Leary, 2013), and assumes the researcher can construct knowledge by gathering, and analysing data through social research, e.g., surveys, interviews, and observations (Newman, 2003).

The epistemology in this research was based on the relationship between the researcher, and the participants (Punch, 2014). Data were gathered from participants in the form of accounts, i.e., interviews and questionnaires (Opie, 2004). The challenge for the researcher is to ensure participants provide data that are true, from their point of view (Opie, 2004). Knowledge held by participants is subjective, based on their culture and experiences, and the researcher was tasked with uncovering what is known (Cohen et al., 2007). The opinions, beliefs, and feelings gathered from the participants were used to construct one picture of reality in each of the participant schools.

\title{
3.2 Methodological Approach
}

A research paradigm "is a way of thinking about a subject, and proceeding with research" (Newby, 2010, p. 44). Within educational research there are three main paradigms: quantitative research; qualitative research; and mixed methods research (Johnson \& Christensen, 2012). This research was conceived in the qualitative paradigm. In qualitative research "the researcher relies on the views of participants; asks broad, general questions; collects data consisting largely of words...[and] describes and analyzes those words for themes" (Creswell, 2008, p. 46). The methodological approach taken was a collective case study (Johnson \& Christensen, 2012), exploring and comparing data from two different cases (Yin, 2003):

\begin{abstract}
A case study is an empirical inquiry that investigates a contemporary phenomenon within its real-life context, especially when the boundaries between phenomenon and context are not clearly evident. The case study inquiry copes with the technically distinctive situation in which there will be many more variables of interest than data points, and as one result relies on multiple sources of evidence, with data needing to converge in a triangulating fashion, and as another result benefits from the prior development of theoretical perspectives to guide data collection and analysis. (Yin, 2003, p. 13)
\end{abstract}

Case studies aim to identify processes that are creating patterns by using the data collected to identify trends and themes (Newby, 2010). A case study can explore data "to find out what is going on, to throw light on something that we have never met before or do not understand" (Newby, 2010, p. 52). 
This research explored two cases, the boundaries of which were set around each of the two participant schools (Cohen, Manion, \& Morrison, 2011). The use of collective case study allowed the focus of each case to be both the individuals within the schools, and the classroom, school, and students' home environments (Cohen et al., 2011). The data collected from each case were explored in the hope that a theory would emerge that might suggest reasons for differences in students' mathematics achievement in two case schools.

Whilst this case study sits within the qualitative paradigm, some quantitative data were also collected (Creswell, 2008; Strauss \& Corbin, 1998; Yin, 2003). "Virtually all case studies produced in social sciences today include some quantitative and qualitative components" (Gerring, 2007, p. 11).

Grounded theory analysis was used in order to generate a theory from the data (Glaser \& Strauss, 1967). "Grounded theory is an important method of theory generation. It is more inductive than content analysis, as theories emerge from, rather than exist before, the data" (Cohen et al., 2007, p. 491). Grounded theory was used to analyse the everyday interactions between people, allowing the complexity of school and classroom life to be included as a whole, rather than broken down into individual components (Cohen et al., 2007).

\subsection{Research Settings}

The following section describes both participant schools and research participants (pseudonyms have been used).

\subsubsection{Participant schools}

The research focused on two case schools, Pīwakawaka School and Whio School. Both schools were located in a rural environment, a short drive from cities, in the lower half of New Zealand's North Island. The school selection was based on the following factors:

- contrasting deciles, allowing for cross-case analysis between schools of differing SES;

- both having either a long or short ERO review cycle in an attempt to control the effectiveness of school function as a potential influence on achievement; 
- being coeducational to attempt to control gender as a potential influence on achievement; and

- being state schools that are accessible to everyone, rather than schools of special character, which constrain who enrols.

Table 3.1 shows the composition data for each school (ERO, n.d.). This table shows that $91.1 \%$ of Pîwakawaka School students achieved at or above national standards in 2014 , compared with $64 \%$ of students at Whio School. Additionally, at Pīwakawaka School 0.7\% of students achieved well below national standards in 2014, compared with $8.7 \%$ of students at Whio School.

Table 3.1: Pīwakawaka and Whio School Composition Data

\begin{tabular}{|c|c|c|c|}
\hline & & $\begin{array}{l}\text { Pīwakawaka } \\
\text { School }\end{array}$ & Whio School \\
\hline \multicolumn{2}{|l|}{ Decile } & 10 & 3 \\
\hline \multicolumn{2}{|c|}{ School Roll (approximate) } & 200 & 100 \\
\hline \multicolumn{2}{|c|}{ School Type } & \multicolumn{2}{|c|}{ Full Primary (years 1 to 8 ) } \\
\hline \multicolumn{2}{|c|}{ ERO Cycle } & \multicolumn{2}{|c|}{ Every three years } \\
\hline \multirow[t]{2}{*}{ Gender } & Male & $49 \%$ & $53 \%$ \\
\hline & Female & $51 \%$ & $47 \%$ \\
\hline \multirow[t]{4}{*}{ Ethnicity } & New Zealand European & $93 \%$ & $53 \%$ \\
\hline & Māori & $7 \%$ & $43 \%$ \\
\hline & Pacific & $0 \%$ & $2 \%$ \\
\hline & Asian & $0 \%$ & $2 \%$ \\
\hline \multirow{2}{*}{\multicolumn{2}{|c|}{$\begin{array}{l}\text { Mathematics National Standards Data } 2014 \\
\text { Above }\end{array}$}} & $40.4 \%$ & $21.2 \%$ \\
\hline & & $50.7 \%$ & $43.8 \%$ \\
\hline \multicolumn{2}{|c|}{ At } & $8.2 \%$ & $26.3 \%$ \\
\hline \multicolumn{2}{|c|}{ Below } & $0.7 \%$ & $8.7 \%$ \\
\hline
\end{tabular}

Note: National Standards are discussed in Section 1.6

\subsubsection{Research participants}

Figure 3.1 identifies the four separate groups of research participants within each school: the principal; teachers; students; and families, and the tools used to gather data from each group. Teachers from different year levels volunteered to participate, allowing data to be gathered from across each school. Participants from Pīwakawaka School have been given pseudonyms beginning with 'P', and those from Whio School have been given pseudonyms beginning with ' $\mathrm{W}$ '. The scope of this research only allowed for data to be gathered from three classrooms within each school, meaning that 
no data were gathered at the year 7 and 8 levels. Participation rates were $64 \%$ of students and their families across three classes at Pīwakawaka School and 53\% of students and their families across three classes at Whio School.

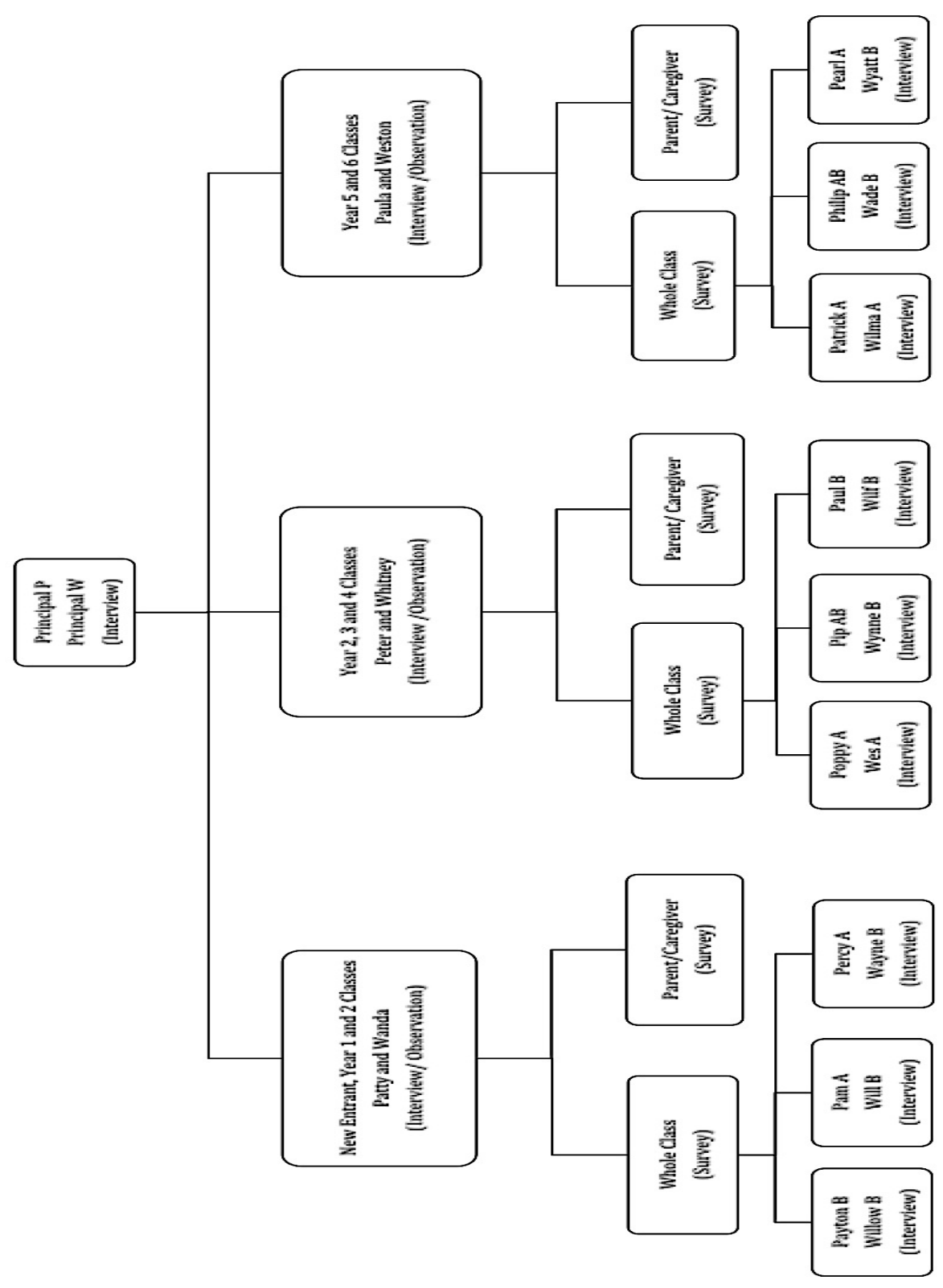

Figure 3.1: Research Participants

The intention was to identify three students in each class - one working 'below' or 'well below', one working 'at', and one working 'above' the national standards expectations - who were appropriate to interview, and invite them to participate in an individual interview. The students' achievement level is indicated in Figure 3.1 by the letter following their name ( $\mathrm{AB}$ is 'above', $\mathrm{A}$ is 'at' and $\mathrm{B}$ is 'below' or 'well below'). Levels of mathematics achievement for participant students varied between the schools, 
which meant it was instead necessary to interview three students whose mathematics achievement level was representative of their class.

\subsubsection{Participant classroom organisation}

Table 3.2 shows how the participant teachers structured their mathematics lessons, and mathematics groups. Wanda was the only teacher seen to be working with three groups in each mathematics lesson, and Paula was the only teacher observed using groups based solely on identified student needs, rather than numeracy strategy stages and identified student needs.

Table 3.2 Organisation of Mathematics Lessons in Participant Classrooms

\begin{tabular}{|c|c|c|c|c|}
\hline Teacher & Lesson Time & Lesson Structure & Groups per lesson & Additional adults \\
\hline Patty & $10: 10-11: 00$ & $\begin{array}{l}\text { Whole class starter } \\
\text { Groups } \\
\text { Plenary }\end{array}$ & $\begin{array}{l}\text { Two - ability } \\
\text { based }\end{array}$ & N/A \\
\hline Peter & 09:05 - 10:00 & Groups & $\begin{array}{l}\text { Two - ability } \\
\text { based }\end{array}$ & $\begin{array}{l}\text { Parent helper once a } \\
\text { week }\end{array}$ \\
\hline Paula & $11: 35-12: 30$ & $\begin{array}{l}\text { Whole class starter } \\
\text { Groups } \\
\text { Plenary }\end{array}$ & $\begin{array}{l}\text { Two - flexible, } \\
\text { needs based }\end{array}$ & N/A \\
\hline Wanda & $11: 50-12: 50$ & $\begin{array}{l}\text { Whole class starter } \\
\text { Groups }\end{array}$ & $\begin{array}{l}\text { Three - flexible, } \\
\text { ability based }\end{array}$ & $\begin{array}{l}\text { Teacher aide, and a } \\
\text { parent helper once a } \\
\text { week }\end{array}$ \\
\hline Whitney & $11: 50-12: 50$ & $\begin{array}{l}\text { Whole class starter } \\
\text { Problem solving } \\
\text { Groups } \\
\text { Plenary }\end{array}$ & $\begin{array}{l}\text { Two - one target } \\
\text { group (the same } \\
\text { students each day), } \\
1 \text { ability group }\end{array}$ & $\mathrm{N} / \mathrm{A}$ \\
\hline Weston & $09: 20-10: 20$ & $\begin{array}{l}\text { Whole class starter } \\
\text { Groups }\end{array}$ & $\begin{array}{l}\text { Two - ability } \\
\text { based }\end{array}$ & $\begin{array}{l}\text { Part-time teacher aide, } \\
\text { not always present for } \\
\text { mathematics }\end{array}$ \\
\hline
\end{tabular}

\subsection{Data Collection}

This research collected five types of data commonly used in case studies (Yin, 2003). The data types were:

- interviews, i.e., semi-structured interviews, and surveys;

- direct observation;

- archival records, i.e., national standards data;

- physical artefacts, i.e., observation of physical items such as tools or computers; and

- audio and video recordings. 
The first four data types listed above required data collection tools that were specifically designed for this research, although they were based on existing tools. Before beginning data collection, it was necessary to carefully consider, and design, tools that would ensure the data collected were comprehensive, and could be analysed, allowing a theory to emerge (Punch, 2014) (Section 3.5). Both qualitative and quantitative data were collected from research participants using the different methods outlined in Tables 3.3 and 3.4.

Table 3.3: Qualitative Data

\begin{tabular}{ll}
\hline Data Collection Tools & Participants \\
\hline Semi-structured Interviews & Principals \\
& Teachers \\
Surveys & Students \\
& Families \\
Observations & Students \\
& Teachers \\
\hline
\end{tabular}

Table 3.4: Quantitative Data

\begin{tabular}{ll}
\hline Data Collection Tools & Participants \\
\hline Achievement Data & Students \\
Physical Artefacts & School \\
\hline
\end{tabular}

\subsubsection{Interviews}

Two separate types of interview techniques were used to gather data: semistructured interviews (Cohen et al., 2011; Guthrie, 2010); and surveys (Yin, 2003). Semi-structured interviews, which were audio recorded, used a guide with structured questions, but the order of questions was not set, and follow-up questions were asked to gather further information (Guthrie, 2010). This type of interview allowed flexibility with questions, yet still permitted data gathered from the different interviews to be compared (Guthrie, 2010). All the interviews were audio recorded, and transcriptions of each entire interview were made. All transcriptions were carried out by the researcher.

Surveys, in the form of questionnaires, used structured questions to gather individual data (Newby, 2010). This allowed large amounts of data to be collected without the need for interviewing every individual participant (Newby, 2010). 


\subsubsection{Direct observations}

Four mathematics lessons were observed in each classroom corresponding to the number of mathematics lessons per week, totalling 24 observations. Each nonparticipant observation (Guthrie, 2010) was also video recorded to allow multiple viewings and clarification of events. Observations occurred over two weeks, and allowed for unforeseeable circumstances such as teacher absence. The timetable for lesson observations was developed with each participant teacher to ensure usual classroom routines were followed. Field notes were taken in each observed lesson to record events, e.g., lesson interruptions, and to ensure data were available in case of technology issues (Guthrie, 2010).

\subsubsection{Archival records}

Archival record data were collected about participating students in the form of national standards mathematics achievement data. It was important to consider "the conditions under which [the archival data] was produced as well as its accuracy" (Yin, 2003, p. 89) before using it in the analysis. The practising teacher criteria require teachers to "analyse, and appropriately use assessment information, which has been gathered formally and informally" (Education Council of Aotearoa New Zealand, n.d.); therefore, the data should be considered reliable, as discussed in Section 3.7.

\subsubsection{Physical artefacts}

Data on the physical artefacts observed within each school were collected (Yin, 2003). Physical artefacts were used to gather data about resources available in each school, and whilst they provided information about school decisions, e.g., using ICT in mathematics lessons, they did not provide information about why those decisions had been made (Cohen et al., 2011).

\subsection{Data Collection Tools}

The broad variety of factors identified in the literature as potentially influencing student achievement meant that the data collection tools needed to cover a range of different sources, and a range of different constructs (Section 1.3). Appendix A identifies the links between the potential influences on student achievement identified in Figure 1.1 and the data collection tools developed for this research. 


\subsubsection{Interviews}

Semi-structured interviews (Guthrie, 2010) were used to gather data from principals (Appendix B), teachers (Appendix C), and three participant students from each class (Appendix D).

Questions in the principal interview were designed to collect data about factors that may be influencing student achievement at a whole school level. Teacher interviews were based on Hattie's (2002b) attributes of excellent teachers, and designed to collect data about teacher practices and beliefs. Student interviews were based on Absolum's (2006) writing on using formative assessment in the classroom and were intended to provide rich data on students' thoughts, and feelings about mathematics. Table 3.5 shows the potential influences on student achievement that were covered within each of the different interviews.

Table 3.5: Potential Influences on Student Achievement Addressed in Interviews

\begin{tabular}{|c|c|c|}
\hline Principal & Teacher & Student \\
\hline $\begin{array}{l}\text { School culture, including } \\
\text { school organisation, and } \\
\text { leadership; (Boonen et al., } \\
\text { 2014) }\end{array}$ & $\begin{array}{l}\text { Beliefs (Janosz et al., 2012; } \\
\text { Wilson et al., 2005) }\end{array}$ & $\begin{array}{l}\text { Engagement (Bodovski \& } \\
\text { Farkas, 2007; Fredricks et al., } \\
\text { 2004; Hemmings et al., 2011) }\end{array}$ \\
\hline $\begin{array}{l}\text { The resources in the schools } \\
\text { (Clayton, 2011) }\end{array}$ & $\begin{array}{l}\text { Use of feedback (Hattie, } \\
\text { 2002b; Hattie \& Timperley, } \\
\text { 2007; Parr \& Timperley, } \\
\text { 2008) }\end{array}$ & $\begin{array}{l}\text { Mathematics self-efficacy } \\
\text { (Bandura, 1993; Shores, } \\
\text { Shannon, \& Smith, 2010) }\end{array}$ \\
\hline $\begin{array}{l}\text { Home/school partnerships } \\
\text { (González \& Jackson, 2012) }\end{array}$ & $\begin{array}{l}\text { Professional development } \\
\text { (Gomez Zwiep \& Benken, } \\
\text { 2013) }\end{array}$ & $\begin{array}{l}\text { Classroom practices (Bottia et } \\
\text { al., 2014; Megowan- } \\
\text { Romanowicz et al., 2013) }\end{array}$ \\
\hline $\begin{array}{l}\text { Professional development } \\
\text { (Gomez Zwiep \& Benken, } \\
\text { 2013) }\end{array}$ & Collaboration (Jenkins, 2010) & $\begin{array}{l}\text { Motivation (Megowan- } \\
\text { Romanowicz et al., 2013; } \\
\text { Suárez-Álvarez et al., 2014) }\end{array}$ \\
\hline $\begin{array}{l}\text { Teacher collaboration } \\
\text { (Moller, Mickelson, Stearns, } \\
\text { Banerjee, \& Bottia, 2013) }\end{array}$ & $\begin{array}{l}\text { Expectations (Rosenthal \& } \\
\text { Jacobson, 1968; Woolley et } \\
\text { al., 2010) }\end{array}$ & $\begin{array}{l}\text { Home/school partnerships } \\
\text { (Robinson, 2013; Wylie, } \\
\text { 2001a) }\end{array}$ \\
\hline $\begin{array}{l}\text { School community (Dobbie } \\
\& \text { Fryer, 2011; Moller et al., } \\
\text { 2013) }\end{array}$ & $\begin{array}{l}\text { Pedagogical and content } \\
\text { knowledge (Ball, Thames \& } \\
\text { Phelps, 2008; Hill, 2007; } \\
\text { Hill, et al., 2005) }\end{array}$ & \\
\hline
\end{tabular}

\subsubsection{Questionnaires}

Participating families completed a structured questionnaire (Appendix E) either online (through SurveyMonkey), or on paper. Questionnaires were informed by Marks's 
(2014) research into inequalities in student achievement in Australia, and were designed with closed questions to remove the need for families to add personal details, to make the questions easy to answer (Newby, 2010), and to increase the number of responses. Data were collected about:

- family SES (Marks, 2014; Martins \& Veiga, 2010; Wylie 1999, 2013);

- parental education (Wylie, 1999, 2001b);

- home/school relationships (Biddulph, Biddulph, \& Biddulph, 2003; Stylianides \& Stylianides, 2010; Wylie, 1999); and

- opportunities to learn mathematics at home (Hiebert \& Grouws, 2007).

All participating students completed an attitudinal questionnaire (Appendix F), which was administered by myself. A Likert scale, ranging from 1: strongly disagree to 5: strongly agree, was used to ensure that responses were consistent, and accessible to all age ranges (Cohen et al., 2011). Data from Likert scales are ordinal as data generated from different respondents are not necessarily comparable (because a 1 generated by two different respondents can have completely different meanings) and as such it is not appropriate to use quantitative techniques to analyse this data. Whilst the questions within the survey were consistent, the format of the survey was altered to make it accessible for junior students. Student questionnaires gathered data on student attitudes towards mathematics (Chiu \& Klassen, 2010; Hemmings et al., 2011) and mathematics done at home (Wylie, 2001a).

\subsubsection{Lesson observations}

Formal observations were conducted in each of the participant classrooms. Mathematics lessons were observed using an anecdotal recording technique, i.e., noting what happened throughout the lesson (McMillan \& Meade, 1985), and were video recorded. Anecdotal recording was chosen as it provided a systematic way of recording what was happening, and the time it occurred, in the classroom environment. Events recorded in this way provided an account of what actually happened, not what was perceived as happening by the teacher or students (McMillan \& Meade, 1985; Wragg, 1994). Reflections on the observed classes were added after each observation to provide data on potentially key influences on student achievement such as student motivation. Lesson observations provided data on, amongst many things, teaching style, teacher effectiveness, use of feedback, and classroom practices. 


\subsubsection{Archival records}

All participating students' mathematics achievement data were collected in the form of the most recent national standards data. Their data were used to identify differences in achievement between the two schools. Achievement data were also linked to a student's SES background through the use of a numbered survey link. The ability to link student achievement data to family SES allowed data to be filtered to identify the strongest relationships, both within and across schools, which may have potentially been influencing student achievement.

\subsubsection{Physical artefacts}

A checklist (Appendix G) was developed based on the MoE's (2008a) Numeracy Book 3, and used to gather data about the availability and use of physical artefacts, such as ICT equipment, mathematics resources and books, within each school (Yin, 2003).

\subsubsection{Trialling}

Trialling of all data gathering tools took place prior to data collection to establish their efficacy (Johnson \& Christensen, 2012). Feedback from the trial participants was taken and changes to the data gathering tools were made as necessary (Creswell, 2008).

\subsection{Data Analysis}

Yin (2003) suggests that three overarching analytical strategies can be used in case studies:

1. relying on theoretical propositions, i.e., using the original ideas that informed the research design to inform the analysis;

2. thinking about rival explanations, i.e., outlining and testing different explanations;

3. developing a case description, i.e., using descriptive schema to analyse the case.

The overarching strategy within this research was to develop a case description. However, in order to use the data analysis to generate a theory, grounded theory was used to analyse the data (Glaser \& Strauss, 1967). There are three stages of data analysis in grounded theory, collectively called the constant comparative method (Strauss \& 
Corbin, 1998). The first stage in grounded theory analysis is to label the data through the use of open coding (Glaser \& Strauss, 1967). However, the codes are not used to describe the data, they are used to label concepts within the data that emerge as part of the constant comparison process (Strauss \& Corbin, 1998). As new data are collected and analysed they are compared with existing data, and the codes are modified to ensure they provide suitable concept labels for all the data (Cohen et al., 2007; Punch, 2014). The second stage of grounded theory data analysis is conceptual ordering using axial coding (Glaser \& Strauss, 1967; Strauss \& Corbin, 1998). Axial coding is used to identify the relationships between the open codes (Cohen et al., 2007; Punch, 2014). The third stage is referred to as theorising (Strauss \& Corbin, 1998), and is used to construct a theory through the use of selective coding, i.e., selecting one code that can be developed into the main theory (Strauss \& Corbin, 1998; Punch, 2014). It is important to note that whilst each of these stages is conceptually different, it is usual for the analysis to move backwards and forwards between the stages until it appears that saturation has been reached, i.e., no new codes are produced (Cohen et al., 2007; Strauss \& Corbin, 1998).

Before analysis of the qualitative data could begin it was necessary to prepare the raw data by turning them into data that could be analysed (Newby, 2010). Video recordings were already in a useable format; however, all other qualitative data needed preparation (Newby, 2010). Notes taken during interviews were written up into detailed text, and transcriptions of audio recordings were made (Newby, 2010). To change anecdotal notes taken during the lesson observations from raw data to useable data, they were written up in full immediately after each lesson observation (Newby, 2010).

\subsubsection{Coding}

Initially, data from lesson observations were open coded, identifying many individual concepts such as how students were interacting with mathematics and the different ways in which mathematics time was spent in each classroom, and then axial coded to find any relationships between the open codes, such as how the teacher managed the number of students interacting with mathematics. Next, data from both teacher and student interviews were coded, again modifying codes as necessary. Codes were modified when they were found to be describing similar concepts, for example time spent tidying the classroom and time spent with the teacher or students off task can be modified as they both cover the concept of not interacting with mathematics. As the 
codes were developed and modified, similarities began to emerge across the data sources. Where these similarities occurred, the same codes were used across these data sources. Appendix $\mathrm{H}$ shows the master list of codes, and their meanings, used throughout this research.

The first set of codes to emerge from the lesson observation coding were focused on the use of allocated time. This initial set of codes highlighted the different types of interactions between teachers, students, and the mathematical tasks, as well as the differences in the nature of classroom interruptions, prompting the development of a second and third set of codes for the interactions between teachers, students, and the mathematical tasks, and for interruptions respectively. A fourth set of codes was developed to analyse the different sections of the mathematics lesson, the types of activities students were doing, and how students were interacting with those activities. A more detailed breakdown of the analysis for each class can be found in Appendix I. A fifth set of codes, this time using a traffic light system of colour, was developed to highlight the area of student knowledge a teacher was working within (Sections 1.8 and 2.1.4) (Appendix H).

When analysing the data it was necessary to determine the types of knowledge the teacher and student were working with. To be allocated to existing knowledge (highlighted green) students had to clearly indicate that they already knew what was being taught. This could be indicated in a range of ways including: a student quickly giving the correct answer to the first, and often subsequent, teacher questions; a student providing an answer which indicated they had knowledge beyond that which was currently being taught; a student interrupting the question to correctly answer it; or a student completing a set task very quickly. To be allocated to accessible knowledge (highlighted orange) students needed to indicate that, at the start of teaching, they did not know what was being taught, but by the end of teaching they could do what was being taught independently. Students could indicate that they did not know what was being taught by: saying they did not know; giving the wrong answer only; or being able to reach the correct answer with the support of scaffolds. To be allocated to inaccessible knowledge (highlighted red) a student needed to indicate that they could not do the mathematics being taught both at the start and end of teaching. Students could indicate that the knowledge being taught was inaccessible by saying that they could not do the mathematics or they were being taught a possibly accessible concept or procedure, which required existing knowledge that the student indicated they did not have, thereby 
making the mathematics inaccessible. When data were allocated to 'other mathematics' (highlighted blue) the observed mathematics interactions did not require the students to work with existing, accessible, or inaccessible knowledge such as the teacher launching the task, or the type of knowledge being used could not be clearly allocated to existing, accessible, or inaccessible knowledge. When observed interactions were nonmathematical they were allocated to 'other' (highlighted yellow).

Additionally, data from the family survey were coded into Excel using the codes shown in Appendix J. Data from the student survey were then entered into Excel using the numerical scale from the survey. Finally, national standards data were coded into Excel as follows: 1: 'well below'; 2: 'below'; 3: 'at'; and 4: 'above', to allow the PivotTable function to be used to quickly compare data within and between the cases.

Any ideas emerging from the quantitative data became part of the constant comparative cycle needed for grounded theory analysis (Strauss \& Corbin, 1998). Again, codes were altered as necessary to allow for selective coding (Cohen et al., 2007; Punch, 2014). Through this iterative use of describing, conceptual ordering, and theorising using both qualitative and quantitative data (Strauss \& Corbin, 1998), two selective codes emerged:

- the amount of mathematics students were doing, the focus of Chapter 4; and

- the opportunities students had for learning mathematics, discussed in Chapter 5.

Following the analysis of all the data sources, classroom observations were identified as providing the strongest data about why there may be differences between the two schools. Many of the analyses done did not appear to identify any differences between the two schools, for example the national standard OTJ did not appear to be influenced by a student's perception of enjoying participting in mathematics alone or in a group. For this reason, classroom data have been prioritised throughout this thesis as differences in the classrooms were clearly evident between the two schools.

\subsubsection{Determining socioeconomic status}

The family survey data were initially used to define home SES for each student as students from a range of SES backgrounds attended each school irrespective of the decile (MoE, 2014). As discussed in Section 1.3, in this study three measures of SES (parental education, parental income, and parental occupation) were used to calculate 
family SES in order to provide as much information as possible. These data were collected through the family survey (Appendix E).

In New Zealand, there is general agreement that an income below $60 \%$ of the median household disposable income is considered below the poverty line (Ministry of Social Development, 2014). Only basic data were collected through the family survey; therefore, data about total household income, not total disposable household income, were collected, meaning this study used a measure of total household income as opposed to disposable household income. In 2014, the median annual household income was \$72,394 (Statistics New Zealand, 2014). Therefore, households with a total annual income below $\$ 45,000$ (approximately $60 \%$ of the 2014 median annual household income) were considered to be below the poverty line in this study. Households with an income between $\$ 45,001$ and $\$ 105,000$ were considered to have an average income (approximately $\$ 30,000$ below and above the median income), and households with an income above $\$ 105,000$ were considered to have a high income.

The New Zealand government target is for $85 \%$ of 18 -year-olds to achieve NCEA Level 2 by 2017 (Education Counts, 2015). As NCEA Level 2 is currently being targeted as the minimum level of qualification needed, this study has classified parents with NCEA Level 2 or below as having low levels of education, parents with NCEA Levels 3, 4, or a diploma as having a medium level of education, and parents with a Bachelor degree or higher as having high levels of qualifications.

Statistics New Zealand use the Australian and New Zealand Standard Classification of Occupations to allocate jobs to one of five categories ranging from 'lower skilled' to 'highly skilled' (Statistics New Zealand, 2013). This scale was used in this study to allocate parental employment to one of three categories: lower skilled (machine operator, hospitality, assistant, or labourer), skilled (tradesperson, clerk, office, sales, or service staff), and highly skilled (business manager, professional, senior management, or qualified professional). Anyone stating that their main job was 'no paid employment' or 'stay at home parent' was not allocated to a category, as it is not possible to determine a skill level, and these data were not used to determine family SES.

Figure 3.2 shows how three factors were used to determine family SES. For a family to be allocated to a SES category, at least two out of three factors were needed. If one factor fell into each category, students were allocated to middle family SES. 

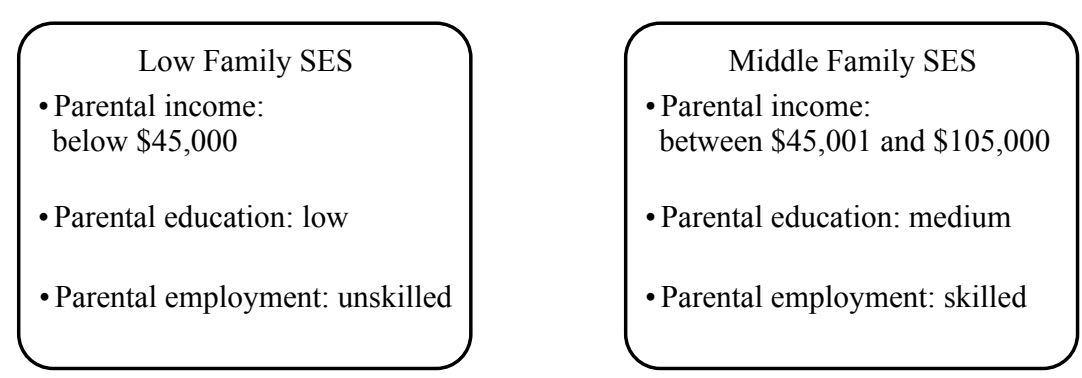

$$
\begin{aligned}
& \text { High Family SES } \\
& \text { - Parental income: } \\
& \text { above } \$ 105,001 \\
& \text { - Parental education: high } \\
& \text { - Parental employment: highly }
\end{aligned}
$$$$
\text { above } \$ 105,001
$$

- Parental education: high skilled

Figure 3.2: Determinants of Family SES

Table 3.6 shows the percentage of students from each SES background that participated in the research.

Table 3.6: Family SES of students at Pīwakawaka and Whio Schools

\begin{tabular}{lcc}
\hline Family SES & Pīwakawaka School & Whio School \\
\hline High & $53 \%$ & $5 \%$ \\
Middle & $39 \%$ & $27 \%$ \\
Low & $8 \%$ & $68 \%$ \\
\hline
\end{tabular}

\subsection{Validity and Reliability}

Validity is required in both quantitative and qualitative research, as without it the research is considered invalid (Cohen et al., 2007). In qualitative research, validity is operationalised as trustworthiness, and can be considered as the degree to which the tools used actually measured the constructs for which they were intended (Opie, 2004). Trustworthiness is "addressed through honesty, depth, richness and scope of the data achieved, the participants approached, the extent of triangulation and the...objectivity of the researcher" (Cohen et al., 2007, p. 133).

In case study research, four tests can be used to establish the level of trustworthiness of the research (Yin, 2003). These tests examine the construct validity, the internal validity, the external validity, and the reliability (Yin, 2003). Furthermore, the use of several data collection methods allows for triangulation (Cohen et al., 2007).

Construct validity refers to how accurately the constructs within the research are measured and defined (Cohen et al., 2007). In case study research, construct validity is used during the data collection phase (Yin, 2003) and is developed through the "use of multiple sources of evidence [and] establish[ing] a chain of evidence." (Yin, 2003, p. 35). In this research, data about the range of potential influences on student achievement 
in mathematics were gathered from a range of sources (Appendix A), and through a range of data collection methods (Cohen et al., 2007). Additionally, the data collection tools used in this research were based on those from other researchers, but adapted to meet the requirements of this study. The definitions of the constructs, discussed in Chapter 2, apparently influencing student achievement in mathematics also add to the construct validity of this research (Cohen et al., 2007; Johnson \& Christensen, 2012).

Internal validity refers to the need for the data gathered to support the explanations given (Cohen et al., 2011), that is, it should be possible to find evidence in the data which may be causing the effects observed (Johnson \& Christensen, 2012). Yin (2003) suggests that in case study research, internal validity is established during the data analysis phase and is strengthened through the development of explanations, whilst also considering alternative explanations. Internal validity requires data to be transparent, thereby allowing causal relationships to be supported (Cohen et al., 2011; Yin, 2003). In this research, the use of several data collection methods helps to build the transparancy of data.

External validity refers to whether the findings can be generalised to other situations (Cohen et al., 2011; Yin, 2003). External validity is built into the research at the design phase, through the use of replication logic (Yin, 2003). Due to the limited scope of this research, findings cannot be viewed as generalisable to other schools. However, generalisability was not the purpose of the research. The purpose of this research was to find any theories that emerged from the data that may suggest reasons for the influence of SES on students' mathematics achievement. In this sense, the findings are generalisable to the theories that have been developed as the outcome of the research (Yin, 2003). Additionally, the repeated use of the data gathering tools in other settings may, over time, allow for replication logic (Johnson \& Christensen, 2012; Yin, 2003).

Reliability is a term generally used in quantitative research and is often considered as referring to the scores achieved in tests. In this research, the national standards mathematics data gathered for participant students could be considered reliable (see Section 3.4.3). In qualitative research, the term reliability is frequently substituted for dependability. Dependability refers to how accurately the data gathered reflect the actual events, and whether the data would be replicated at different times, or in different places (Yin, 2003). Dependability is developed through the data collection phase, through the use of case study data collection methods (Section 3.4). To develop 
dependability, the data gathering tools used should result in data and findings that are the same every time (Suter, 2006). The use of trialling (Section 3.5.6) for the data gathering tools helped to increase the level of dependability (Johnson \& Christensen, 2012). Throughout this research, the practices that enhance dependability (reliability) and validity, e.g., triangulation, were consistently used.

The strength of the evidence contributing to the emergent theories from the analysis was increased through the use of data collected from several sources (Johnson \& Christensen, 2012):

Triangulation is the way to get to the finding in the first place - by seeing or hearing multiple instances of it from different sources by using different methods and by squaring the findings with others it needs to be squared with. (Miles, Huberman, \& Saldaña, 2014, p. 300)

Through the iterative process of grounded theory, it was possible to triangulate the data during analysis. Several data collection methods were used for triangulation, helping reduce the amount of researcher bias, as data gathered from different sources, in different ways, were used to build a broad understanding of the construct (Cohen et al., 2007).

\subsubsection{Researcher bias}

Researcher bias suggests that a researcher may find what they were looking for in the data because they wanted to find it (Johnson \& Christensen, 2012). By basing data collection tools on those used by others, the influence of the researcher on the data collected was reduced. The researcher and participants inevitably interact with, and therefore influence, each other (Guba \& Lincoln, 1999). However, when managed well, this interaction can be beneficial, rather than problematic (Guba \& Lincoln, 1999). To do this, the researcher must:

recognize that their own backgrounds shape their interpretation, and position themselves in the research to acknowledge how their interpretation flows from their personal, cultural, and historical experiences. (Creswell, 2014, p. 8)

Researcher bias can be reduced through the use of reflexivity (Johnson \& Christensen, 2012); therefore, in this research I thought critically about my biases, conceptions, and beliefs. I have worked in both high and low decile schools in New Zealand and overseas, experiencing first hand the differences family SES and school 
SES appear to have on students' mathematical achievement. It was these experiences that were catalysts for this research.

Yin (2003) suggests that one way to reduce researcher bias is to be open to unexpected and alternative findings. As a classroom teacher, and mathematics leader, I had developed ideas about influences on student achievement. I believed I knew what made my students successful, and also recognised that every student, teacher, school, and home is different. For this reason, I did not believe in a 'one-size-fits-all' approach to teaching and learning. I expected to find a range of factors in all four areas (teacher, student, school, and home) that influenced student achievement positively and negatively. During the data collection and analysis phases I remained open to unexpected findings. Whilst the findings did suggest that a range of factors were influencing students' mathematics achievement, the nature of these factors, and the way in which they were interacting, was unexpected.

\subsection{Ethical Considerations}

This research was approved by the Victoria University of Wellington Human Ethics Committee. Informed consent was sought from the schools' principals, participant teachers, participant students, and participant families. All participants were given an information sheet, and provided a signed consent form (Appendices $\mathrm{K}$ and $\mathrm{L}$ ). In the case of minors, both students, and their parents provided a signed consent form (Johnson \& Christensen, 2012). The names of participant schools, principals, teachers, students, and their families were kept confidential to myself, and my supervisors. 


\section{Chapter 4: The Amount of Mathematics Undertaken}

The data gathered in this research contained multiple elements that occurred simultaneously, working both independently and interacting with each other, which may have been influencing student achievement. This web of construct interaction mirrors the complexity of teaching. Through the iterative use of describing, conceptual ordering, and theorising (Strauss \& Corbin, 1998), it was possible to construct two main theories which are the foci of Chapters 4 and 5 .

This chapter focuses on the emergent theory that the amount of mathematics students undertake possibly influences their level of achievement. Factors contributing to the amount of mathematics students undertook varied, and included: time spent teaching and learning mathematics (Walberg, 1988) (Section 4.2.2); classroom mathematics interactions (NCTM, 2000; Protheroe, 2007) (Section 4.2.6); and home mathematics interactions (Cotton, 1990) (Section 4.2.7). The amount of mathematics refers to the time spent interacting with mathematics tasks, the number of mathematics tasks students interacted with, and the potential learning afforded by the mathematical tasks. The data from classroom observations, interviews, and surveys suggest that students at Pīwakawaka School interacted with more mathematics tasks, at more appropriate levels of challenge, and for more time, than students at Whio School. Excerpts within this chapter reflect what was typically happening during lesson observations, and what was being said during principal, teacher, and student interviews.

Chapter 5 focuses on the emergent theory that the number of opportunities provided in which students can learn mathematics possibly influences their level of achievement. Historically, research has considered the concept of opportunities to learn as being composed of many factors, including time spent on teaching (Baker, Fabrega, Galindo, \& Mishook, 2004; Sørenson \& Hallinan, 1977). However, research has shown that student achievement benefits from a focus on both quantity and quality of instructional classroom time (Moore \& Funkhouser, 1990). For this reason, this research separates time spent on learning mathematics from opportunities to learn, and instead considers it as part of the amount of mathematics undertaken. 


\subsection{A Model for Teacher-Student-Mathematics Interactions}

This chapter begins by introducing a new model for the different ways in which teacher and students interact both with each other and the mathematical task. In mathematics lessons, teachers and students in both whole class and group situations can interact with mathematics and each other in different ways. Generally speaking, these types of interactions can be divided into five scenarios:

1. no-one interacts with mathematics;

2. one student interacts with mathematics, and the teacher;

3. some students interact with mathematics, and the teacher;

4. all students interact with mathematics, and the teacher;

5. all the students interact with the mathematics task, and the teacher observes.

Figure 4.1 represents scenario one where no-one in the group or class, including the teacher, is interacting with mathematics. It is in this scenario that students undertake the least amount of mathematics. Throughout this thesis, these types of interaction are referred to as no mathematical interactions (NMI).
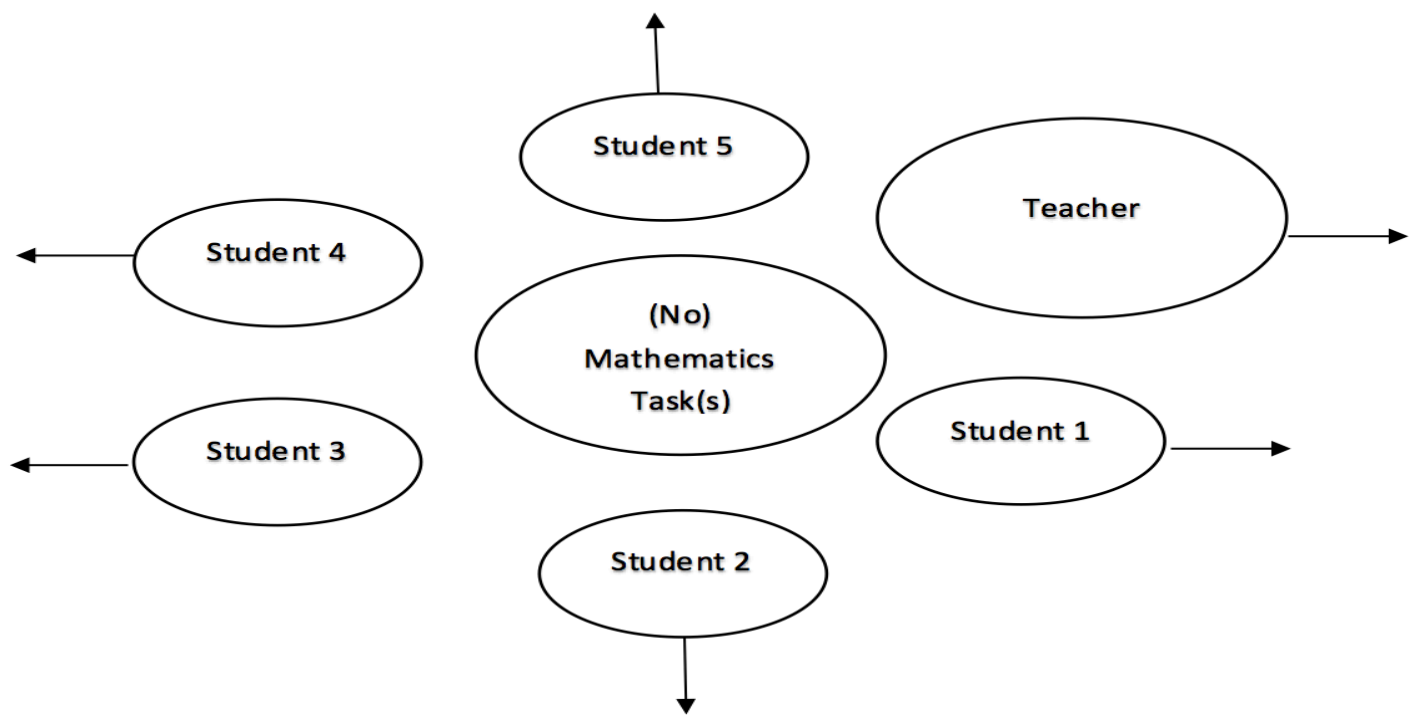

Figure 4.1: No Mathematical Interactions

Figure 4.2 represents scenario 2 where one student interacts with mathematics, and the teacher, but the other students in the class or group do not. This scenario may arise when:

- the teacher sets a mathematical task, and the students not working with the teacher choose to not interact with it; 
- the teacher sets a mathematical task, and expects each student to interact with it in turns; or

- when working with a student the teacher does not set a mathematical task for other students to interact with.

In this scenario only one student is interacting with mathematics at any given time, potentially greatly reducing the amount of mathematics the other students in the class or groups is undertaking. Throughout this thesis, these type of interactions will be referred to as single mathematical interactions (SMI).
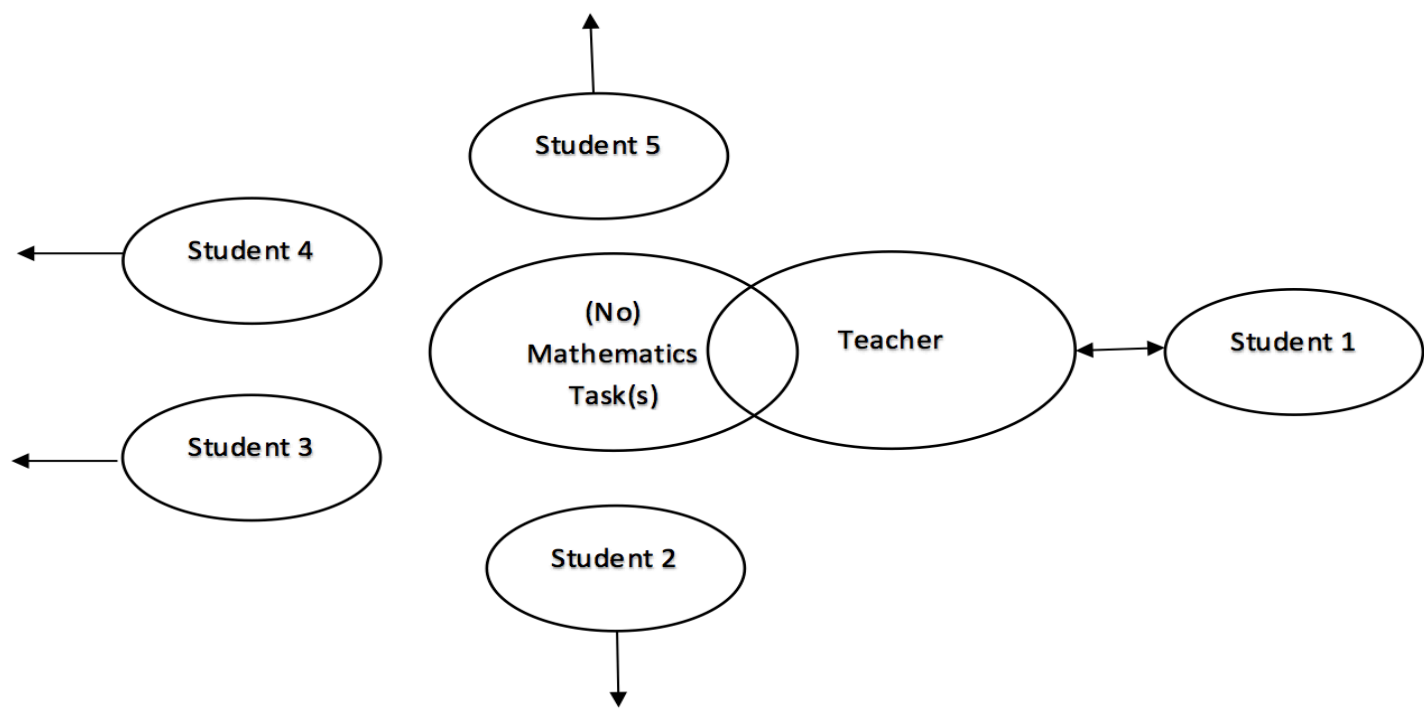

Figure 4.2: Single Mathematical Interactions

Scenario 3 is represented in Figure 4.3, and reflects a situation where some students in the class or group interact with the mathematics task while the teacher works one to one with a student, but some other students do not interact with the mathematics task. Whilst the amount of mathematics students undertake in this scenario is greater than in scenarios 1 and 2, there is still time spent not interacting with mathematics. These types of interactions are referred to as intermittent mathematical interactions (IMI). 

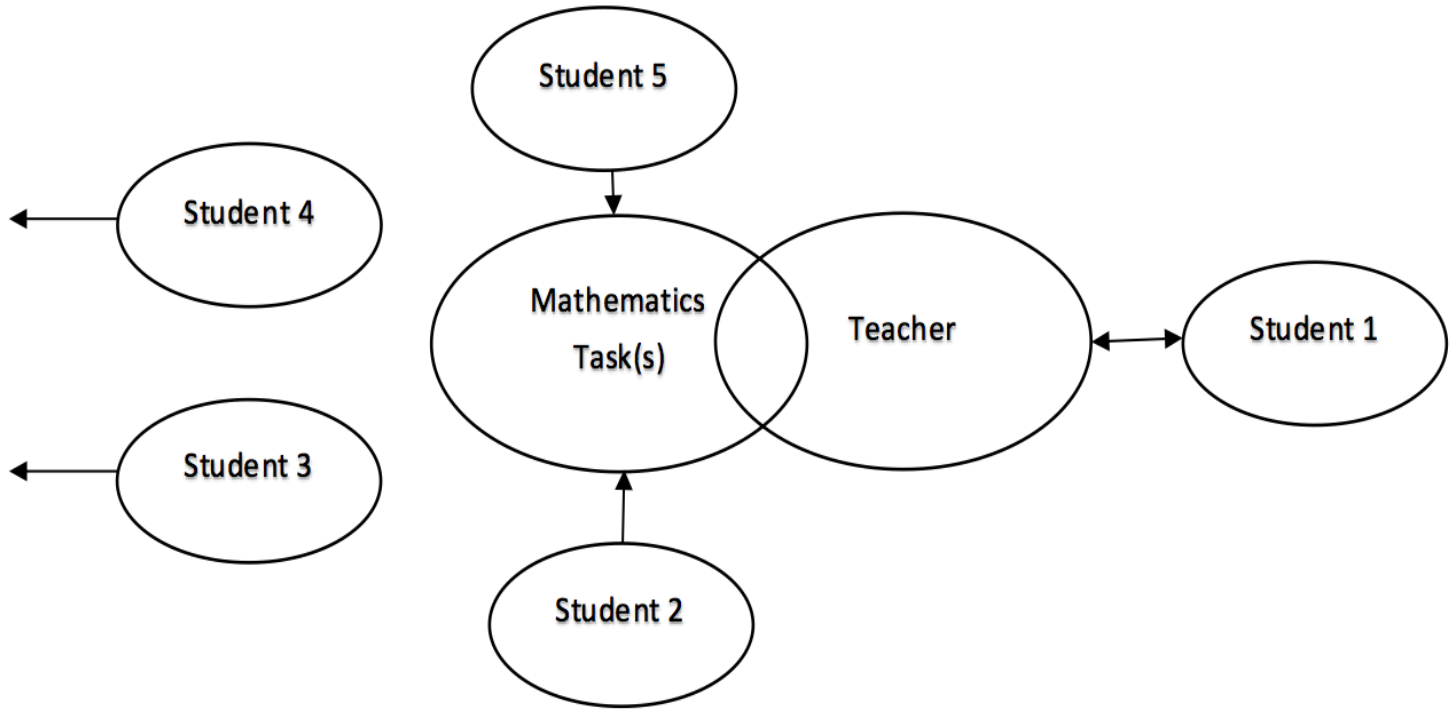

Figure 4.3: Intermittent Mathematical Interactions

The fourth scenario, shown in Figure 4.4, represents a situation where the teacher has engaged all students in the group or class so that they are interacting with a mathematics task at all times, and the teacher is also working one to one with a student. It is in this scenario that students undertake the greatest amount of mathematics. These types of interactions are referred to as complete mathematical interactions (CMI).

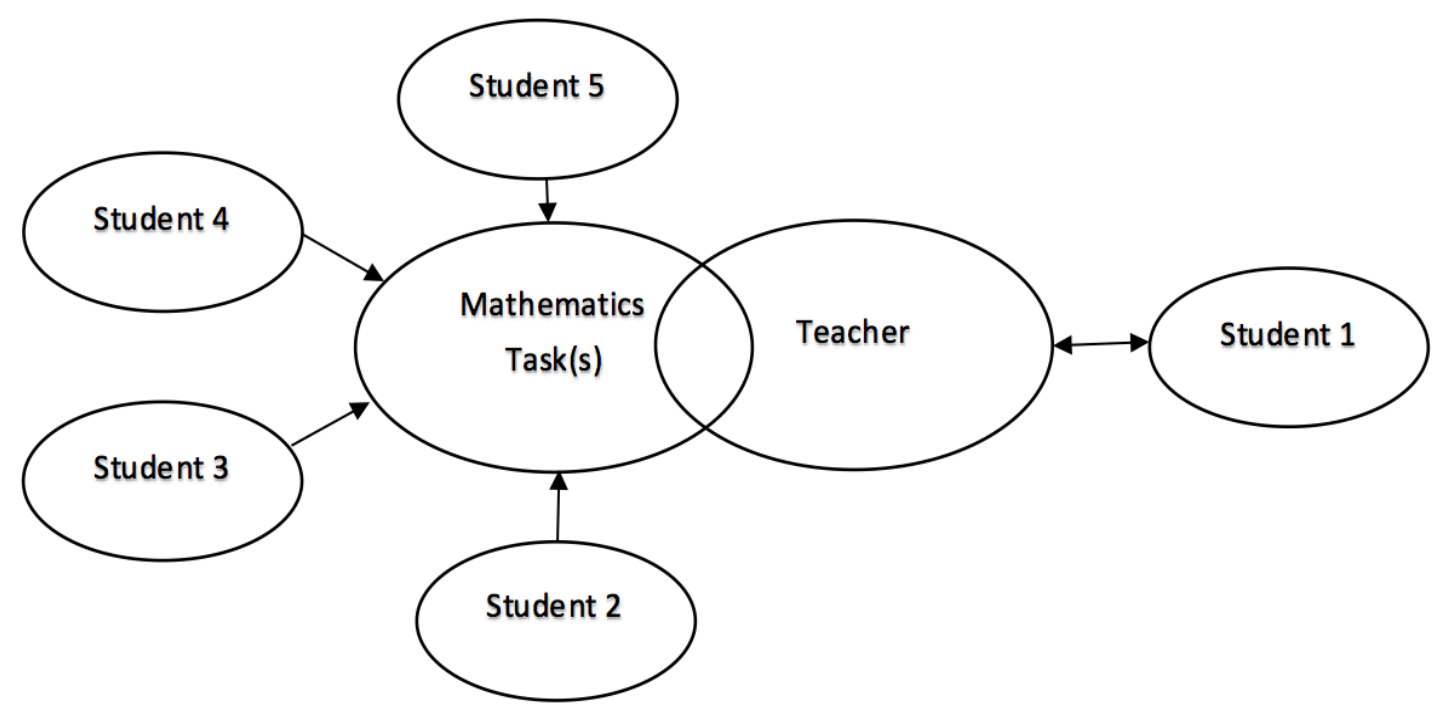

Figure 4.4: Complete Mathematical Interactions

The fifth scenario, shown in Figure 4.5, shows a situation where the teacher engages all students in the group or class so that all students are interacting with mathematics, while the teacher observes the students working, but does not interact with them. Along with scenario 4, this scenario allows students to undertake the greatest amount of mathematics. This scenario is referred to as group mathematical interaction (GMI). 


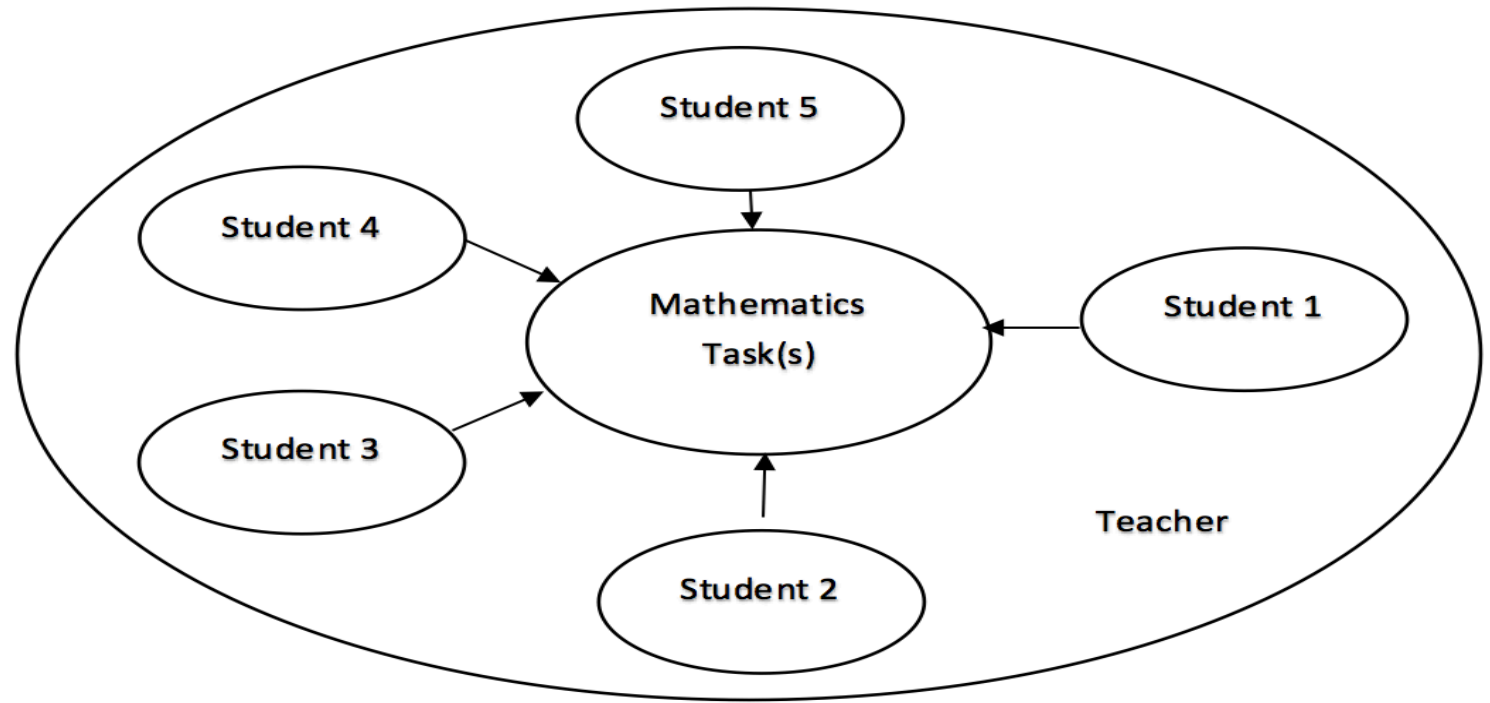

Figure 4.5: Group Mathematical Interactions

\subsection{Results and Discussion}

Each of the following subsections present the results of the data analysis, and is immediately followed by a discussion of the results for the amount of mathematics students had undertaken, both in lessons and at home.

\subsubsection{The use of mathematical interactions}

\section{Results}

All five of the scenarios outlined in the model above were seen during classroom observations of both whole class and group teaching in both schools. During the analysis of observation data, for a student to be determined as not interacting with mathematics, they had to be observed engaging in off-task behaviours (Section 2.1.7). Examples of observed off-task behaviours included leaving the group table, talking to students from outside the group, and climbing on their chair whilst facing away from the teacher. If a student was not observed engaging in these off-task behaviours, they were considered to be on task as it was possible they were listening to the mathematical conversation. Due to the practicalities of classroom observations, when the observation focused on group teaching what was happening in the rest of the class not recorded and it was assumed the remainder of the class was interacting with mathematics while working independently.

At Whio School, the most frequently observed interaction types identified in the model for student-teacher-mathematics interactions were SMI and IMI, with NMI seen to occur in two out of the three participant classrooms. NMI were caused by either an 
external interruption, or the teacher not being prepared for students quickly completing the set task. In the excerpt below, taken from the second observation in Wanda's classroom, Wanda's students were moving between tasks when two external interruptions occured, leaving the students without any mathematical tasks:

Wanda asks her group to tidy away and move to the next activity. Two older students come into the classroom to deliver milk for students at lunchtime. At the same time, a parent interrupts the lesson to take a student out of school. The teacher asks the students to leave the milk and begins a conversation with the parent. The students in the class are moving around and chatting, and no one has moved to the next activity. (Observation 2, Wanda)

A typical SMI scenario at Whio School is exemplified in an excerpt taken during Whitney's first lesson observation. Whitney expected each student in her group to take a turn repeating the name of a fraction shown on a card. This appeared to be a task that students had previously completed as they knew what to do without being asked. As the students knew they only had to name the fraction shown to them, it was possible that they did not need to think about what to say either before or after their turn. Additionally, students could be identified in data from video recordings as not being on task as some were looking away from the table, whilst others were climbing on their chair:

Whitney moves to her group table and picks up a fractions die. She rolls it and asks each of the students to take a turn naming the fraction she rolls. She then takes out a set of cards with unit fractions written on them. Whitney puts a card down in front of one student and asks that student to name the fraction. This is then repeated with the second student, then the third and finally the fourth. (Observation 1, Whitney)

This example of IMI involving a group, taken from the first observation in Wanda's classroom, shows some students interacting with the mathematics task, but not others. Wanda has asked the group to work in pairs. By using buddies, Wanda has up to four students in the group interacting with mathematics, although there are six students in the group:

Wanda asks two students from different pairs to simultaneously count out 10 beans each, and then asks their buddy to check that they have counted out 10 . One student finds counting 10 beans very difficult and is moving her finger faster than she is counting. Wanda works with this student to support her counting and matching. Once this student is successful, the teacher moves to the next pair and asks them to count out their beans. While the teacher is working with this pair, another student is climbing around her chair and off-task. (Observation 1, Wanda) 
At Pīwakawaka School, the most commonly observed interaction types identified were CMI, along with some GMI. The example below is typical of a CMI at Pīwakawaka School, involving a group of three students, and was taken from the first observation carried out in Patty's classroom:

\begin{abstract}
Patty puts a 1-20 number line in front of each student. She asks the students to count aloud from 1 to 20 using the number line, touching each number as they go, and then cover the numbers $1-13$ with counters. When she asks the students to add on three counters, all students do this, and one student gives her the answer. Patty asks what number the student started counting from, and all the students refer back to their number line to check. After the students have answered a few questions in this way, Patty writes individual equations in each student's workbook. Whilst the students are working on their own equations, Patty discusses the mathematics one to one with each student. This sequence goes on, with Patty writing new equations in individuals' workbooks as needed. (Observation 1, Patty)
\end{abstract}

In the excerpt below, Paula set her group a problem and was scaffolding them, through the use of equipment and small steps, to a solution. She spent time watching what the students did so she knew exactly what scaffolds were required:

Paula gives her group enough time to count out 32 beans, watching how the students do this. The students talk to each other about what they are doing as they count out the beans. Once the students have 32 beans, Paula introduces the next step in solving the problem. (Observation 3, Paula)

\title{
Discussion
}

The teacher-student-mathematics interaction model illustrates that when teachers use SMI, only one student is expected to attend to mathematics, whereas when teachers use CMI, all students are being expected to attend to mathematics. Abadzi (2009) suggests that "ideally, students should be engaged in learning during the entire time they are in class... It is impossible to have $100 \%$ student compliance and time use, but some systems can become fairly efficient" (p. 8). The differences in the ways in which teachers and students interacted with the mathematics tasks, and each other, in both a whole class or a group situation, appeared to be making an important contribution to the number of students' mathematical interactions.

Throughout this chapter, the results indicate that teachers at Pîwakawaka School, where possible, appeared to use CMI, and teachers at Whio School used a high proportion of SMI, suggesting that students at Pīwakawaka School undertook more mathematics than students at Whio School. 


\subsubsection{Time on mathematics in each participant classroom}

\section{Results}

The scope of this thesis did not allow for all the observations in each participant classroom to be analysed in depth. Instead, an in-depth analysis of one group session from each classroom was conducted. As a result, the time spent on IMI was not calculated, instead the number of students interacting with mathematics was counted. These figures are not the same as the number of students who were expected to be interacting with mathematics by the teacher, i.e., those involved in an IMI, as they may have been off-task when the teacher was not specifically focused on them.

New entrant students are usually less independent than year 6 students, and therefore allocated time is used differently with students of different ages. For this reason, this section compares the time spent on mathematics across different year groups (Figure 3.1), rather than across all classes.

In the analysis of a group observation, shown in Table 4.1, data show that Patty and Wanda spent similar amounts of time working one to one with students. However, the data also show that Wanda spent $41 \%$ of the lesson on SMI, but Patty spent only $5 \%$ of the lesson on SMI. Given that these are new entrant classes, it was to be expected that more time would have been spent working one to one than in classes with older students.

Table 4.1: A Comparison between Schools of the Use of Teaching Time

\begin{tabular}{|c|c|c|c|c|c|c|}
\hline Group Teaching & $\begin{array}{c}\text { Patty } \\
\left(n^{l}=3\right)\end{array}$ & $\begin{array}{c}\text { Wanda } \\
(n=4)\end{array}$ & $\begin{array}{l}\text { Peter } \\
(n=8)\end{array}$ & $\begin{array}{c}\text { Whitney } \\
(n=4)\end{array}$ & $\begin{array}{c}\text { Paula } \\
(n=9)\end{array}$ & $\begin{array}{c}\text { Weston } \\
(n=5)\end{array}$ \\
\hline Length of group session (minutes) & 13 & 12 & 17 & 8 & 14 & 17 \\
\hline All students interacting with mathematics & $48 \%$ & $33 \%$ & $90 \%$ & $15 \%$ & $94 \%$ & $57 \%$ \\
\hline 1 student not interacting with mathematics & $22 \%$ & $8 \%$ & $0 \%$ & $2 \%$ & $0 \%$ & $6 \%$ \\
\hline 2 students not interacting with mathematics & $4 \%$ & $3 \%$ & $0 \%$ & $2 \%$ & $0 \%$ & $0 \%$ \\
\hline 3 students not interacting with mathematics & $26 \%$ & $41 \%$ & $0 \%$ & $81 \%$ & $0 \%$ & $0 \%$ \\
\hline 4 students not interacting with mathematics & $\mathrm{N} / \mathrm{A}$ & $15 \%$ & $0 \%$ & $0 \%$ & $0 \%$ & $31 \%$ \\
\hline 5 students not interacting with mathematics & $\mathrm{N} / \mathrm{A}$ & $\mathrm{N} / \mathrm{A}$ & $0 \%$ & $\mathrm{~N} / \mathrm{A}$ & $0 \%$ & $6 \%$ \\
\hline 8 students not interacting with mathematics & $\mathrm{N} / \mathrm{A}$ & N/A & $10 \%$ & $\mathrm{~N} / \mathrm{A}$ & $5 \%$ & $\mathrm{~N} / \mathrm{A}$ \\
\hline 9 students not interacting with mathematics & $\mathrm{N} / \mathrm{A}$ & $\mathrm{N} / \mathrm{A}$ & $\mathrm{N} / \mathrm{A}$ & $\mathrm{N} / \mathrm{A}$ & $1 \%$ & $\mathrm{~N} / \mathrm{A}$ \\
\hline Total & $100 \%$ & $100 \%$ & $100 \%$ & $100 \%$ & $100 \%$ & $100 \%$ \\
\hline CMI & $48 \%$ & $33 \%$ & $90 \%$ & $15 \%$ & $94 \%$ & $57 \%$ \\
\hline SMI & $39 \%$ & $42 \%$ & $9 \%$ & $85 \%$ & $5 \%$ & $31 \%$ \\
\hline GMI & $4 \%$ & $6 \%$ & $38 \%$ & $0 \%$ & $44 \%$ & $3 \%$ \\
\hline No mathematics interaction from teacher & $5 \%$ & $13 \%$ & $0 \%$ & $0 \%$ & $1 \%$ & $6 \%$ \\
\hline
\end{tabular}


In the year 3/4 classes, the duration of Peter's group session was recorded as more than twice that of Whitney. Furthermore, Peter had all students in his group engaged in CMI for $90 \%$ of the lesson, and spent only $9 \%$ on SMI, compared with Whitney who used CMI for only $15 \%$ of the group time, but spent $87 \%$ of group time on SMI. One way in which Peter increased the time spent on CMI was by ensuring that all the students in the group had access to their own tools for writing:

The group working with Peter at the group table are told what equipment they needed to bring with them, which is a whiteboard, whiteboard pen, pencil, and maths book. (Observation 2, Peter)

For three out of four students, $81 \%$ of Whitney's group time did not involve interacting with mathematics. The following example shows that students who were not interacting with the teacher were not given any other mathematical task to interact with. Additionally, the data from the video recording, capturing students' behaviour, show students were not attending to the mathematical conversation taking place between teacher and student:

Whitney takes out a set of cards with unit fractions written on them. She puts a card down in front of one student and asks that student to name the fraction. This is then repeated with the second student, then the third and finally the fourth. Each fraction is named correctly. Whitney repeats this activity with a second set of cards, and again the students name them correctly. Each student gets four turns, except one who gets 3 turns. (Observation 1, Whitney)

In the year $5 / 6$ class comparison, Weston spent $30 \%$ of group time on SMI and with only one student interacting with mathematics for $31 \%$ of the time, compared with Paula who spent $5 \%$ of time on both having only one student interacting with mathematics and SMI.

\section{Discussion}

The above analysis found apparent differences in participant classrooms in the amount of time students interacted with mathematics in three areas. The first area was the time spent on SMI (Tiberius, 1990; Van de Walle \& Lovin, 2006). In the observed lessons, the most important factor in relation to the amount of mathematics undertaken was that during the time the teacher was interacting with one student, the other students in the group were not seen to be interacting with mathematics. In the group analysis for Whitney, the total allocated group teaching time was eight minutes, and for over six of 
those minutes, three out of four students did not seem to be interacting with mathematics. Also of interest is the observation that Patty appeared to work both one to one with a student, and get the rest of her group interacting with mathematics for nearly half the group time, whereas Wanda did not appear to have the remainder of the group interacting with mathematics while she worked one to one with a student. Again, it is worth noting that for a student to be determined not to be interacting with mathematics, they had to be observed engaging in obvious off-task behaviours (Section 4.2.1).

The second finding was the apparent difference in time spent with all students in the group interacting with mathematics (Mid-continent Research for Education Learning, 2010). Both Peter and Paula were observed spending almost all their group lesson on CMI, whereas Whitney appeared to spend only $15 \%$ of the group lesson on CMI.

The third difference is the observation that students at Pīwakawaka School seemed to spend more group time on GMI (Chappell et al., 2004). There is little evidence to suggest that teachers at Whio School used GMI, whereas the evidence suggests both Peter and Paula allocated over a third of the group time to GMI. During GMI, teachers appeared to gather formative assessment data (Section 5.1.3) by observing their students working, and listening to their discourse. "It is only when teachers know what students do and do not understand that they can structure instruction to support students' learning" (Chapin \& O'Connor, 2007, p. 118).

The combination of these three findings suggest that student achievement in mathematics at Whio School could be increased by changing the nature of interactions in mathematics lessons (Rossmiller, 1983), and further adds to the argument that "gains in student achievement are likely to occur when...effective teaching practices... are tailored to learning needs" (Moore \& Funkhouser, 1990, p. 16).

\subsubsection{Time on mathematics in each school}

\section{Results}

Each of the four lessons observed in each classroom was analysed to find out how teachers were using the time allocated to mathematics. The results, in Table 4.2, show that teachers at Whio School spent 4\% less allocated time teaching mathematics than teachers at Pīwakawaka School. The areas where there were the greatest differences in the use of time were transitions between groups and activities, and in tidying up both after and during the lesson. 
Table 4.2: Use of Allocated Mathematics Time

\begin{tabular}{lcc}
\hline & Pīwakawaka School & Whio School \\
\hline Total teaching & $82.9 \%$ & $79.0 \%$ \\
Total interruptions & $2.9 \%$ & $1.7 \%$ \\
Total behaviour management & $2.7 \%$ & $3.3 \%$ \\
Behaviour management whilst students are engaged & $0.9 \%$ & $0.9 \%$ \\
Teacher off-task & $3.7 \%$ & $3.8 \%$ \\
Transition & $6.0 \%$ & $8.6 \%$ \\
Tidying & $0.9 \%$ & $2.7 \%$ \\
\hline
\end{tabular}

\section{Discussion}

Overall, whilst there were small variations in allocated time between Whio School and Pīwakawaka School (Section 3.3.3), it appeared that teachers at each school used that allocated time slightly differently. At Whio School the average observed lesson length was 60 minutes, and at Pīwakawaka School the average observed lesson length was 53 minutes. Whilst the variations in lesson length could have impacted on the amount of mathematics students at the two schools interacted with, this appears not to be the case. At Whio School, the frequent use of SMI in both whole class and group teaching (Section 4.2.2), as well as the increased amount of time spent on transitions and tidying, suggest that any additional allocated time was not used to increase the amount of mathematics students undertook. Additionally, the data suggest that teachers at Pīwakawaka School spent 4\% more of the allocated time on teaching, i.e., engaged time (Walberg et al., 1994) compared with teachers at Whio School.

These findings suggest that students at Pīwakawaka School appeared to spend slightly more allocated time interacting with mathematics than students at Whio School. If those lessons observed were typical, then over the course of a year this may contribute to the observed differences in the levels of mathematics achievement between the two schools.

\subsubsection{Lesson interruptions}

\section{Results}

Table 4.3 identifies reasons mathematics lessons were interrupted during all four observations in each classroom in both schools. While the total number of interruptions to mathematics lessons were similar, the causes of those interruptions were different. 
Table 4.3: Interruptions to Mathematics Lessons

\begin{tabular}{llcc}
\hline & & Pīwakawaka School & Whio School \\
\hline External & Late students & 2 & 3 \\
& Message & 14 & 2 \\
Internal & Early finishers & 10 & 23 \\
& ICT issues & 11 & 20 \\
& Teacher explanation & 16 & 3 \\
& Personal & 4 & 6 \\
& Unknown & 0 & 1 \\
& Mathematics equipment & 6 & 8 \\
Total & & 63 & 66 \\
\hline
\end{tabular}

Table 4.3 shows the causes of interruptions that differed between the two schools are early finishers, students needing support with ICT, and the teacher stopping the class to give mathematical explanations. This would suggest that most observed interruptions at Pîwakawaka School appeared to be either out of the teachers' control, or increased the amount of mathematics students were interacting with. At Whio School, however, most observed interruptions appeared to be within the control of the teacher, and reduced the amount of mathematics students were interacting with.

\section{Discussion}

Lesson interruptions can be divided into two categories: those that come from outside the classroom, and those that originate from within the classroom (Leonard, 2001b). The evidence from classroom observations suggests that students at Pīwakawaka School experienced a greater number of external interruptions than students at Whio School.

The number of internal interruptions from students finishing their work before the end of the session and for issues relating to ICT appeared to be more frequent at Whio School than at Pīwakawaka School. These types of interruptions may possibly have been reducing the amount of mathematics done, and it may have been possible to reduce their frequency through altered classroom management strategies (Leonard, 2001b). For example, many of the interruptions for ICT at Whio School appeared to be because students were asking for a password to access the internet. It may have been possible to avoid this form of interruption by prompting the device to remember the password. 
On 23 observed occasions, students at Whio School finished the mathematics given to them by the teacher before the end of the lesson. The apparent lack of further planned mathematics suggests that they may have also finished earlier than the teacher expected them to, and this may have reduced the amount of mathematics students were attending to (Chappell et al., 2004). Additionally, this may suggest that participant teachers at Whio School were more likely to underestimate the amount of mathematics students were able to cover in a lesson than participant teachers at Pīwakawaka School. A further difference in internal interruptions appeared to be that of the teacher interrupting the class to give further explanations and discuss the mathematics expected of students, thereby possibly increasing the amount of mathematics undertaken at Pīwakawaka School.

\subsubsection{Behaviour management}

\section{Results}

Table 4.4 shows the number of observed behaviour management events, at classroom level, for each school. These were behaviour management events that were recorded as being managed by the teacher, but there were others managed by teaching assistants (Section 3.3.3) which, for practical reasons, were not recorded. In general, behaviour management events that were not managed by the teacher were not recorded.

Table 4.4: Number of Behaviour Management Events

\begin{tabular}{lcc}
\hline & Pīwakawaka School & Whio School \\
\hline New Entrant/year 1 and 2 & 38 & 118 \\
Year 3/4 & 17 & 41 \\
Year 5/6 & 30 & 29 \\
Total & 85 & 188 \\
\hline
\end{tabular}

Almost three times more behaviour management events took place in Wanda's new entrant/year 1 classroom than in any other participant classroom, and more than in all the Piwwakawaka School classrooms combined. It is of note that the large majority of behaviour management events in Wanda's classroom appeared to be minor, not lasting more than one or two seconds, but they were frequent and continual. 


\section{Discussion}

The difference in the frequency of behaviour management events between the two schools suggests that the flow of teaching, and students' thinking and learning, were being interrupted approximately twice as often in Wanda's new entrant/year 1 classroom. The increased frequency of behaviour management issues may possibly have impacted on the amount of mathematics students were interacting with at Whio School. Behaviour management events at Pīwakawaka School were typically less frequent, but took a little longer to deal with. It is possible that one of the reasons Peter's year 3/4 class had the least number of behaviour management events is that he appeared to be proactive in ensuring his students were interacting with mathematics, both through the tasks he chose and also his expectations for the way in which his students interacted with those mathematics tasks.

The data analysis of classroom observations suggest that students were being repeatedly interrupted while they were working (Ranallo, Bareham, \& Chandler, 1997), thereby reducing the amount of 'productive time' (Walberg, 1988) spent on mathematics.

\subsubsection{Classroom mathematics tasks and interactions}

Classroom mathematics interactions can be broken into two categories:

1. the types of mathematical tasks students do; and

2. the way in which students interact with those mathematics activities.

Tables 4.5 and 4.6 show both the number of mathematical activities, and mathematical interactions observed, by school and by teacher respectively (Section 3.5.3).

Table 4.5: Summary of Types of Mathematics Tasks and Interactions by School

\begin{tabular}{llcccc}
\hline & & Piwakawaka School & \multicolumn{2}{c}{ Whio School } \\
\hline & & $\begin{array}{c}\text { Number } \\
\text { of events }\end{array}$ & Percentage & $\begin{array}{c}\text { Number } \\
\text { of } \\
\text { events }\end{array}$ & Percentage \\
\hline $\begin{array}{l}\text { Total Students Absent } \\
\text { Task }\end{array}$ & 14 & 5 & 13 & 9 \\
Type & Worksheet (W) & 26 & 26 & 5 & 5 \\
& Written Teacher Questions (WTQ) & 39 & 39 & 19 & 17 \\
& Oral Teacher Questions (OTQ) & 12 & 12 & 38 & 36 \\
& ICT Based (ICT) & 17 & 17 & 17 & 15 \\
& Mathematics Games (MG) & 7 & 6 & 31 & 28 \\
\hline
\end{tabular}




\begin{tabular}{lcccc}
\hline Interactions & & & & \\
Student Oral Mathematics (OM) & 19 & 21 & 42 & 36 \\
OM 1-1 & 0 & 0 & 24 & 21 \\
Written Mathematics (WM) & 50 & 57 & 31 & 27 \\
Teacher Written Mathematics & 3 & 7 & 0 & 0 \\
(TWM) & & & & \\
TWM 1-1 & 0 & 0 & 2 & 2 \\
Digital Mathematics (DM) & 17 & 19 & 17 & 14 \\
\hline
\end{tabular}

Table 4.6: Summary of Types of Mathematics Activities and Interactions by Teacher

\begin{tabular}{|c|c|c|c|c|c|c|}
\hline & Patty & Wanda & Peter & Whitney & Paula & Weston \\
\hline $\begin{array}{ll}\text { Use } & \text { of } \\
\text { worksheets }\end{array}$ & 5 & 0 & 8 & 0 & 12 & 5 \\
\hline Use of WTQ & 6 & 0 & 16 & 14 & 15 & 5 \\
\hline Use of ICT & 5 & 0 & 6 & 12 & 6 & 5 \\
\hline Use of MG & 4 & 24 & 3 & 4 & 0 & 3 \\
\hline Use of OM & 7 & 27 & 3 & 12 & 5 & 3 \\
\hline Use of OM1-1 & 0 & 12 & 0 & 9 & 0 & 3 \\
\hline Use of WM & 10 & 0 & 25 & 12 & 15 & 19 \\
\hline
\end{tabular}

\section{Attendance}

\section{Results}

Over the course of the observations, the number of students absent was very similar in both schools. However, when viewed as a percentage, it can be seen that, during the observations, while low, the rate of absence at Whio School was almost double that at Pīwakawaka School. Additionally, 6 out of Pīwakawaka School's 14 absences came from one class, in one day, as on that day the students in that class suffered from an infectious medical condition. However, there tended to be one or two students absent from each class during each observation at Whio School. This evidence suggests that the rate of absence may not be typical for Pīwakawaka School, but may have been typical for Whio School.

\section{Discussion}

In order to increase achievement, students need to interact with mathematics in a range of different ways, and contexts within the classroom (Mid-continent Research for Education Learning, 2010). Whilst there is no right way to teach mathematics (NCTM, 2000), students should be "provided with a variety of opportunities to communicate mathematically." (Protheroe, 2007, p. 54), and use "manipulatives and other tools" 
(Protheroe, p. 54). When students do not attend school, for whatever reason, they are missing out on the opportunity to interact with mathematics in the classroom, which may lead to lower levels of achievement (Parke \& Kanyongo, 2012). The levels of absence suggest that, on average, students at Whio School may be absent more frequently than those at Pīwakawaka School, which implies that the amount of mathematics undertaken was reduced for some students at Whio School.

The following sections discuss four of the different ways in which the teachers at Pīwakawaka School and Whio School appeared to be using tasks to increase the amount of students' mathematical interactions.

\section{Written mathematics}

\section{Results}

The amount of written mathematics interactions (Section 2.1.8) students were observed having in each school appeared to be different. In Pīwakawaka School, students in all classes were observed interacting with tasks that required them to do written mathematics 50 times over the course of the observations. However, students at Whio School were observed interacting with tasks that required them to attend to written mathematics 31 times. Furthermore, the students in Wanda's class were recorded as not being given any written mathematics. This difference also applied to the written mathematics that students saw their teacher do. There were 42 tasks recorded as having been written by the teacher at Pīwakawaka School compared with only 19 tasks observed as having been written by the teacher at Whio School.

\section{Discussion}

The use of written mathematics is important for the development of deep knowledge, as well as clarification of students' understanding (Mid-continent Research for Education Learning, 2010). Teachers at Pīwakawaka School appeared to provide tasks that ensured their students were using, and observing the use of, written mathematics in every observed lesson, but this did not seem to be the case at Whio School. The observation data indicated that students in Wanda's class did not do written mathematics over the four observations, and Wanda was observed modelling mathematical writing only once. The written mathematics observed being done by students in Whitney's class seemed to be limited to providing numerical answers to equations, or writing a mathematical symbol when requested. Students in Weston's class 
were observed being provided with many opportunities to interact with written mathematics, including watching their teacher model mathematics.

It is in the context of tasks for practising written mathematics that worksheets appeared to be used in both schools. Over the course of the observations, students at Pīwakawaka School were observed being given worksheets as a task 20 more times than at Whio School. Each participant teacher in each observed lesson at Pīwakawaka School gave students worksheets as independent activities, which allowed them to practise writing mathematics, and practise doing mathematics, without the teacher being there. Only Weston was observed using worksheets for written mathematics at Whio School, suggesting most students were not getting to practise written mathematics independently. The apparent differences in the frequency of the use of worksheets in each of the schools also appeared to provide varying opportunities for students to interact with written mathematics.

The amount of written mathematics being used in each school (Table 4.6) seems to be different. Students in the observed lessons at Pīwakawaka School appear to have been interacting with written mathematics more frequently than students in the observed lessons at Whio School. This suggests that students at Pīwakawaka School may have been developing a deeper knowledge and understanding of mathematics than students at Whio School.

\section{Oral mathematics}

\section{Results}

Oral mathematics (Section 2.1.8) refers to tasks that were designed to be done through the use of discourse, rather than writing, and does not include the mathematical discourse that occurred as part of an activity originally given as a written task. The use and type of discourse in mathematics lessons appeared to be different at the two schools. At Pīwakawaka School, opportunities for students to do tasks that involved talking about mathematics were limited to mathematics games and whole class discussion. At Whio School, opportunities for doing tasks by talking, which is promoted in recent literature, appeared to be frequent, and encouraged by teachers, although students often appeared reluctant to discuss their mathematics:

The students work alone on the question, and the teacher asks if they have discussed it with their buddy, telling them it does not matter if they are right or 
wrong. When the students do not talk to their buddy the teacher again asks them to discuss their idea. (Weston, Observation 2)

A further difference was the number of tasks that were answered orally during SMI. This was not observed happening at Pīwakawaka School, but there were 24 observed incidents (24\%) of students answering questions orally, which predominantly required only an answer to a problem, during SMI at Whio School. In Whitney's class, answering questions orally during SMI took place during group teaching. In Wanda's class, answering questions orally during SMI occurred both during the starter and during group work with the teacher. In Weston's class, three out of the four lesson starters observed involved SMI where students took turns to answered questions orally. The following excerpts are both taken from the whole class starter part of the lesson, and reflect the differences observed in the use of oral mathematics between the schools:

\footnotetext{
When the students are ready, the teacher rolls the dice, and chooses a student to answer the question. This is repeated for seven questions after which a student says they have won and the starter ends. (Weston, Observation 4)

The students are all asked to stand and show $1 / 2,1 / 4$ and $1 / 3$ with their bodies. Patty models this by moving her arms and repeating the fraction names. The students copy. One student is reluctant to join in, but does so when he sees what everyone else is doing. (Patty, Observation 1)
}

\section{Discussion}

The oral mathematics students were observed using at Whio School appeared to follow the social norms of turn taking, with the teacher taking the lead role in the IRF exchange (Initiation-Response-Feedback) in both whole class and group situations (Dalton-Puffer, 2007). Furthermore, the way in which teachers at Whio School appeared to be using the IRF exchange meant that only the student selected to provide a response seemed to be interacting with mathematics (Dalton-Puffer, 2007; Galton, Hargreaves, Comber, Wall, \& Pell, 1999).

Data from both observations and teacher interviews suggested that productive classroom discourse (Chapin \& O'Connor, 2007) was apparently being used infrequently at Whio School, despite teachers reporting experiencing professional development in this area. However, mathematical discourse (Chapin \& O'Connor, 2007) was observed being used during whole class discussions in two out of the three participant classrooms at Pīwakawaka School. 
These findings, and the data from teacher interviews, suggest that teachers at Pīwakawaka School enacted more constructivist beliefs (Sections 1.6 and 2.1.1) than teachers at Whio School, and therefore expected their students to construct mathematical knowledge and understanding through the use of discourse.

\section{ICT and mathematics}

\section{Results}

Although the number of tasks that required students to use ICT (Section 2.1.8) were the same in each school, the way teachers talked about how they used ICT varied between the schools. Teachers at Pîwakawaka School all used the same online programme (Mathletics), and they all had a clear, planned purpose for using ICT. The following excerpt is taken from Peter's interview, where he discusses planning for the use of ICT. Additionally, teachers at Pīwakawaka School expected students to use ICT at home to further interact with mathematics:

We've got Mathletics...for homework... It's all set up for them [students] based on their level, so...the Stage 5 kids, they get Stage 5 stuff... Every week...I assign tasks and this week it's all fractions stuff because that's what we're doing in class... [and] there's a little bit of decimal work on there for knowledge. Each group gets one session a week in class...for those kids who... have limited internet access at home. (Peter)

Mathletics...is very strong...the good thing with that is [students] can continue...learning at home... I think the ICT is quite good for making their knowledge more instant...it's good for improving their basic recall and basic facts and number knowledge. (Patty)

At Whio School, teachers were using different programmes, and time spent on devices frequently appeared to be allocated to early finishers rather than being planned. Additionally, teachers at Whio School did not appear to expect students to use ICT at home (Section 4.2.7):

To be honest I'm probably not using it to the best ability at the moment... We do have Ten Monkey Maths, but I was actually doing that as a whole class little thing... I put it on the screen and we'd have turns coming up and counting things or doing it as a little activity together. (Wanda)

I usually restrict them to one sort of activity at a time...at the moment we're...using something called Ten Monkey Maths and it's free at the moment... When that trial finishes...we will stop using it...and I will go back to using...Studyladder...and maybe a specific app...I find that if you...say...use 
maths apps...on the iPad...they just wander all over the place and don't really do anything specific. (Whitney)

I have downloaded some...fraction app games... We also have...fraction games... on the computers... We're doing proportions and ratios and fractions this term, that's what they are allowed to go on. (Weston)

\section{Discussion}

When ICT in mathematics is planned, and matches student needs, it can increase levels of student achievement (Moseley et al., 1999). The way in which students used ICT appeared to vary between Pīwakawaka School and Whio School. The observation and interview data suggest that ICT may have been strategically used at Pīwakawaka School to provide students with additional purposeful opportunities to interact with mathematics at an appropriate level (NCTM, 2000; Townsend, 2012). However, whilst students at Whio School appeared to have the same number of opportunities to interact with mathematics through ICT, these opportunities seemed less purposeful and more generic, and did not appear to be targeted at a specific level of challenge (Thorvaldsen et al., 2012). Additionally, the use of ICT to occupy early finishers suggests that at Whio School ICT may not have been regularly experienced equally by all students.

\section{Mathematics games}

\section{Results}

With the exception of Wanda at Whio School, and Paula at Pīwakawaka School, teachers at both schools used mathematics games, but in different ways. Teachers at Pīwakawaka School planned for their use, whereas teachers at Whio School appeared to use them to give early finishers something to do. Wanda did appear to plan for mathematics games, which were used to practise counting. The following excerpts are taken from observations of whole class teaching:

A student approached Whitney to tell her he has no work. She tells him to find a mathematics game to do until the end of the lesson. (Whitney, Observation 3)

The students are asked to get out their number jars, select four numbers, put them in order, and practise counting backwards. The students do this, and practise counting backwards. (Whitney, Observation 1)

Patty shows the students a game where the number word and digit have to be matched. She also shows them a game where two dice are rolled, and the students have to match the number of fish to the digit represented on each die, and then add them together. (Patty, Observation 1) 


\section{Discussion}

Research suggests that when the use of mathematical games is planned, and they meet the purpose of teaching, they may increase levels of student achievement (Sherer, 2012). As with ICT, the frequency of tasks that used games to interact with mathematics was similar across both schools, with the exception of Wanda (Table 4.6). However, the way in which mathematics games were used was different. When Patty asked her students to interact with mathematics games, the evidence from observations suggests that she took the time to explain how to play them, and discussed the mathematical ideas involved (Van de Walle \& Lovin, 2006). Wanda appeared to have identified a need for her students to improve their ability to count backwards, and had created a game which allowed them to do this for a short time each day. However, when students in Whitney's and Weston's classes were observed being given mathematics games, they appeared to be "peripheral to the main business of teaching and learning...as...time fillers and rewards...[with] little relation to the curriculum, either in content or pedagogical focus" (Sherer, 2012, p. 75).

The findings suggest that teachers at Pīwakawaka School were using games to increase the amount of mathematics student undertook, whereas it appeared that teachers at Whio School were more often using mathematical games to fill in time or reward students for completing the tasks set.

\subsubsection{Home mathematics interactions}

Interactions with mathematics at home fell into two categories: homework set by teachers, and other mathematics done at home. The results from the analysis of the parent survey in Table 4.7 show that students at Pīwakawaka School were provided with more opportunities to do mathematics at home, and they also spent more time working with their parents than students at Whio School. The increased number of opportunities to interact with mathematics at home may be a factor possibly contributing to increased levels of student achievement (Trautwein, 2007; Wylie, 2001a). 
Table 4.7: Frequency of doing Mathematics Homework with a Parent

\begin{tabular}{lcccc}
\hline Amount of time & \multicolumn{2}{c}{ Pìwakawaka School } & \multicolumn{2}{c}{ Whio School } \\
& Mother & Father & Mother & Father \\
\hline Everyday & $37 \%$ & $9 \%$ & $0 \%$ & $0 \%$ \\
3 or 4 times per week & $41 \%$ & $26 \%$ & $19 \%$ & $13 \%$ \\
Once a week & $8 \%$ & $21 \%$ & $29 \%$ & $20 \%$ \\
Once a fortnight & $3 \%$ & $3 \%$ & $4 \%$ & $7 \%$ \\
Sometimes & $8 \%$ & $26 \%$ & $38 \%$ & $53 \%$ \\
Never & $3 \%$ & $15 \%$ & $10 \%$ & $7 \%$ \\
\hline
\end{tabular}

\section{Homework}

\section{Results}

At Pīwakawaka School all students were expected to access Matheletics activities from home. Paula discussed how she used ICT to increase the amount of homework students did, and one of her students, Pearl A, discussed the homework that was set in class. Homework was not regularly observed being set by teachers at Whio School, with only Weston expecting students to learn their times tables at home. Paula discussed the use of a single website to create links to all the online resources she wanted her students to use. She suggested that this not only encouraged students to interact with mathematics at home, but it also encouraged her students to do more homework than they would if they were given written work:

I...find these resources on the internet, and I put them all in one place... The kids can give me feedback on the lessons, and so I know what they're struggling with, and I get a daily update... The homework that I gave out last week...is not due until next Monday. Those haikus on the wall are the homework...they've written the poems and sent them to me... If I'd asked them to write...in their homework books and bring them into me, I would have had half a dozen of them on Monday...but because they do it online...it's had 73 views. Now I've only got 27 kids in my class which means they are looking at it over and over... They're able to give me feedback about what they like, and whether they understand things. (Paula)

The Mathletics is on the computer and the basic facts...we glue...into our homework books. (Pearl A)

The students spent the first 20 minutes of the day writing times tables and spellings in their homework notebook. (Weston, Observation 1)

Tables 4.7 and 4.8 show data collected through the family survey about how often students were doing mathematics homework, and the average time spent on all homework with a parent. At Pīwakawaka School three out of the 37 (8\%) participant students lived with a solo mother. At Whio School, 6 out of 22 (27\%) participant 
students lived with a solo mother, and an additional $2(9 \%)$ students lived with a solo father. This suggests that some students may not have had the opportunity to do mathematics with both parents, but the number of solo families does not account for the differences shown in Tables 4.7 and 4.8 as absent parents were not included in the data. However, it should be noted that data were not collected on the mathematical interactions students may have had with other appropriate adults, e.g., older siblings, aunts, or additional tuition.

Table 4.8: Average Time Spent on All Homework with a Parent Each Week

\begin{tabular}{lcccc}
\hline Amount of time & \multicolumn{2}{c}{ Pīwakawaka School } & \multicolumn{2}{c}{ Whio School } \\
& Mother & Father & Mother & Father \\
\hline Up to 1 hour & $11 \%$ & $59 \%$ & $51 \%$ & $38 \%$ \\
Up to 2 hours & $54 \%$ & $12 \%$ & $4 \%$ & $0 \%$ \\
Up to 3 hours & $16 \%$ & $3 \%$ & $5 \%$ & $6 \%$ \\
Up to 4 hours & $5 \%$ & $0 \%$ & $18 \%$ & $0 \%$ \\
Up to 5 hours & $3 \%$ & $0 \%$ & $0 \%$ & $6 \%$ \\
More than 5 hours & $8 \%$ & $0 \%$ & $4 \%$ & $0 \%$ \\
Never & $3 \%$ & $26 \%$ & $18 \%$ & $50 \%$ \\
\hline
\end{tabular}

The data from parent surveys in Tables 4.7 and 4.8 suggest that irrespective of school decile, mothers spent more time with their children on homework than fathers. Additionally, they show that parents at Pīwakawaka School were helping their children with mathematics homework for longer each week than parents at Whio School. They also suggest that the number of students spending up to 2 hours a week on homework was $50 \%$ greater at Pīwakawaka School than at Whio School.

\section{Discussion}

The evidence from interviews suggests that teachers at Pîwakawaka School were providing homework that matched learning objectives (Mid-continent Research for Education Learning, 2010), provided motivation (Cotton, 1990), was given to students regularly (Paschal, Weinstein, \& Walberg, 1984), and provided feedback (Cotton, 1990). When ICT is used to provide homework, it is more likely that parents will become involved in their child's learning (Becta, 2008), which has been shown to increase student achievement (Townsend, 2012). This purposeful use of mathematics homework at Pīwakawaka School seems to have provided students with more opportunities to interact with mathematics than the students at Whio School received. 
Data from parent surveys suggest that a high percentage of fathers in both schools (85\% at Pīwakawaka School and $88 \%$ at Whio School) spent an hour or less doing mathematics homework with their child. However, at Pīwakawaka School 86\% of mothers spent 2 or more hours doing mathematics homework with their child, compared with $31 \%$ of mothers at Whio School. However, it is important to note that classroom observations suggest that no mathematics homework was being set by Wanda or Whitney at Whio School. This would suggest that students at Pīwakawaka School were undertaking more mathematics at home than students at Whio School.

\section{Mathematics at home}

\section{Results}

Additional mathematics, i.e., mathematics not set by a teacher as homework, can take many forms including playing board games, baking, answering questions set by a parent, or using mathematics websites. Students at both schools discussed doing additional mathematics at home during their interviews, with eight out of the nine interviewed students at Pīwakawaka School saying they did mathematics at home. At Whio School, seven out of nine interviewed students said they did additional mathematics at home, but the nature of the mathematics undertaken appeared to be different:

We do Mathletics at home and...the maths test... once a night, or if I find time, and find them difficult...more than once a night... We sometimes...do other stuff...like mum might ask us some times tables during dinner. (Philip AB)

I don't really do maths at home unless there's calculators.

[Do you have a calculator at home?]

Yes, my very own one.

[What do you do with it?]

I just count up numbers. (Wilf B)

Table 4.9 shows data collected through the student survey about how much students enjoy doing mathematics at home.

Table 4.9: Percentage of Students who Enjoy Mathematics at Home

\begin{tabular}{lcc}
\hline & Pīwakawaka School & Whio School \\
\hline Agree & $56 \%$ & $70 \%$ \\
Neutral & $19 \%$ & $11 \%$ \\
Disagree & $22 \%$ & $19 \%$ \\
Do not know & $3 \%$ & $0 \%$ \\
\hline
\end{tabular}


Table 4.10 uses data from the student survey to show whether students perceived their parents as helping them with mathematics at home or not. It should be noted that the question asked about mathematics in general, not mathematics homework.

Table 4.10: Percentage of Students with Parents who Help with Mathematics at Home

\begin{tabular}{lcc}
\hline & Pīwakawaka School & Whio School \\
\hline Agree & $67 \%$ & $61 \%$ \\
Neutral & $11 \%$ & $14 \%$ \\
Disagree & $22 \%$ & $18 \%$ \\
Do not know & $0 \%$ & $7 \%$ \\
\hline
\end{tabular}

Table 4.11 uses data from the student survey to show whether or not students were playing mathematics games at home.

Table 4.11: Percentage of Students who Play Mathematics Games at Home

\begin{tabular}{lcc}
\hline & Pīwakawaka School & Whio School \\
\hline Agree & $81 \%$ & $78 \%$ \\
Neutral & $3 \%$ & $4 \%$ \\
Disagree & $16 \%$ & $7 \%$ \\
Do not know & $0 \%$ & $11 \%$ \\
\hline
\end{tabular}

The data in Table 4.10 show that more students at Pīwakawaka School did mathematics with their parents at home than students at Whio School. However, there did not appear to be much difference in the percentage of students who played mathematics games at home.

\section{Discussion}

The findings suggest that students at Pīwakawaka School may not only have been given the opportunity to interact with mathematics through homework set by the teacher, but their parents also appeared to be providing additional opportunities for them to interact with mathematics at home (Wylie, 2013). Students at Whio School indicated that they were doing mathematics at home, but parents appeared to indicate they were spending less time on mathematics with their children than parents at Pīwakawaka School. Similar proportions of students from both schools seemingly indicated that they played mathematical games at home, which has been found to be the most common way students interact with mathematics outside the classroom (Winter, 2010). 
Students at Pîwakawaka School seemed to have more opportunities to undertake additional mathematics at home with a parent than students at Whio School.

\subsection{Summary}

The evidence provided in this chapter suggests that students at Pīwakawaka School may have undertaken more mathematics when compared with students at Whio School. Teachers at Pîwakawaka School appeared to be using the time allocated to increase the amount of mathematics their students were undertaking, and they also appeared to be providing students with a variety of purposeful ways to interact with mathematics. Additionally, students at Pīwakawaka School also appeared to be doing more mathematics at home, both as homework set by the teacher, and with their parents. The combination of these factors would suggest that students at Pîwakawaka School may have been doing more mathematics than students at Whio School. 


\section{Chapter 5: Opportunity for Learning}

This chapter explores the emergent theory that students who are given more opportunities to learn mathematics have higher mathematics achievement. Opportunities to learn were discussed in Section 2.1.3, and this chapter focuses on three of the classroom-based factors identified by Hiebert and Grouws (2007): level of challenge, including task choice; teacher expectations; and teacher use of assessment, including the use of goals.

Opportunities to learn have been found to extend beyond the classroom and include: materials at home to support mathematics (Wylie, 2013); parental education (Sirin, 2005; Wylie, 2001a); and parental income (Stylianides \& Stylianides, 2010; Wylie, 1999, 2013).

\subsection{Results and Discussion}

In this chapter each section discusses the results of the analysis of data from classroom observations, interviews, and surveys around the opportunities to learn mathematics that students experienced both in and out of mathematics lessons, and is immediately followed by a discussion of these results. As with Chapter 4 , the excerpts used throughout this chapter reflect what was typically happening during lesson observations and being said during principal, teacher, and student interviews. Students' perceptions are considered at the end of the chapter to support triangulation of the data.

\subsubsection{Level of challenge}

\section{Results}

The data in Table 5.1 show the percentage of observed lessons coded: students working in inaccessible knowledge; students working in accessible knowledge; students working in existing knowledge; time on mathematics that could not be allocated to an area of student knowledge; and other non-mathematical activities that took place during observations. The figures in this table reflect that during observations teachers at Pīwakawaka School, the high decile school, spent more time working with accessible knowledge than with existing knowledge (Sections 1.8, 2.1.4, and 3.6.1). On the other hand, teachers at Whio School, the low decile school, were observed spending a much 
higher proportion of instructional time working with existing knowledge than accessible knowledge.

Table 5.1: Percentage of Codes Used

\begin{tabular}{lccccc}
\hline Teacher & $\begin{array}{c}\text { Inaccessible } \\
\text { (Red) }\end{array}$ & $\begin{array}{c}\text { Accessible } \\
\text { (Orange) }\end{array}$ & $\begin{array}{c}\text { Existing } \\
\text { (Green) }\end{array}$ & $\begin{array}{c}\text { Other } \\
\text { Mathematics } \\
\text { (Blue) }\end{array}$ & $\begin{array}{c}\text { Other } \\
\text { (Yellow) }\end{array}$ \\
\hline $\begin{array}{l}\text { Pīwakawaka } \\
\begin{array}{l}\text { School } \\
\text { Whio School }\end{array}\end{array}$ & $0 \%$ & $24 \%$ & $11 \%$ & $57 \%$ & $8 \%$ \\
\hline
\end{tabular}

All three teachers at Pīwakawaka School were observed continually establishing the boundary between existing knowledge and accessible knowledge before teaching in the area of accessible knowledge. These teachers were not observed providing students with answers when they found the work challenging; rather, they used questions to scaffold students' thinking. In the excerpts taken from observations in Patty's and Paula's classrooms, which represent typical interactions, students can be seen to start working with existing knowledge (highlighted green), and then begin working with accessible knowledge (highlighted orange) where scaffolds are provided. Additionally, Patty was able to make decisions about what her students could and could not do as she could see what they were writing. At the end of the excerpts, accessible knowledge is becoming existing knowledge indicating learning has taken place:

\begin{abstract}
Patty asks her class to draw a square and they do. She then asks them to draw a circle, and again they can. Next, Patty asks them to draw a rectangle. The students do not immediately draw the rectangle and begin looking at what others are doing. Some of the students ask what a rectangle is. Patty asks one student, who says he knows, to describe a rectangle, but he appears to lack the vocabulary. She asks this student how many sides a rectangle has, and he tells her four. Patty draws a square on the board and reminds her class that a square has four sides of equal length. She then draws a rectangle on the board and shows her students that a rectangle has two long sides and two short sides. Patty draws some different rectangles on the board (some with longer horizontal sides, some with longer vertical sides), so that her students can see them in different positions. The students then draw a rectangle as asked. The next shape is a hexagon, and again students are unsure, so Patty scaffolds their knowledge until they can all draw a hexagon independently. (Observation 3, Patty)
\end{abstract}

Paula checks each group has 32 beans.

Paula: Of my 32 beans I want to find out $5 / 8$ of 32 .

Paula writes this on the whiteboard, and asks how many groups they need if they are dividing the beans into eighths. The students do not respond.

Paula: If I cut a pizza into eighths, how many pieces will I have?

Immediately the students know it is eight pieces.

Paula: If I'm splitting my beans into eighths, how many groups am I making?

Student: Eight. (Observation 3, Paula) 
In comparison, all three teachers at Whio School spent more time working within the existing knowledge of their students. Whio School teachers also typically provided answers, or changed the direction of teaching, when students began to experience challenge (Section 2.1.4), as shown in the first excerpt below. The data also show participant teachers at Whio School typically did not reach the boundary between existing and accessible knowledge until the end of the lesson, thereby limiting the opportunity to learn. The second and third excerpts below show typical interactions in which the students in the group immediately demonstrate existing knowledge of what is being taught, which is not picked up by the teachers. The use of oral SMI by Whio School participant teachers shows that using formative assessment to establish who had, and did not have, existing knowledge was difficult:

The teacher asks each student to count in 2 s, two students say they cannot, and the teacher does not continue with the task. (Observation 3, Wanda)

To make eighths, the students tell Whitney to fold the already quartered circle in half again, and when she asks what the fraction is, she is told eighths. Whitney asks how many bits there will be when she unfolds it, and a different student tells her eight. She unfolds it, and checks by counting each of the eight pieces, then she asks what fraction one piece is. A third student tells her $1 / 8$. (Observation 4 , Whitney)

\begin{abstract}
The question says that $1 / 2$ of a meat lovers' pizza has been eaten. Weston asks how much is left. A student immediately picks up a circle, and folds it in half showing only half a circle. Weston asks the student to shade in half, and then he shows the shaded circle to the rest of the group. The next question asks the students to show $1 / 4$ of a chicken pizza, and Weston asks a student to prove it is $1 / 4$. The student immediately folds a circle in half, and half again, and shades in $1 / 4$. Weston asks the students if it shows $1 / 4$, and they say it does. (Observation 1, Weston)
\end{abstract}

Additionally, in one classroom at Whio School it appeared that a small amount of time was spent with students working beyond their accessible knowledge. In the excerpt below, Weston can be seen teaching a new concept (finding non-unit fractions of amounts), and scaffolding his students to work with accessible knowledge. However, the lack of some students' knowledge of the 6 times table meant that they were having to work with two unknown ideas, making the knowledge being taught inaccessible. Supporting students to spend time working in both existing knowledge and inaccessible knowledge indicated that teachers were not maximising their students' opportunities for learning: 


\begin{abstract}
Weston informs his students they are going to use the 6 times table, and asks if they know them. Some students say they do, some do not answer. Weston checks their results from a times table test last week, and realises that some do not know their 6 times tables...He asks the students to find $2 / 6$ of $42 \ldots$ Weston notices that some students are struggling, and reminds them to do $6 \mathrm{x} \square=42$. He asks them what to write in the box, but they don't answer him. He asks again if they know the 6 times table, but they do not. Weston asks if they know $5 \times 6$, and they say they do not, until he reminds them it is the same as $6 \times 5$. One of the struggling students suggests 30 and Weston asks what one more group of 6 would be, $30+6$ and a student says 36 . Weston tells them that is 6 sixes, and asks what another group of 6 would be. He reminds them they have added two extra groups onto the 5 , so what is $5+2$. Weston asks the others in the group how they solved it. Weston tries to explain to the struggling students where to start. Just as he begins a student explains that she did $6 \times \square=42$. When asked what she had in the box, she replies 7 . Weston says $7 \times 6=42$ and reminds the group that the times table knowledge is important. (Observation 3, Weston)
\end{abstract}

In their interviews, all three teachers from Pīwakawaka School discussed focusing on the next learning steps for students, and were observed constantly attempting to build on students' existing knowledge. The principal at Pīwakawaka School discussed using formative assessment to inform next learning steps for students. Teachers from Whio School did not specifically mention next learning steps in their interviews. Rather, the observation data suggest that teachers at Whio School focused on what students could already do. Additionally, during the interview the principal at Whio School only mentioned next learning steps in relation to summative assessment:

My biggest belief is...to take the kids from where they're from, and grow them as much as possible...it's just taking them to that next step, and exposing them to as much as possible. (Patty)

So it...opened up, and actually explored a few other key ideas that I wasn't expecting. I was very impressed with the way they were able to do that. (Wanda)

Looking at what the kids actually need to make the next step has been a focus, and then...looking at the planning, and looking at the deliberate acts of teaching that come out of that to meet the needs. (Principal, Pīwakawaka School)

Over the twenty four lesson observations, there were examples of all the participant teachers, except Patty, continuing with a teaching point after most students in the class or group showed that they already had the knowledge and understanding being taught. Table 5.2 shows the number of repetition events that appeared to occur in each classroom. It is worth noting that the total number of observed repetition events for Pīwakawaka School was lower than the number of observed repetition events in any one 
classroom at Whio School, suggesting that repetition events were typical during teaching at Whio School.

Table 5.2: Repetition Events within each Participant Classroom

\begin{tabular}{cc}
\hline Teacher & Number of repetitions \\
\hline Patty & 0 \\
Peter & 6 \\
Paula & 2 \\
Wanda & 10 \\
Whitney & 17 \\
Weston & 9 \\
\hline
\end{tabular}

Peter takes answers from the students, who all got it correct. He then explains how to work it out. (Observation 3, Peter)

The next question is sharing 48 beans between 2 . Immediately a student shouts out 24. Whitney keeps explaining that they already know half of $40=20$. More students call out 24 and Whitney keeps explaining. (Observation 3, Whitney)

Weston asks if anyone else got $18 / 3$ and a student says that makes 6 wholes. Weston ignores this, and asks the other students to convert ${ }^{18} / 3$. Another student says 6 wholes. (Observation 2, Weston)

\section{Discussion}

The observation and interview data suggest that students at Pīwakawaka School spent more time working in the area of accessible knowledge, and less time working within their existing knowledge than students at Whio School. As the principal stated, teachers at Pīwakawaka School appeared to focus on finding the boundary between existing knowledge and accessible knowledge (Sections 1.8, 2.1.4, and 3.6.1), and appeared to focus their teaching and students' learning within this area. By giving students mathematical tasks that were just beyond their existing knowledge, and scaffolding their learning, teachers at Pīwakawaka School appeared to be meeting the challenge of giving "problems that most students [were] not able to do [without teacher scaffolding]" (Mousley et al., 2007, p. 466). However, students at Whio School seemed to spend a large percentage of their time working with their existing knowledge. "Teachers believe that they are matching instruction to the level of the students' ability but the evidence suggests that many pupils find the work they are given is inappropriate; often it is too easy" (Blatchford et al., 2008, pp. 27-28).

Although teachers at both schools wanted their students to feel successful, what participant teachers considered to be success seemed different. The data from 
observations and teacher interviews suggest that participant teachers at Whio School may have wanted their students to feel successful by getting the answer correct most of the time, and not experiencing, and overcoming, struggle. Data from observations and interviews suggest participant teachers at Pīwakawaka School considered their students successful when they had experienced challenge, and learned something new. Pogrow (1988) found that when teachers provide easy, feel good tasks, students were not building confidence in their ability to solve problems, persevere with a task, or use higher level thinking skills. It is when students engage and persist with challenging tasks that they can make connections between the big ideas in mathematics and develop a deep understanding of mathematical concepts (Anthony \& Walshaw, 2007; Cheeseman et al., 2013; Clarke et al., 2014).

The findings suggest that students at Pīwakawaka School were being given increased opportunities to learn as they were provided with challenging tasks that enabled them to access new learning on a daily basis.

\subsubsection{Teacher expectations}

\section{Results}

Although data from teacher interviews showed that all participant teachers believed they held high expectations for their students, data from lesson observations suggest that beliefs about what high expectations are considered to be varied between the two schools. Interview data show all three teachers at Pîwakawaka School considered their lessons successful when they could see that new learning had happened:

I'd rate the success on how much the children understand...if it's a concept...they know already, they haven't learned anything, so...there's no achievement... The real achievement comes if it's something new that they've mastered. (Patty)

Both teacher interviews and classroom observations indicate that teachers at Pīwakawaka School expected their students to find the work challenging, but they were prepared in case they did not. All three Pīwakawaka School teachers provided differentiation within the group, and used various techniques to scaffold learning:

This sequence goes on, with Patty writing new individual equations in workbooks for the students. The equations are made easier, or harder depending on how the student is doing. (Observation 1, Patty) 
I brushed through...halves, and quarters very quickly because I feel like that wasn't really the issue, so we spent.... a lot of time on thirds and...fifths... and then...I only did a little bit of tenths at the end but I felt like that wasn't... an issue either. There was a lot of time spent on thirds, and fifths cos I felt those were the two more complicated...concepts to grasp. (Peter)

Paula asks if students can do this independently, and most put their hand up. Those without their hand up are allocated to a buddy who does have their hand up, and they are asked to sit next to each other to support each other. (Observation 3, Paula)

Teachers at Pīwakawaka School were observed giving students plenty of wait time, an indicator of high expectations:

Peter then allows 10 more seconds before asking around the group if students are finished. Most students have finished, but not all so they are given more time. (Observation 2, Peter)

In their interviews, teachers at Whio School discussed considering a lesson successful when students appeared engaged and completed the work asked of them:

I would rate it as very successful, the level of engagement was very high. I think it was successful because I actually related it to literacy, and we wrote about fraction kites today so integration of round the curriculum. All children were able to identify the four quarters, [and] they were able to put it together. (Wanda)

During their interviews, teachers at Whio School mentioned being surprised when students were successful. Additionally, during lesson observations Whio School participant teachers appeared unprepared when further challenge was needed:

One student calls out that they should cut the sandwich in half, and have half
each. Whitney ignores this, and tells the students that they have one sandwich
between the two people, and asks what they should do. (Observation 3, Whitney)

But in maths he's surprising. He comes up with some quite good things. (Whitney)

\footnotetext{
Weston praises the student that had the right answer from the beginning. When Weston asked who had the right answer they all say they did. (Observation 2, Weston)
}

Lesson observations typically showed students at Whio School were given short wait times, and occasionally no wait time at all:

The wait time is short, just a few seconds, and then Weston asks the students to share. (Observation 1, Weston) 


\section{Discussion}

The work that students do in the classroom determines how students think about, and understand mathematics (Doyle, 1988). Teachers' expectations determine the tasks they give their students (NCTM, 2000; Sullivan, 2011). Teacher expectations have been shown to have a self-fulfilling prophecy, i.e., when teachers expect students to achieve highly they do, and when teacher expectations are low, so is achievement (Rosenthal \& Jacobson, 1968).

The data from classroom observations and interviews indicate that teachers in the different schools may have held different expectations for their students. Research indicates that the amount of wait time (Chapin \& O'Connor, 2007) teachers give their students may indicate the level of teacher expectations (Brophy, 1983). When teachers hold lower expectations for their students they tend to give short wait times, but when they hold higher expectations for their students they give them longer wait times (Brophy, 1983). Increased student achievement is linked to longer wait time (Askew \& Wiliam, 1995; Swan, 2005). The data from lesson observations suggest that teachers at Whio School may have been giving students shorter wait times than teachers at Pīwakawaka School. In order to learn mathematics, students need to be both doing mathematics and accessing new mathematics (Ottmar et al., 2013; Rotherham \& Willingham, 2009). It is the role of teachers "to make mathematics teaching more effective by challenging learners to become more active participants." (Swan, 2005, p. 4). The data from lesson observations suggest that teachers' definitions of a successful lesson may have varied between the schools. Observation and teacher interview data suggest teachers at Pīwakawaka School considered their lesson successful if students demonstrated that they had learned something new, while teachers at Whio School appeared to consider their lessons successful if the students had done the tasks that were asked of them. This suggests that students at Pīwakawaka School may have had more opportunities to learn new mathematics than students at Whio School.

Teachers at Pīwakawaka School appeared to have planned to provide both additional support, including providing manipulatives or differentiating individual questions, and extension activities to ensure challenge and scaffold students to work in accessible knowledge (Anthony \& Walshaw, 2007; Mousley et al., 2007; Sullivan, 2011; Sullivan, et al., 2006). The data from classroom observations further suggest that teachers at Whio School may have decided what students would be learning prior to the 
lesson, and taught that area of mathematics with the expectation that it was new learning for all students. It appeared that the teachers considered that all students would access the learning at the same rate (Mousley et al., 2007), as exemplified in the excerpts from Observation 2, Weston, and Observation 3, Whitney.

Results suggest that teachers at Pīwakawaka School may have expected their students to find the tasks provided challenging, but appeared to be prepared when students found the work either too challenging or too easy (Alton-Lee, 2003). The results also indicate that teachers at Whio School tended to present students with tasks that were too easy, which may have reduced the number of opportunities to learn that students at Whio School experienced (Williams, 2002).

\subsubsection{Use of assessment data}

\section{Results}

The principal at Pīwakawaka School indicated that formative and summative assessment data were collected at both a whole school level, and at a class level with the expectation that teachers would use it to inform their teaching decisions:

\footnotetext{
We analyse data together as a staff. ...We'll look at it, and say what patterns are we seeing? Where are the needs? We do some moderation together... which sort of enhances that. We have a close look at our PAT data and our NumPA data, and...work out where we might need to expend some effort. (Principal, Pīwakawaka School)
}

As the quotes and excerpts provided exemplify, data from teacher interviews and classroom observations also suggest that teachers at Pīwakawaka School routinely used a range of both summative and formative assessment data to inform the next teaching steps, set learning goals, and provide challenge for their students:

I look at what they can't do..., and then I know what I need to give them, and that helps me group them, and then set new goals for them. That also sometimes makes me aware of what I thought I'd taught them, and hasn't sunk in, and what I need to actually revisit, or what I don't need to bother teaching because they actually already know it. (Patty)

The student who demonstrated good understanding finishes, and is asked to join the next group up. She is told she will work with that group from now on as the current group is too easy for her. (Observation 3, Peter)

So tomorrow is 'prove to me you can do it' day. So if kids feel...they have a handle on...the stuff we've learned this week...they're going to be able to come in, and explain it to me, and show me that they are able to do it because they are all very keen to tick the bits and pieces of their 'I can' charts... In which case, 
next Monday, everything will have changed again, because... some of them will be moving on to the next step, some of them will be staying where they are, so because they are all running on this individual programme...they will be working on, either on what they've already worked on, because they need more help with it, or on their next step. (Paula)

The data from the principal interview at Whio School indicated that summative assessment data were being collected, and used to inform planning, and form groups:

Actually one of the things we did this year was we got onto NZCER marking service. So the amount of data we could drag out easily from online really helped, and really pedagogically it helped the teachers work out where the kids, or what groups we've got and where they need to go. (Principal, Whio School)

However, data from both teacher interviews and lesson observations suggest that teachers had made decisions about what to teach based on what had previously not been taught, rather than what students needed to learn.

So we're just finishing up on fractions and I want to then go in to looking at probably like an algebra, but looking more at just patterns and sequencing.

[And what's informing that. Is that school wide?]

Well, Whitney and I thought we would look at that next. I haven't done anything on patterns yet as well, so I do want to explore that (Wanda)

Furthermore, the data from lesson observations suggest that at least one of the three teachers at Whio School may have inaccurately used formative assessment. The first two excerpts below, coded green to show it was existing knowledge, were taken from lesson observations and suggest that students could already do the mathematics being taught, and did not need the equipment as a scaffold. The third exceprt below, taken from Weston's interview, highlights Weston's perception of the mathematics that students could not do, and why they found the equipment useful:

Weston asks if $1 / 2$ or $1 / 3$ is bigger. A student says $1 / 2$, and Weston writes the next question, $1 / 10$ or $1 / 5$. He says the students can use the equipment if needed. A student says $1 / 5$ is bigger and is asked why. The student identifies the denominator. The next question asks $1 / 5$ or $1 / 4$ and a different student replies $1 / 4$. Weston asks why, and the same student responds saying there's $4 / 4$ in a whole, and $1 / 4$ is more. Weston reminds the students that the smaller the denominator the bigger the fraction. The last question asks which is smaller $1 / 10$ or $1 / 8$. Another student immediately says $1 / 8$ is bigger, and Weston asks them to show it with the fraction tower. The same student says the bigger the denominator the smaller the piece gets. (Observation 1, Weston)

A student says $3 / 4$ is bigger than $1 / 2$. The students in the group discuss the answer and why it is right. One student says that it is because half is $2 / 4$ and plus $1 / 4$ 
because $1 / 2=2 / 4$, plus another quarter is $3 / 4$, and another student says that if the 3 were a 2 they would use the equals sign. Weston then gets out a large, wooden fraction wall. He asks one student to point to where $3 / 4$ ends and he asks another student to point to where $1 / 2$ ends. He asks them to keep their fingers there so the group can see that $3 / 4$ is greater than $1 / 2$. (Observation 2 , Weston)

I think it proved to me that the group do need a little more extra help, they thought using the big fraction board was valuable, but you know they were all ready, willing to give it a go and I think the understanding was slowly coming especially with the use of the board and I think they worked well on their own using the fraction towers. (Weston)

Teachers at Pīwakawaka School were repeatedly observed using formative assessment to extend individuals within the group, ensuring that students were continually working in the area of accessible knowledge, and building on their existing knowledge (coded orange), exemplified in the excerpts below (Section 3.6.1):

Patty supports individuals to do the calculations, questioning when they arrive at the wrong answer. The student who is getting them right is given more to do with slightly larger numbers, e.g., $8+7$. (Observation 1 , Patty)

Paula works with the student who asked for help, questioning and supporting thinking, but not giving away any answers. (Observation 3, Paula)

Teachers at Pīwakawaka School discussed the use of student learning goals in their interviews, and were observed using these during mathematics teaching:

When it comes to student data, the main thing I go on is the 'I Cans' for maths... So what I do is, each student has their own individual sheet and as they begin to master things on each stage, I highlight them off so I can see... what they can do and what they need to work on. (Peter)

Observation data from Whio School show that students were occasionally given the opportunity to work with accessible knowledge, but teachers appeared to quickly revert to working with existing knowledge when students found the mathematics challenging:

The student says the pattern is building on each time adding 1 , then, 2,3 , and 4 . Wanda asks how many are needed each time and prompts the student to say one more. One of the students is struggling, so Wanda borrows the completed pattern to show him what to do. She praises him when he sees the pattern and tells him to keep working. (Observation 2, Wanda) 
Over the course of the four lesson observations, Whitney taught her class about dividing a circle into eighths at least nine times, although most students demonstrated they understood how to do this during the first lesson observed. Additionally, students in Weston's class indicated that they had knowledge beyond that which was being taught. If these teachers had more experience with using questioning to gather formative assessment data, students in these teachers' classes may have had more opportunities to learn:

\section{Whitney asks how many pieces there will be if the cake is cut into eighths, and all the students in her group can tell her eight. (Observation 1, Whitney)}

When asked about how they used assessment data, teachers at Whio School did not mention setting goals with students. However, as shown in the excerpt below, Whitney was observed discussing whole class goals with her students at the end of a lesson. Additionally, the discussion was oral, so neither Whitney, nor her students, had a written record of the goals:

The whole class are sitting on the mat and Whitney asks them all to look at the maths posters displayed on the wall. Whitney focuses on the Stage 5 poster [Appendix M] and goes through each 'I can' statement. She asks all the students in the class to show her thumbs up or down to indicate whether they think they can have met that goal or not. (Observation 3, Whitney)

\section{Discussion}

ERO (2013) found that highly effective schools used assessment data to decide which areas of the mathematics curriculum would be taught, partially effective schools ensured that all areas of the curriculum were taught, and minimally effective schools ensured that all teachers were covering the same content. Teachers with high expectations set individual goals with students whereas teachers with low expectations do not do this (Rubie-Davies et al., 2015). It should be noted that evidence of formative assessment is difficult to record and analyse as it is frequently kept in a teacher's head, and not written down (Parr \& Timperley, 2008).

Teachers at both schools discussed using summative assessment data from previous years to group students and to track progress over time (Crooks, 2002). By using assessment data in this way, teachers were able to focus on students' needs, and on improving students' achievement (ERO, 2013). However, the data from observations and 
interviews suggest that there were apparent differences between the two schools in the way teachers used formative assessment data.

Data from teacher interviews suggest that teachers at Pīwakawaka School were using summative assessment data from previous years and previous topics to plan their overall classroom programme. Teachers at Pīwakawaka School also appeared to use questioning and observation to constantly assess what students knew and understood by watching them work, talking to them, and questioning them, and seemed able to move learning forward based on individual needs (Alton-Lee, 2003; Bobis et al., 2004; Finlayson, 2014; NCTM, 2000). By using formative assessment throughout group and whole class teaching, Pīwakawaka School teachers appeared to extend students who showed they understood the mathematics (Swan, 2005), or provided scaffolding for those who needed it (Sullivan, 2011). In other words, teachers at Pīwakawaka School were observed differentiating learning for students within the group (Alton-Lee, 2003; Swan, 2005) and ensuring that students were "work[ing] on learning goals just a little ahead of independent performance" (Parr \& Timperley, 2008, p. 57). Additionally, teachers at Pīwakawaka School appeared to adapt learning goals to suit individual students based on formative assessment.

Data from interviews and observations suggest that teachers at Whio School appeared not to continually use formative assessment to adapt their teaching when students showed knowledge and understanding, and therefore students were more frequently observed working within their existing knowledge rather than building on existing knowledge (Mousley et al., 2007; NCTM, 2000). Additionally, in their interviews, teachers at Whio School discussed trying to cover all areas of the mathematics curriculum, whether students had existing knowledge or not. At Whio School, learning goals were only observed being used in Whitney's class, and this was done orally at a whole class level.

These findings suggest that teachers at Pîwakawaka School were using both summative and formative assessment to inform their planning and teaching, as well as setting individual learning goals for their students. However, the data from observations and interviews suggest that teachers at Whio School were predominantly using summative data, and where goals were set, it was at a whole class level. 


\subsubsection{Opportunity to do mathematics at home}

Maternal education has been shown to have a larger influence on student achievement than paternal education (Wylie, 1999). Parental income has also been linked to students' achievement in mathematics. Higher levels of income may lead to higher levels of home possessions, and greater opportunities to access extra-curricular learning, such as private tutoring, both of which provide additional opportunities to learn mathematics (Wylie, 2001b).

\section{Results}

Data collected through the parental survey are shown in Table 5.3. These data show that students at Pīwakawaka School had greater access to materials at home, which possibly provided them with more opportunities to learn mathematics than students at Whio School.

Table 5.3: Percentage of Students with Materials Available at Home to Support Mathematics

\begin{tabular}{lcc}
\hline Material & Pīwakawaka School & Whio School \\
\hline Measuring Equipment & $95 \%$ & $14 \%$ \\
Pencil and Paper & $100 \%$ & $95 \%$ \\
Counters & $82 \%$ & $57 \%$ \\
Mathematics Book & $68 \%$ & $29 \%$ \\
Mathematics Poster & $63 \%$ & $38 \%$ \\
Calculator & $97 \%$ & $90 \%$ \\
Computer & $97 \%$ & $81 \%$ \\
Tablet & $92 \%$ & $67 \%$ \\
Other & $13 \%$ & $5 \%$ \\
\hline
\end{tabular}

Data in Table 5.4 suggest that students' mothers at Pīwakawaka School had a higher level of education ( $67 \%$ with a bachelor degree or higher) than those at Whio School (14\% with a bachelor degree or higher). Furthermore, $48 \%$ of students' mothers and $70 \%$ of students' fathers at Whio School identified as having no formal qualifications. This implies that students at Pīwakawaka School may have parents with better understanding of the concepts being learned. Therefore, parents at Pīwakawaka School could involve their children in the types of tasks that they knew needed to be learned in school more than parents at Whio School. 
Table 5.4: Parental Level of Qualification

\begin{tabular}{lcccc}
\hline Level of Qualification & \multicolumn{2}{c}{ Piwakawaka School } & \multicolumn{2}{c}{ Whio School } \\
& Maternal & Paternal & Maternal & Paternal \\
\hline No formal qualifications & $0 \%$ & $0 \%$ & $48 \%$ & $70 \%$ \\
NCEA Level 1 or equivalent & $0 \%$ & $6 \%$ & $9 \%$ & $6 \%$ \\
NCEA Level 2 or equivalent & $8 \%$ & $9 \%$ & $14 \%$ & $0 \%$ \\
NCEA Level 3 or equivalent & $0 \%$ & $0 \%$ & $10 \%$ & $6 \%$ \\
NCEA Level 4 or equivalent & $8 \%$ & $15 \%$ & $0 \%$ & $6 \%$ \\
Diploma or equivalent & $14 \%$ & $18 \%$ & $5 \%$ & $6 \%$ \\
Bachelor Degree or equivalent & $51 \%$ & $26 \%$ & $14 \%$ & $6 \%$ \\
Post Graduate Diploma & $16 \%$ & $26 \%$ & $0 \%$ & $0 \%$ \\
Other & $3 \%$ & $0 \%$ & $0 \%$ & $0 \%$ \\
\hline
\end{tabular}

Table 5.5 shows that Pîwakawaka School had 15\% more students from average or high income households achieving 'above' National Standards when compared with Whio School.

Table 5.5: Income Level Compared with National Standard Levels

\begin{tabular}{lcccccccc}
\hline Income Level & \multicolumn{3}{c}{ Pīwakawaka School } & \multicolumn{3}{c}{ Whio School } \\
\hline National Standard & Above & At & Below & $\begin{array}{c}\text { Well } \\
\text { Below }\end{array}$ & Above & At & Below & $\begin{array}{c}\text { Well } \\
\text { Below }\end{array}$ \\
\hline $\begin{array}{l}\text { No Income Data } \\
\text { Provided }\end{array}$ & $5 \%$ & $24 \%$ & $3 \%$ & $0 \%$ & $0 \%$ & $22 \%$ & $18 \%$ & $5 \%$ \\
$\begin{array}{l}\text { Low } \\
\text { Below \$45,000) }\end{array}$ & $0 \%$ & $3 \%$ & $0 \%$ & $0 \%$ & $0 \%$ & $22 \%$ & $9 \%$ & $0 \%$ \\
$\begin{array}{l}\text { Average } \\
\text { \$45,001- \$105,000) }\end{array}$ & $10 \%$ & $8 \%$ & $0 \%$ & $0 \%$ & $5 \%$ & $9 \%$ & $0 \%$ & $5 \%$ \\
$\begin{array}{l}\text { High } \\
(\text { Above \$105,001) }\end{array}$ & $10 \%$ & $37 \%$ & $0 \%$ & $0 \%$ & $0 \%$ & $0 \%$ & $5 \%$ & $0 \%$ \\
\hline
\end{tabular}

\section{Discussion}

Although learning mathematics relies on classroom-based learning more than any other subject (Bodovski \& Farkas, 2007), opportunities to learn outside the classroom still have an impact on student achievement (Wylie, 1999). When students have materials at home that can provide opportunities to learn mathematics, and students either know how to use them or can be shown how to use them, levels of achievement increase (Biddulph et al., 2003). Higher levels of materials for learning mathematics at home tend to lead to higher levels of achievement (Suárez-Álvarez et al., 2014). One of the reasons suggested for this is that it is likely to be the mother who generally provides 
opportunities for learning at home (Section 4.2.7), including showing students how to use materials to learn mathematics (Biddulph et al., 2003). The data from parental surveys suggest that students at Pīwakawaka School had access to more materials for learning mathematics at home than students at Whio School. It should be noted that the data collections tools used in this study did not gather data about any private tutoring in mathemetics that students may have been receiving (see Section 6.3).

The data suggest that one of the reasons that students at Pîwakawaka School appeared to be achieving more highly may have been that they had more opportunities to do mathematics homework, to do more mathematics tasks at home (Section 4.2.7), and to interact with mathematical materials with more highly qualified parents (mothers in particular) than students at Whio School.

\subsubsection{Student perceptions}

\section{Results}

When students were interviewed, they talked about their experiences with mathematics both in and out of the classroom. When talking about mathematics in the classroom, students generally appeared to corroborate what their teachers were saying. For example, seven out of nine interviewed students at Pîwakawaka School were able to identify an area of mathematics which they wanted to improve, supporting the idea that conversations about student goals observed in classrooms and mentioned in teacher interviews were a part of regular classroom practice. At Whio School, only four of the nine interviewed students were able to identify an area of mathematics they wanted to improve:

Payton B: I want to be better at doing it really quickly as the other people in my class.

Percy A: Counting.

Poppy A: My fractions.

Paul B: $\quad$ My times tables.

Pearl A: Maybe fractions.

Pam A: I want to get much better at my fractions.

Philip AB: I think I'd like to get a bit better at doing some more better [sic] fractions, cos I'm not super good at fractions, I think. 
Wynne B: I'm quite good at skipping [numbers]. I'm not quite good at three times.

Wilf B: Probably my basic facts because I'm not that good at them, but so far every... question that I've had for basic facts I've done right.

Wade B: Probably my times tables, and divided bys.

Wyatt B: Time

In their interviews, students at Pīwakawaka School talked about learning and doing mathematics frequently, and when they talked about playing it was in the context of using mathematics games for learning:

Poppy A: I made up a game that I played today, and you would have two dice. You roll them and you write the question down and if you get the exact same numbers on both of them you have to do a plus and a take away.

All interviewed students at Pīwakawaka School saw themselves as being expected to work hard, and also wanted to work hard, both in and out of the classroom:

Poppy A: I get my mum to write some really hard questions down, and I have to answer them. I like working independently, so I get work done, finished like faster. [What about using other people to help you?] I sometimes do it, only if I really need it. If I can do it, if I think I can try, I'll do it myself.

Patrick A: There's some fractions games, and some other stuff that I quite like.

Philip AB: I like doing times tables cos it's quite fun, and I like it when our teacher gives us...the maths sheets where you can take them home, and you can learn them, and then there's a test and its fun.

Interviewed students at Whio School described classroom mathematics as playing and socialising rather than learning and constructing knowledge, although some older students mentioned working with a buddy for help. Some students mentioned that they felt bored at mathematics time, and others mentioned that they thought mathematics was about behaving properly:

Wayne B: In a group, because it takes more people, and it's funner [sic], because everyone gets to play, and they don't get left out.

We got to sit on our bottoms, and be kind, and not be loud.

Wes A: I play on the iPad, and I play Puppet Powers 2, but because there is nothing to go on, so I just do that. 
Wynne B: I don't like doing nothing. Like sitting in the couch being boring [sic].

Wilf B: It just means I can get together with some of my friends, and actually try to communicate, and make new friends, and actually do stuff together so it won't be that slow, it'll be quick and easy.

Wilma A: Basic facts stuff on, on the iPad, that's what I play.

After approximately 33 minutes a student can be heard to state, "I'm bored". (Observation 3, Weston)

\section{Discussion}

Working towards learning goals encourages students to work hard, and persevere when the task is difficult, both of which build achievement in mathematics (Alton-Lee, 2003; Boaler, 2013; Dweck, 2006; Rubie-Davies, Peterson, Irving, Widdowson, \& Dixon, 2010). Most interviewed students at Pīwakawaka School were generally aware of areas in mathematics that they needed to improve, whereas fewer students at Whio School could identify an area for improvement in mathematics.

Students find it respectful when teachers provide challenging tasks, and give students the time they need to do the tasks given (Averill \& Clark, 2012). The data suggest that students at Pīwakawaka School appeared to both know that they were expected to undertake challenging tasks, and to want to work on challenging tasks.

\subsection{Summary}

The evidence within this chapter indicates that the opportunities students were given to learn mathematics appeared to differ between Pīwakawaka School and Whio School. Students at Pīwakawaka School also seemed to have more opportunities to learn mathematics at home. They appeared to be provided with challenging tasks, requiring them to work with accesible knowledge to meet their current learning needs. Students at Whio School appeared to be given fewer opportunities to learn as they were more likely to be given repetitive tasks and asked to work with existing knowledge, which provided comparatively less new learning. 


\section{Chapter 6: Discussion and Conclusion}

This chapter begins with a discussion on the results of the study in Section 6.1, and is then followed in Section 6.2 by recommendations. Limitations, including areas for further research, are in Section 6.3.

\subsection{Discussion}

Pīwakawaka and Whio Schools are of different deciles and, as reported in Chapter 3, have noticeable differences in student mathematics achievement (Table 3.1). This research focused on exploring why such differences may exist with a view to identifying evidence-based strategies that may help improve mathematics achievement at Whio School.

In an attempt to cover all the potential influences on students' mathematics achievement identified from the literature, a large amount of data were collected from a range of sources. Once the data from the family survey had been used to identify the family SES of each student, PivotTables were then used to try to identify any patterns in the data both within and across schools. However, this analysis did not reveal any obvious influences on students' mathematics achievement. The data were therefore explored in other ways to identify what was happening differently at the two schools and thus what was potentially contributing to the observed difference in student mathematics achievement at the two schools.

Two useful analysis techniques were developed as part of the data analysis in this study. The first, discussed below in Section 6.1.1, was the development of a model for teacher-student-mathematics interactions. The second was the use of colour coding in a model for working in the accessible, discussed in Section 6.1.2 below.

\subsubsection{A model for teacher-student-mathematics interactions}

One of the tools developed as part of this study was the model for teacherstudent-mathematics interactions (Section 4.1). This model identifies the different possible ways in which students and the teacher interact both with each other and with the task set. The way in which this model simplifies the complexity of these interactions suggests that it could be a useful tool in identifying the specific types of interactions 
taking place during classroom observations, or when analysing data from video recordings.

\subsubsection{A model for working in the accessible}

The second tool developed as part of this study was a model for working in the accessible (Sections 1.8, 2.1.4, 3.6.1, and 5.1.1). This model used a colour code to identify when students were working with existing knowledge (green), accessible knowledge (orange), and inaccessible knowledge (red). Any observed mathematics interactions that did not require the students to learn, e.g., the teacher launching the task or when the type of knowledge being used could not be identified, were coded blue and any observed non-mathematical interactions were coded yellow. This colour coding may be useful following lesson observations as it can be used to identify the proportion of time for which students were working at an appropriate level of challenge.

While a large number of factors identified in the literature were observed to be at play in the two schools, these did not seem to be the major causes of the disparity in students' mathematics achievement. Rather, these minor factors seemed to be contributing to other overarching factors: the amount of mathematics students were undertaking, and the opportunities students had to learn new mathematics. It is possible that the broad nature of this research and analysis, as opposed to an in-depth focus on one or two perceived factors, allowed for the identification of these two overarching factors.

\subsubsection{The amount of mathematics undertaken}

The results from the analysis of observation, interview, and survey data on the amount of mathematics students did in each school suggest that students at Pīwakawaka School undertake much more mathematics than students at Whio School. In addition, especially at the junior school level, the mathematics done at Whio School was predominantly oral, suggesting students were not being given the opportunity to develop their understanding of, and facility with mathematical symbols, and may therefore have been unable to improve on their existing written ability. Table 6.1 identifies each of the possible influences on the amount of mathematics students were undertaking and summarises what was found to possibly be happening in each school. 
Table 6.1: A Summary of the Identified Possible Influences on the Amount of Mathematics Undertaken

\section{Possible Influence on Student Mathematics Achievement}

\begin{tabular}{|c|c|c|}
\hline $\begin{array}{l}\text { Teacher-student- } \\
\text { mathematics interaction }\end{array}$ & CMI were typically observed & SMI were typically observed \\
\hline Time on mathematics & $\begin{array}{l}\text { Instructional time typically } \\
\text { CMI }\end{array}$ & $\begin{array}{l}\text { Instructional time typically } \\
\text { SMI }\end{array}$ \\
\hline Behaviour management & $\begin{array}{l}\text { Few in number, particularly in } \\
\text { Peter's class }\end{array}$ & $\begin{array}{l}\text { High in number in Wanda's } \\
\text { class }\end{array}$ \\
\hline \multicolumn{3}{|l|}{$\begin{array}{l}\text { Classroom mathematics } \\
\text { interactions: }\end{array}$} \\
\hline $\begin{array}{l}\text { Written } \\
\text { mathematics }\end{array}$ & $\begin{array}{l}\text { Observed being used in all } \\
\text { participant class for all } \\
\text { observations }\end{array}$ & $\begin{array}{l}\text { Observed being used in some } \\
\text { participant classes for some } \\
\text { observations }\end{array}$ \\
\hline Oral mathematics & $\begin{array}{l}\text { Mathematical discourse } \\
\text { typically used in whole class } \\
\text { and group teaching }\end{array}$ & $\begin{array}{l}\text { IRF exchange typically used in } \\
\text { whole class and group } \\
\text { teaching }\end{array}$ \\
\hline ICT & $\begin{array}{l}\text { Typically purposeful, } \\
\text { consistent across the school, } \\
\text { feeds through to home }\end{array}$ & $\begin{array}{l}\text { Typically generic, variation in } \\
\text { programmes used across the } \\
\text { school, no observed } \\
\text { expectations for use at home }\end{array}$ \\
\hline Mathematics games & $\begin{array}{l}\text { Planned as part of mathematics } \\
\text { rotation by two out of three } \\
\text { teachers }\end{array}$ & $\begin{array}{l}\text { Used to fill time for early } \\
\text { finishers by two out of three } \\
\text { teachers }\end{array}$ \\
\hline All Homework & $\begin{array}{l}65 \% \text { of mothers, and } 71 \% \text { of } \\
\text { fathers report spending up to } \\
\text { two hours per week on all } \\
\text { homework, regardless of } \\
\text { subject }\end{array}$ & $\begin{array}{l}55 \% \text { of mothers, and } 38 \% \text { of } \\
\text { fathers report spending up to } \\
\text { two hours per week on all } \\
\text { homework, regardless of } \\
\text { subject }\end{array}$ \\
\hline Mathematics Homework & $\begin{array}{l}\text { Set regularly, including the use } \\
\text { of ICT (Mathletics) }\end{array}$ & $\begin{array}{l}\text { Older students asked to learn } \\
\text { times tables }\end{array}$ \\
\hline
\end{tabular}

Pīwakawaka School

Whio School 
differences in the opportunities to learn mathematics that students experienced, both in the classroom and outside school.

Table 6.2: A Summary of the Identified Possible Influences on Opportunities to Learn

\begin{tabular}{|c|c|c|}
\hline $\begin{array}{l}\text { Potential Influence on } \\
\text { Student Achievement }\end{array}$ & Pīwakawaka School & Whio School \\
\hline Level of challenge & $\begin{array}{l}\text { Students typically observed } \\
\text { working with accessible } \\
\text { knowledge }\end{array}$ & $\begin{array}{l}\text { Students typically observed } \\
\text { working with existing } \\
\text { knowledge }\end{array}$ \\
\hline Teacher expectations & $\begin{array}{l}\text { Teachers discussed expecting } \\
\text { students to learn new material }\end{array}$ & $\begin{array}{l}\text { Teachers discussed expecting } \\
\text { students to complete the work } \\
\text { set }\end{array}$ \\
\hline Student engagement & $\begin{array}{l}\text { Students were observed being } \\
\text { engaged in mathematical tasks } \\
\text { throughout lessons. } \\
\text { Teachers discussed having } \\
\text { additional tasks prepared } \\
\text { before the lesson, and were } \\
\text { observed giving these tasks to } \\
\text { students }\end{array}$ & $\begin{array}{l}\text { Students were observed } \\
\text { finishing their work early or } \\
\text { heard commenting about } \\
\text { boredom. } \\
\text { Teachers were observed using } \\
\text { games and ICT to occupy } \\
\text { students if they finished early }\end{array}$ \\
\hline Use of assessment & $\begin{array}{l}\text { Both formative and } \\
\text { summative assessment } \\
\text { observed and discussed as } \\
\text { being used to set individual } \\
\text { goals, provide feedback, and } \\
\text { determine curriculum } \\
\text { coverage }\end{array}$ & $\begin{array}{l}\text { Summative assessment } \\
\text { observed being used to } \\
\text { determine curriculum } \\
\text { coverage. Whole class goals } \\
\text { discussed in one class }\end{array}$ \\
\hline \multirow[t]{2}{*}{ Opportunities at home } & $\begin{array}{l}\text { Most households reported } \\
\text { having a wide range of } \\
\text { materials available to support } \\
\text { mathematics }\end{array}$ & $\begin{array}{l}\text { Most households reported } \\
\text { having some materials } \\
\text { available to support } \\
\text { mathematics }\end{array}$ \\
\hline & $\begin{array}{l}\text { The majority of mothers } \\
\text { reported holding a Bachelor } \\
\text { degree or higher }\end{array}$ & $\begin{array}{l}\text { The majority of mothers } \\
\text { reported holding } \\
\text { qualifications at NCEA Level } \\
2 \text { or below }\end{array}$ \\
\hline Student perceptions & $\begin{array}{l}\text { Students discussed knowing } \\
\text { their learning goals and } \\
\text { wanting to work hard }\end{array}$ & $\begin{array}{l}\text { Students discussed seeing } \\
\text { mathematics as a time for } \\
\text { playing and socialising }\end{array}$ \\
\hline
\end{tabular}


Figure 6.1 introduces a visual representation of the possible influences on student mathematical achievement identified in this research.

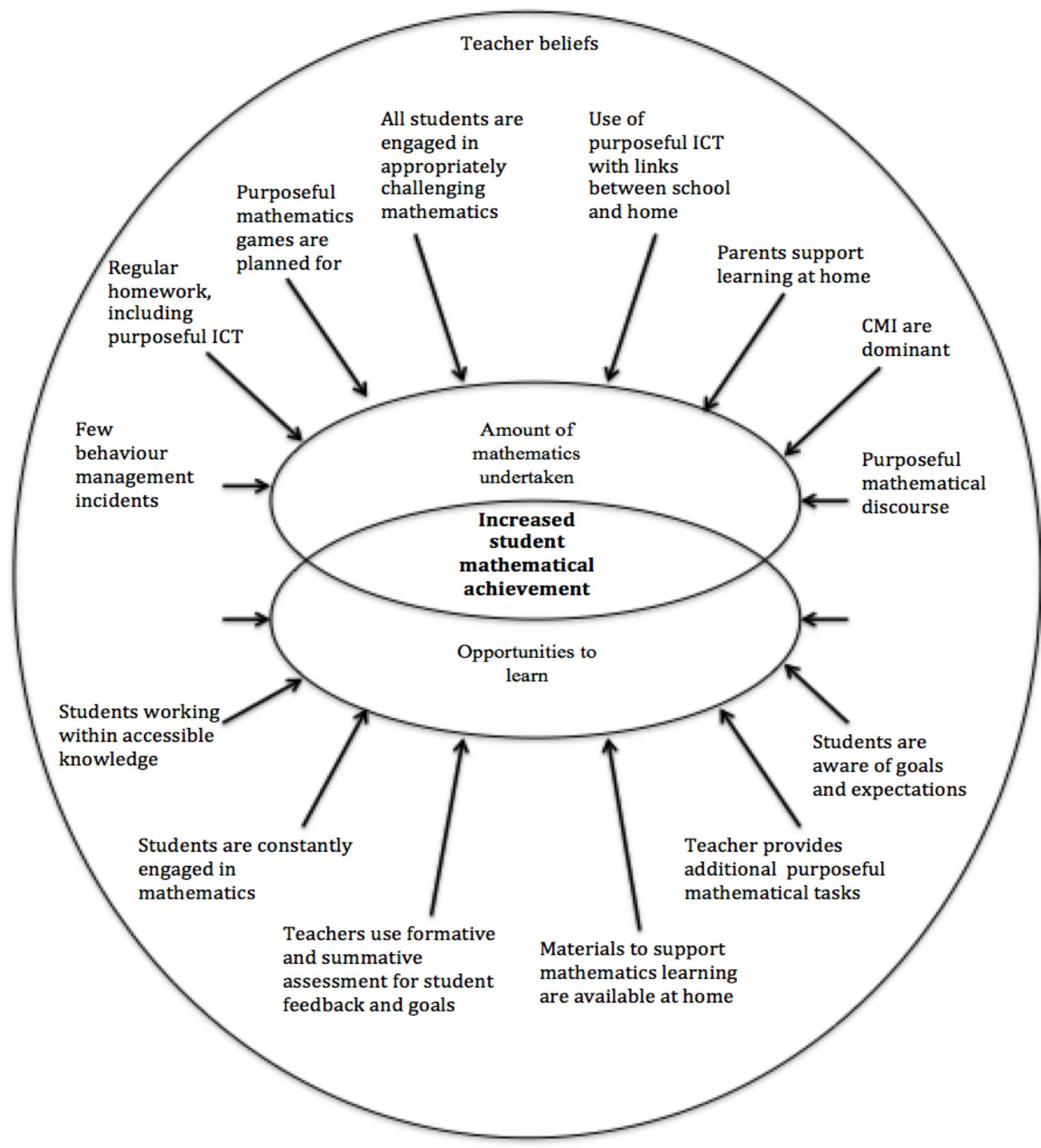

\section{Figure 6.1: Possible Influences on Student Achievement}

Teachers at Pīwakawaka School and Whio School both showed and discussed holding high expectations for their students. All participant teachers grouped their students for instruction, as suggested by the MoE (2008a). However, participant teachers at Whio School appeared to treat students in the group as homogenous with preset learning needs, whereas students at Pīwakawaka School were treated as heterogeneous 
with varying learning needs. At Whio School it appeared that the teaching focus for a lesson was predetermined, although at Pîwakawaka School it seemed that the focus of teaching was flexible, driven by what students showed they already knew and needed to learn next. Teachers at Whio School appeared to predominantly work in students' existing knowledge, whilst teachers at Pīwakawaka School seemed to scaffold learning to enable both the group and individuals to work within accessible knowledge. Furthermore, teachers at Whio School discussed having constructivist-based beliefs, but the way in which set tasks were used and the types of questions they asked suggested they were actually enacting a more traditional style. However, the data from both classroom observations and teacher interviews suggest that teachers at Pīwakawaka School both had constructivist beliefs and enacted those more consistently. The differences between the two schools would suggest that it was not teaching beliefs that was influencing student achievement in mathematics, but the way in which the teaching practice was understood and implemented (Adam, 2012). When students experience appropriate levels of challenge (productive struggle) in mathematics they are more likely to develop both higher levels of mathematical knowledge and a deeper understanding of mathematical concepts (Anthony \& Walshaw, 2007; Warshauer, 2015).

On a broader level, the apparent differences in both the amount of mathematics undertaken and the number of opportunities to learn found in the participant schools may be influences on students' mathematics achievement that are in play more generally, so may be contributing to the increasing gap in student mathematics achievement observed between high and low decile schools (Caygill et al., 2013; Crooks et al., 2010).

\subsection{Recommendations}

This study has several recommendations to support teachers to increase levels of student achievement in mathematics.

The research suggests that in New Zealand the disparity in the range of levels of mathematics achievement between students from high and low decile schools is the third largest when compared with the 63 countries taking part in TIMSS 2010/2011 (Caygill et al., 2013). The vast and, at times, confusing array of research-based advice focused on how teachers and schools can improve student achievement in mathematics has had limited impact, in spite of over a decade of reform. In addition, exisiting ideas from PLD 
are commonly dropped when teachers implement new ideas from more recent PLD in their classroom (Wiliam, 2011). Whilst all the advice on improving student achievement in mathematics is evidence-based, it is generic, and not specific to any particular school seeking to improve the mathematics achievement of their students. The replication of this study would be therefore be useful for identifying whether or not these results occur in other pairs of high and low deciles schools, and whether the method results in other schools being able to identify school-specific factors that might help lift mathematics achievement.

While this research focused on two case schools, it may have wider implications for practice. For example, schools seeking to improve student achievement should look at quantity of mathematics students undertake and the purposeful opportunities to learn mathematics student receive. This study has developed some tools that could be used in schools to identify context specific, evidence-based foci for improving students' mathematics achievement. Alternatively, it may be valuable for schools to plan for PLD by considering whether or not these two constructs may be at play in their environment, then seek support in how they could change their practice. Currently, policy has focused on teachers' lack of content and pedagogical knowledge. Teachers at Whio School were receiving PLD around their content and pedagogical knowledge but this may not on its own be sufficient to address how teachers might go about increasing the quantity of mathematics students engage in or the opportunities to learn they receive. This suggests that it may be easier for teachers to address their currently practice and examine how these two variables are influencing student achievement in their own context.

\subsection{Limitations}

Throughout this research, attention has been paid to the trustworthiness of the results. Data were collected from several different sources using several different data collection tools to support the triangulation of data. During data analysis, videos taken during data collection were repeatedly viewed to support the accuracy of the results. Despite this, the study has a number of limitations. For example, whilst confidence has been placed in the data collected from both student and parent surveys, it is possible parents over-stated some of the information provided. Additionally, students may have misread questions or misinterpreted the scales when answering questions in the student survey. In addition, some possibly relevant pieces of data were not collected in the 
family survey. Firstly, families were not asked about other adults living in, or close to, the household that may have been able to provide help with homework or do additional mathematics at home. Secondly, data about private tutoring in mathematics that students may have been receiving were also not gathered. Thirdly, neither the principal nor teacher interviews asked a question about the school's homework policy, which may have provided an insight into the expectations for homework in each school.

The scope of this study imposed a further limitation, the use of only two case schools, in which only three teachers each participated in four observations. Therefore, caution has to be taken when seeking to generalise what has been observed, written, or discussed. In general, care has been taken to trianguate data from observations with that collected from interviews and surveys to ensure interpretations are as valid as possible. However, data were not collected to establish that the teachers and observed occurences were typical of all lessons and all teachers within the school. In future, repeating the research with a greater number of schools and teachers is important to establish the generalisability of the findings.

A further limitation was the time available to analyse the data. Due to the large amount of data collected in this study, it was not possible to review everything many times. Video recordings were watched repeatedly and in detail, and transcripts from interviews were also closely read and analysed. However, once data from family and student surveys had been analysed in PivotTables, it was not revisited in depth.

A final limitation was the lack of school entry mathematics data. It was originally planned to collect these data for each participant student to track rates of progress in mathematics. However, neither participant school had these data available. One reason for the lack of availability was that the first national standard OTJ is not made until a student has been at school for 40 weeks. Therefore, new entrants, year 1, and some year 2 students had not been assessed against the national standards. Additionally, national standards were not introduced in New Zealand until 2010, meaning that year 6 and some year 5 students were not assessed against the national standards after 40 weeks. Furthermore, a conversation with Whitney suggested that Whio School had recently changed their electronic school management system, meaning that historic data were no longer accessible. Over time, collecting these data should become possible, and as an important indicator of the schools' ability to "add mathematical value" to their students, should be both collected and analysed in an ongoing manner not only within schools but in reports to the MoE. 
Further research is needed into each of the theories that emerged from the research, that there appeared to be a difference in the amount of mathematics students undertook and the opportunities students had to learn, both of which may have contributed to the observed differences in mathematical achievement of students at the two participant schools. However, given the limited sample, some caution is needed to interpret the findings as it is not possible to categorically state this is what was happening. There is also work needed to find out if this is the case between other high and low decile schools.

In summary, this study has made an initial attempt to fill the gap in the New Zealand literature on the possible influences on student achievement in a high and a low decile school. The results suggest the amount of mathematics students undertake and the opportunities student have to learn may be powerful influences on the differences in levels of student achievement between high and low decile schools. Further research in New Zealand is needed to explore the possibility that these influences may be at play in other schools. 


\section{References}

Abadzi, H. (2009). Instructional time loss in developing countries: Concepts, measurement, and implications. The World Bank Research Observer, 24(2), 267290. doi.org/10.1093/wbro/lkp008

Absolum, M. (2006). Clarity in the classroom: Using formative assessment-building learning-focused relationships. Auckland, NZ: Hodder Education.

Adam, M. S. (2012). Primary teachers' mathematical beliefs and practices in the Maldives. Victoria University of Wellington. Retrieved from http://hdl.handle.net/10063/2268

Alton-Lee, A. (2003). Quality teaching for diverse students in schooling: Best evidence synthesis. Wellington: Ministry of Education.

American Psychological Association. (2016). Education and socioeconomic status. Retrieved from http://www.apa.org/pi/ses/resources/publications/factsheeteducation.aspx

Andrews, T. (2012). What is social constructionism? Grounded theory review: An International Journal, 11(1), .

Anthony, G., \& Walshaw, M. (2007). Effective pedagogy in mathematics/pāngarau: Best evidence synthesis iteration (BES). Wellington,NZ: Ministry of Education.

Appleton, J. J., \& Lawrenz, F. (2011). Student and teacher perspectives across mathematics and science classrooms: The importance of engaging contexts. School Science and Mathematics, 111(4), 143-155.

Askew, M. (2012). Transforming primary mathematics. Oxon: Routledge.

Askew, M., Brown, M., Rhodes, V., Wiliam, D., \& Johnson, D. (1997). Effective teachers of numeracy in primary schools: Teachers' beliefs, practices and pupils' learning. Paper presented at the British Educational Research Association Annual Conference, University of York. Retrieved from http://musicmathsmagic.com/page4/files/EffectiveTeachersofNumeracy.pdf

Askew, M., \& Wiliam, D. (1995). Recent research in mathematics education (Vol. 53, pp. 5-16). London: HMSO.

Averill, R., \& Clark, M. (2012). Respect in teaching and learning mathematics: Professionals who know, listen to and work with students. Set: Research Information for Teachers, 3, 50-57. 
Baker, D., Fabrega, R., Galindo, C., \& Mishook, J. (2004). Instructional time and national achievement: Cross-national evidence. Prospects, XXXIV(3), 311-334. doi.org/10.1007/s11125-004-5310-1

Baker, D. P., Goesling, B., \& LeTendre, G. K. (2002). Socioeconomic status, school quality, and national economic development: A cross-national analysis of the "Heyneman-Loxley Effect" on mathematics and science achievement. Comparative Education Review, 46(3), 291-312. doi.org/10.1086/341159

Ball, D., \& Rowan, B. (2004). Introduction: Measuring instruction. The Elementary School Journal, 105(1), 3-10. doi.org/10.1086/428762

Ball, D., Thames, M. H., \& Phelps, G. (2008). Content knowledge for teaching: What makes it special? Journal of Teacher Education, 59(5), 389-407. doi.org/10.1177/0022487108324554

Bandura, A. (1993). Perceived self-efficacy in cognitive development and functioning. Educational Psychologist, 28(2), 117-148. doi.org/10.1207/s15326985ep2802 3

Barker, M., \& Bunting, C. (2016). How do people learn?: Understanding the learning process. In D. Fraser \& M. Hill (Eds.), The professional practice of teaching in New Zealand (5th ed.). Australia: Cengage Learning.

Battey, D. (2013). "Good" mathematics teaching for students of color and those in poverty: The importance of relational interactions within instruction.

Educational Studies in Mathematics, 82(1), 125-144. doi.org/10.1007/s10649012-9412-z

Becta. (2008). What the research says about using ICT in maths. Retrieved from http://webarchive.nationalarchives.gov.uk/20130401151715/http://www.educatio n.gov.uk/publications/eOrderingDownload/15014MIG2799.pdf

Berliner, D. C. (1990). What's all the fuss about instructional time? In M. Ben-Peretz \& R. Bromme (Eds.), The nature of time in schools theoretical concepts, practitioner perceptions. New York: Teachers College Press.

Biddulph, F., Biddulph, J., \& Biddulph, C. (2003). The complexity of community and family influences on children's achievement in New Zealand: Best evidence synthesis. New Zealand: Ministry of Education.

Blatchford, P., Hallam, S., Kutnick, P., \& Creech, A. (2008). Classes, groups and transitions: Structures for teaching and learning. Primary Review Research Survey 9/2. Cambridge: University of Cambridge. 
Blömeke, S., Kaiser, G., \& Suhl, U. (2011). Teacher education effectiveness: Quality and equity of future primary teachers' mathematics and mathematics pedagogical content knowledge. [Report]. Journal of Teacher Education, 62(2), 154-171. doi.org/10.1177/0022487110386798

Blömeke, S., \& Klein, P. (2013). When is a school environment perceived as supportive by beginning mathematics teachers? Effects of leadership, trust, autonomy and appraisal on teaching quality. International Journal of Science and Mathematics Education, 11(4), 1029-1048.

Blömeke, S., Suhl, U., Kaiser, G., \& Döhrmann, M. (2012). Family background, entry selectivity and opportunities to learn: What matters in primary teacher education? An international comparison of fifteen countries. Teaching and Teacher Education, 28(1), 44-55. doi.org/10.1007/s10763-013-9424-х

Boaler, J. (2013). Ability and mathematics: The mindset revolution that is reshaping education. Forum, 55(1), 143-152. doi.org/10.2304/forum.2013.55.1.143

Bobis, J., Mulligan, J., \& Lowrie, T. (2004). Mathematics for children: Challenging children to think mathematically (2nd ed.). Frenchs Forest, NSW: Pearson Education Australia.

Bodovski, K., \& Farkas, G. (2007). Mathematics growth in early elementary school: The roles of beginning knowledge, student engagement, and instruction. The Elementary School Journal, 108(2), 115-130. doi.org/10.1086/525550

Bodovski, K., \& Youn, M.-J. (2011). The long term effects of early acquired skills and behaviors on young children's achievement in literacy and mathematics. Journal of Early Childhood Research, 9(1), 4-19. doi.org/10.1177/1476718X10366727

Bonner, E. P. (2014). Investigating practices of highly successful mathematics teachers of traditionally underserved students. Educational Studies in Mathematics, 86(3), 377-399. doi.org/10.1007/s10649-014-9533-7

Boonen, T., Speybroeck, S., de Bilde, J., Lamote, C., Van Damme, J., \& Onghena, P. (2014). Does it matter who your schoolmates are? An investigation of the association between school composition, school processes and mathematics achievement in the early years of primary education. British Educational Research Journal, 40(3), 441-466. doi.org/10.1002/berj.3090

Bottia, M. C., Moller, S., Mickelson, R. A., \& Stearns, E. (2014). Foundations of mathematics achievement: Instructional practices and diverse kindergarten students. The Elementary School Journal, 115(1), 124-150. 
Bottle, G., \& Canterbury Christ Church University College Primary Mathematics Team. (2005). Teaching mathematics in the primary school. London: Continuum.

Boucher, V., Bramoullé, Y., Djebbari, H., \& Fortin, B. (2014). Do peers affect students' achievement? Evidence from Canada using group size variation. Journal of Applied Econometrics, 29(1), 91-109. doi.org/10.2139/ssrn.1566956

Brophy, J. E. (1983). Research on the self-fulfilling prophecy and teacher expectations. Journal of Educational Psychology, 75(5), 631-661. doi.org/10.1037/00220663.75.5.631

Bruner, J. S. (1996). The culture of education. Cambridge, MA: Harvard University Press.

Caygill, R., Kirkham, S., \& Marshall, N. (2013). Mathematics, year 5 students' mathematics achievement in 2010/11: New Zealand results from the Trends in International Mathematics and Science Study (TIMSS). Wellington, NZ: Ministry of Education.

Chang, M., \& Choi, N. (2011). Interplay among school climate, gender, attitude toward mathematics, and mathematics performance of middle school students. [Article]. Middle Grades Research Journal, 6, 15-24.

Chapin, S. H., \& O'Connor, C. (2007). Academically productive talk: Supporting students' learning in mathematics. In W. G. Martin, M. E. Strutchens \& P. C. Elliott (Eds.), The learning of mathematics: Sixty-ninth yearbook (pp. 113-128). Reston, VA: National Council of Teachers of Mathematics.

Chappell, M. F., Schielack, J. F., \& Zagorski, S. (2004). Empowering the beginning teacher of mathematics in elementary school. Reston, VA: National Council of Teachers of Mathematics.

Cheeseman, J., Clarke, D., Roche, A., \& Wilson, K. (2013). Teachers' views of the challenging elements of a task. Mathematics education: Yesterday, today and tomorrow: Proceedings of the 36th annual conference of the Mathematics Educational Research Group of Australasia, Melbourne: MERGA.

Chiu, M. M. (2010). Effects of inequality, family and school on mathematics achievement: Country and student differences. Social Forces, 88(4), 1645-1676. doi.org/10.1353/sof.2010.0019

Chiu, M. M., \& Klassen, R. M. (2010). Relations of mathematics self-concept and its calibration with mathematics achievement: Cultural differences among fifteen- 
year-olds in 34 countries. Learning and Instruction, 20(1), 2-17.

doi.org/10.1016/j.learninstruc.2008.11.002

Clarke, D., Roche, A., Cheeseman, J., \& Sullivan, P. (2014). Encouraging students to persist when working on challenging tasks: Some insights from teachers. The Australian Mathematics Teacher, 70(1), 3-11.

Clayton, J. K. (2011). Changing diversity in U.S. schools: The impact on elementary student performance and achievement. Education and Urban Society, 43(6), 671695.

Cobb, P., Wood, T., \& Yackel, E. (1996). Discourse, mathematical thinking, and classroom practice. In E. Forman, N. Minick, \& C. Stone (Eds.), Contexts for learning: Sociocultural dynamics in children's development. New York: Oxford University Press.

Cohen, L., Manion, L., \& Morrison, K. (2007). Research methods in education. New York: Routledge.

Cohen, L., Manion, L., \& Morrison, K. (2011). Research methods in education (7th ed.). Oxon: Routledge.

Coleman, J. S. (1966). Equality of educational opportunity. Washington: Office of Education, US Dept. of Health, Education, and Welfare.

Corey, D. L., Phelps, G., Ball, D. L., Demonte, J., \& Harrison, D. (2012). Explaining variation in instructional time: An application of quantile regression. Educational Evaluation and Policy Analysis, 34(2), 146-163. doi.org/10.3102/0162373711431098

Cotton, K. (1990). Educational time factors. Portland, OR: Northwest Regional Education Laboratory.

Creswell, J. W. (2008). Educational research: Planning, conducting, and evaluating quantitative and qualitative research (3rd ed.). New Jersey: Pearson.

Creswell, J. W. (2014). Research design: Qualitative, quantitative and mixed methods approaches (4th ed.). London: SAGE.

Crooks, T. (2002). Educational assessment in New Zealand schools. Assessment in Education: Principles, Policy \& Practice, 9(2), 237-253. doi.org/10.1080/0969594022000001959

Crooks, T., Smith, J. K., \& Flockton, L. (2010). Mathematics: Assessment results 2009 (Vol. 52, p. 52). Dunedin: New Zealand Educational Assessment Research Unit, University of Otago. 
Crotty, M. (1998). The foundations of social research: Meaning and perspective in the research process. London: Sage.

Dalton-Puffer, C. (2007). Discourse in content and language integrated learning (CLIL) classrooms. Amsterdam: John Benjamins.

Dobbie, W., \& Fryer, R. G. (2011). Are high-quality schools enough to increase achievement among the poor? Evidence from the Harlem children's zone. American Economic Journal: Applied Economics, 3(3), 158-187. doi.org/10.1257/app.3.3.158

Doyle, W. (1988). Work in mathematics classes: The context of students' thinking during instruction. Educational Psychologist, 23(2), 167-180. doi.org/10.1207/s15326985ep2302_6

Dweck, C. S. (2006). Mindset: The new psychology of success. New York: Rondom House.

Education Council of Aotearoa New Zealand. (n.d.). Practising teacher criteria. Retrieved from http://www.teacherscouncil.govt.nz/content/registered-teachercriteria-1

Education Counts. (2015). 18-year-olds with a minimum of NCEA Level 2 or equivalent Retrieved from https://www.educationcounts.govt.nz/indicators/main/educationand-learning-outcomes/114325

Education Review Office. (2013). Mathematics in years 4 to 8: Developing a responsive curriculum. Wellington: Author.

Educational Review Office. (2014). Raising achievement in primary schools. Retrieved from http://www.ero.govt.nz/National-Reports/Raising-achievement-in-primaryschools-ALiM-and-ALL-June-2014

Education Review Office. (n.d.). School reports. Retrieved from http://www.ero.govt.nz/Early-Childhood-School-Reports/School-Reports

Ernest, P. (1989). The knowledge, beliefs and attitudes of the mathematics teacher: A model. Journal of Education for Teaching, 15(1), 13-33. doi.org/10.1080/0260747890150102

Ferguson, R. S. (1991). Paying for public education: New evidence on how and why money matters. Harvard Journal on Legislation, 28(2), 465-498.

Finlayson, M. (2014). Addressing math anxiety in the classroom. Improving Schools, 17(1), 99-115. doi.org/10.1177/1365480214521457 
Fontes, P. J., Kellaghan, T., \& O'Brien, M. (1981). Relationships between time spent teaching, classroom organisation, and reading achievement. Education Research Centre, 15(2), 79-91.

Fraser, D. (2016). Developing classroom culture: Creating a climate for learning. In D. Fraser \& M. Hill (Eds.), The professional practice of teaching in New Zealand. Australia: Cengage Learning.

Fredricks, J. A., Blumenfeld, P. C., \& Paris, A. H. (2004). School engagement: Potential of the concept, state of the evidence. Review of Educational Research, 74(1), 59109. doi.org/10.3102/00346543074001059

Fuchs, L., Powell, S., Seethaler, P., Cirino, P., Fletcher, J., Fuchs, D., . . Zumeta, R. (2009). Remediating number combination and word problem deficits among students with mathematics difficulties: A randomized control trial. Journal of educational psychology, 101(3), 561-576. doi.org/10.1037/a0014701

Galton, M., Hargreaves, L., Comber, C., Wall, D., \& Pell, A. (1999). Inside the primary classroom: 20 years on. London: Routledge.

Garden, R. A. (1997). Mathematics and science performance in middle primary school: Results from New Zealand's participation in the Third International Mathematics and science Study. Wellington, NZ: Ministry of Education.

Gerring, J. (2007). Case study research: Principals and practices. New York: Cambridge University Press.

Glaser, B. G., \& Strauss, A. L. (1967). The discovery of grounded theory: Strategies for qualitative research. Chicago: Aldine.

Gomez Zwiep, S., \& Benken, B. (2013). Exploring teachers' knowledge and perceptions across mathematics and science through content-rich learning experiences in a professional developement setting. International Journal of Science and Mathematics Education, 11(2), 299-324. doi.org/10.1007/s10763-012-9334-3

González, R. L., \& Jackson, C. L. (2012). Engaging with parents: The relationship between school engagement efforts, social class, and learning. School Effectiveness and School Improvement, 24(3), 316-335. doi.org/10.1080/09243453.2012.680893

Greenwood, C. (1991). Longitudinal analysis of time, engagement, and achievement in at-risk versus non-risk students. Exceptional Children, 57(6), 521-535. 
Guba, E. G., \& Lincoln, Y. S. (1999). Naturalistic and rationalistic enquiry. In J. P. Keeves \& G. Lakomski (Eds.), Issues in educational research. Amsterdam: Pergamon.

Guthrie, G. (2010). Basic research methods: An entry to social science research. New Delhi: Sage.

Hackman, D. A., Farah, M. J., \& Meaney, M. J. (2010). Socioeconomic status and the brain: Mechanistic insights from human and animal research. Nature Reviews Neuroscience, 11(9), 651-659. doi.org/10.1038/nrn2897

Hansen, A. (2012). Using children's mathematical misconceptions to support teaching and learning. In M. McAteer (Ed.), Improving primary mathematics teaching and learning. Maidenhead, Berkshire: Open University Press.

Hattie, J. (2002a). Teachers make a difference: What is the research evidence? NZ University of Auckland.

Hattie, J. (2002b). What are the attributes of excellent teachers? Paper presented at the New Zealand Council for Educational Research Annual Conference, University of Auckland, New Zealand.

Hattie, J. (2009). Visible learning for teachers: A synthesis of over 800 meta-analyses relating to achievement. London: Taylor and Francis.

Hattie, J., \& Timperley, H. (2007). The power of feedback. Review of Educational Research, 77(1), 81. doi.org/10.3102/003465430298487

Hemmings, B., Grootenboer, P., \& Kay, R. (2011). Predicting mathematics achievement: The influence of prior achievement and attitudes. International Journal of Science and Mathematics Education, 9(3), 691-705. doi.org/10.1007/s10763-010-9224-5

Hess, F. M. (2009). Time needs to be better spent. U.S. News and World Report, 146(4), 13.

Hiebert, J., \& Grouws, D. A. (2007). The effects of classroom mathematics teaching on student learning. In J. Frank \& K. Lester (Eds.), Second handbook of research on mathematics teaching and learning (pp. 371-404). Charlotte: Information Age.

Higgins, S. (2003). Does ICT improve teaching and learning in schools? Nottingham: British Educational Research Association.

Hill, H. C. (2007). Mathematical knowledge of middle school teachers: Implications for the no child left behind policy initiative. Educational Evaluation and Policy Analysis, 29(2), 95-114. doi.org/10.3102/0162373707301711 
Hill, H. C., \& Lubienski, S. T. (2007). Teachers' mathematics knowledge for teaching and school context: A study of California teachers. Educational Policy, 21(5), 747-768. doi.org/10.1177/0895904807307061

Hill, H. C., Rowan, B., \& Ball, D. L. (2005). Effects of teachers' mathematical knowledge for teaching on student achievement. American Educational Research Journal, 42(2), 371-406.

Hofer, M. (2007). Goal conflicts and self-regulation: A new look at pupils' off-task behaviour in the classroom. Educational Research Review, 2(1), 28-38. doi.org/10.1016/j.edurev.2007.02.002

Hollingsworth, H., Lokan, J., \& McRae, B. (2003). Teaching mathematics in Australia: Results from the TIMSS 1999 video study (TIMSS Australia Monograph No. 5). Melbourne: Australian Council for Educational Research.

Ismail, N. A., \& Awang, H. (2008). Differentials in mathematics achievement among eighth-grade students in Malaysia. International Journal of Science and Mathematics Education, 6(3), 559-571. doi.org/10.1007/s10763-007-9109-4

Janosz, M., Chouinard, R., \& Archambault, I. (2012). Teacher beliefs as predictors of adolescents' cognitive engagement and achievement in mathematics. The Journal of Educational Research, 105(5), 319-328.

Jenkins, O. F. (2010). A professional collaboration model. Mathematics Teaching in the Middle School, 16(5), 288-294.

Johnson, B., \& Christensen, L. B. (2012). Educational research: Quantitative, qualitative, and mixed approaches. Thousand Oaks, CA: SAGE.

Kilpatrick, J., Swafford, J. \& Findell, B. (2001). Adding it up: Helping children learn mathematics. Retrieved from http://citeseerx.ist.psu.edu/viewdoc/download?doi=10.1.1.487.9364\&rep=rep1\&t ype $=$ pdf

Konstantopoulos, S., \& Chung, V. (2011). Teacher effects on minority and disadvantaged students' grade 4 achievement. The Journal of Educational Research, 104(2), 73-86.

Leonard, L. J. (2001a). Erosion of instructional time: Teacher concerns. Paper presented at the Annual Meeting of the Mid-South Educational Research Association $\left(30^{\text {th }}\right.$ Conference), Little Rock, Arkansas. 
Leonard, L. J. (2001b). From indignation to indifference: Teacher concerns about externally imposed classroom interruptions. Journal of Educational Research, 95(2), 103-109. doi.org/10.1080/00220670109596578

Lysiak, F. (1980). Time utilization study: Classroom observations 1979-80. Fort Worth, TX: Fort Worth Independent School District, Texas Department of Research and Evaluation.

Mackay, J. (2006). Coat of many pockets. Camberwell, Victoria: ACER Press.

Marks, G. N. (2014). Demographic and socioeconomic inequalities in student achievement over the school career. Australian Journal of Education, 58(3), 223247. doi.org/10.1177/0004944114537052

Martins, L., \& Veiga, P. (2010). Do inequalities in parents' education play an important role in PISA students' mathematics achievement test score disparities? Economics of Education Review, 29(6), 1016-1033. doi.org/10.1016/j.econedurev.2010.05.001

McDonald, B., Polnick, B., \& Robles-Pina, R. (2013). Impact of instructional practices on students' mathematics achievement in urban middle schools. Delta Kappa Gamma Bulletin, 79(2), 52-65.

McMillan, B. W., \& Meade, A. (1985). Observation: The basic techniques. Hawthorn, Vic: Australian and New Zealand Councils for Educational Research.

Megowan-Romanowicz, M., Middleton, J. A., Ganesh, T., \& Joanou, J. (2013). Norms for participation in a middle school mathematics classroom and its effects on student motivation. Middle Grades Research Journal, 8(1), 51-76.

Mid-continent Research for Education Learning. (2010). What we know about mathematics teaching and learning (3rd ed., Edthoughts series ed.). Bloomington, IN: Solution Tree Press.

Miles, M. B., Huberman, A. M., \& Saldaña, J. (2014). Qualitative data analysis: A methods sourcebook. Thousand Oaks, CA: SAGE.

Millot, B., \& Lane, J. (2002). The efficient use of time in education. Education Economics, 10(2), 209-228. doi.org/10.1080/09645290210126922

Ministry of Education. (2007). The New Zealand curriculum. Wellington: Learning Media.

Ministry of Education. (2008a). Numeracy Book 3: Getting started. Wellington NZ: Author. 
Ministry of Education. (2008b). Numeracy Book 1: The number framework. Wellington, NZ; Author.

Ministry of Education. (2009). Understanding the standards. Retrieved from http://nzcurriculum.tki.org.nz/National-Standards/Mathematicsstandards/Understanding-the-standards

Ministry of Education. (2010). Accelerating learning. Retrieved from http://nzmaths.co.nz/accelerating-learning

Ministry of Education. (2011). Overall teacher judgment. Retrieved from http://nzcurriculum.tki.org.nz/National-Standards/Key-information/Factsheets/Overall-teacher-judgment

Ministry of Education. (2012). Key information. Retrieved from http://nzcurriculum.tki.org.nz/National-Standards/Key-information Ministry of Education. (2014). Decile ratings. Retrieved from http://www.minedu.govt.nz/NZEducation/EducationPolicies/Schools/SchoolOpe rations/Resourcing/ResourcingHandbook/Chapter1/DecileRatings.aspx

Ministry of Education. (2015a). Positive behaviour for learning. Retrieved from http://pb4l.tki.org.nz/

Ministry of Education. (2015b). Formative and summative assessment. Retrieved from http://assessment.tki.org.nz/Using-evidence-for-learning/Gatheringevidence/Topics/Formative-and-summative-assessment

Ministry of Education. (2015c). e-asTTle help. Retrieved from http://easttlehelp.vln.school.nz/create-test/attitude-questions-details

Ministry of Social Development. (2014). 2014 incomes report: Overview and summary Retrieved from https://www.msd.govt.nz/about-msd-and-our-work/publicationsresources/monitoring/household-incomes/

Moller, S., Mickelson, R. A., Stearns, E., Banerjee, N., \& Bottia, M. C. (2013). Collective pedagogical teacher culture and mathematics achievement: Differences by race, ethnicity, and socioeconomic status. Sociology of Education, 86(2), 174-194.

Moller, S., Stearns, E., Mickelson, R. A., Bottia, M. C., \& Banerjee, N. (2014). Is academic engagement the panacea for achievement in mathematics across racial/ethnic groups? Assessing the role of teacher culture. Social Forces, 92(4), 1513-1544. doi.org/10.1093/sf/sou018 
Moore, M., \& Funkhouser, J. E. (1990). More time to learn: Extended time strategies for chapter 1 students. Washington, DC: Office of Planning, Budget \& Evaluation, U.S. Dept. of Education, Office of Planning, Budget \& Evaluation. Morris, J., \& Patterson, R. (2013). World class education?: Why New Zealand must strengthen its teaching profession. Wellington: The New Zealand Initiative.

Moseley, D., Higgins, S., Bramald, R., Hardman, F., Miller, J., Mroz, M., . . Stout, J. (1999). Ways forward with ICT: Effective pedagogy using information and communications technology for literacy and numeracy in primary schools. Newcastle upon Tyne: University of Newcastle upon Tyne.

Mousley, J., Sullivan, P., \& Zevenbergen, R. (2007). Keeping all students in the learning path. Paper presented at the International Conference Mathematics Education into the 21st Century Project, Charlotte, North Carolina.

Munn, P. (1998). Number symbols and symbolic function in preschoolers. In C. Donlan (Ed.), The development of mathematical skills. Hove, East Sussex, UK: Psychology Press.

Murayama, K., Pekrun, R., Lichtenfeld, S., \& Vom Hofe, R. (2013). Predicting longterm growth in students' mathematics achievement: The unique contributions of motivation and cognitive strategies. Child Development, 84(4), 1475-1490. doi.org/10.1111/cdev.12036

NCTM. (2000). Principles and standards for school mathematics. Reston, VA: National Council of Teachers of Mathematics.

Nelson, S. (1990). Instructional time as a factor in increasing student achievement. Portland, OR: Northwest Regional Educational Laboratory.

Newby, P. (2010). Research methods for education. New York: Pearson Education.

Newman, R. (2003). Building reality: The social construction of knowledge. Retrieved from http://www.sagepub.com/upm-data/5216_Newman_Reader_Chapter_3.pdf

Newmann, F. (1992). Student engagement and achievement in American secondary schools. New York: Teachers College Press.

Nguyen, C., \& Griffin, P. (2010). Factors influencing student achievement in Vietnam. Procedia - Social and Behavioral Sciences, 2(2), 1871-1877. doi.org/10.1016/j.sbspro.2010.03.1001

Nye, B., Konstantopoulos, S., \& Hedges, L. V. (2004). How large are teacher effects? Educational Evaluation and Policy Analysis, 26, 237-257. doi.org/10.3102/01623737026003237 
O'Leary, Z. (2013). Epistemology. Retrieved from http://srmo.sagepub.com/view/thesocial-science-jargon-buster/n38.xml

Opie, C. (2004). Doing educational research. London: SAGE.

Ottmar, E. R., Konold, T. R., Berry, R. Q., Grissmer, D. W., \& Cameron, C. E. (2013). Increasing equity and achievement in fifth grade mathematics: The contribution of content exposure. School Science and Mathematics, 113(7), 345-355. doi.org/10.1111/ssm.12035

Parr, J., \& Timperley, H. (2008). Teachers, schools and using evidence: Considerations of preparedness. Assessment in Education: Principles, Policy \& Practice, 15(1), 57-71. doi.org/10.1080/09695940701876151

Parke, C., \& Kanyongo, G. (2012). Student attendance, mobility, and mathematics achievement in an urban school district. The Journal of Educational Research, 105(3), 161-175. doi.org/10.1080/00220671.2010.547231

Paschal, R., Weinstein, T., \& Walberg, H. (1984). The effects of homework on learning: A quantitative synthesis. The Journal of Educational Research, 78(2), 97-104. doi.org/10.1080/00220671.1984.10885581

Pelech, J., \& Pieper, G. (2010). The comprehensive handbook of constructivist teaching: From theory to practice. Charlotte, NC: Information Age.

Petty, T., Wang, C., \& Harbaugh, A. P. (2013). Relationships between student, teacher, and school characteristics and mathematics achievement. School Science and Mathematics, 113(7), 333-344. doi.org/10.1111/ssm.12034

Phelps, G., Corey, D., DeMonte, J., Harrison, D., \& Ball, D. L. (2012). How much English language arts and mathematics instruction do students receive? Investigating variation in instructional time. Educational Policy, 26(5), 631-662. doi.org/10.1177/0895904811417580

Piaget, J. (1955). The child's construction of reality. London: Routledge \& Paul. Pogrow, S. (1988). Teaching thinking to at-risk elementary students. Educational Leadership, 45(7), 79-85.

Pong, S., Dronkers, J., \& Hampden-Thompson, G. (2003). Family policies and children's school achievement in single versus two-parent families. Journal of Marriage and Family, 65(3), 681-699. doi.org/10.1111/j.17413737.2003.00681.x

Protheroe, N. (2007). What does good math instruction look like? Principal, 87(1), 5154. 
Punch, K. F. (2014). Introduction to social research: Quantitative \& qualitative approaches. Los Angeles: SAGE.

Ranallo, J., Bareham, S., \& Chandler, M. (1997). Student conduct management: The passionate side of teaching. Vancouver, BC: EduServ.

Robinson, K. (2013). Early disparities in mathematics gains among poor and non-poor children: Examining the role of behavioral engagement in learning. The Elementary School Journal, 114(1), 22-47. doi.org/10.1086/670737

Robinson, V., Hohepa, M. K., \& Lloyd, C. (2009). School leadership and student outcomes: Identifying what works and why: Best evidence synthesis iteration (BES). Wellington, NZ: Ministry of Education.

Rosenthal, R., \& Jacobson, L. (1968). Pygmalion in the classroom. The Urban Review, 3(1), 16-20. doi.org/10.1007/BF02322211

Rossmiller, R. (1983). Time on task: A look at what erodes time for instruction. NASSP Bulletin/National Association of Secondary School Principals Bulletin, 67(465), 45-49. doi.org/10.1177/019263658306746509

Rotherham, A. J., \& Willingham, D. (2009). 21 st century skills: The challenges ahead. Educational Leadership, 67(11), 16-21.

Rubie-Davies, C. M., Peterson, E., Irving, E., Widdowson, D., \& Dixon, R. (2010). Expectations of achievement: Student, teacher and parent perceptions. Research in Education, 83, 36-53. doi.org/10.7227/RIE.83.4

Rubie-Davies, C. M., Peterson, E. R., Sibley, C. G., \& Rosenthal, R. (2015). A teacher expectation intervention: Modelling the practices of high expectations teachers. Comtemporary Educational Psychology, 40, 72-85. doi.org/10.1016/j.cedpsych.2014.03.003

Sastry, N., \& Pebley, A. R. (2010). Family and neighborhood sources of socioeconomic inequality in children's achievement. Demography, 47(3), 777-800. doi.org/10.1353/dem.0.0114

Schifter, D. (2005). A constructivist perspective on teaching and learning mathematics. In C. T. Fosnot (Ed.), Constructivism: Theory, perspectives, and practice (2nd ed.). New York: Teachers College Press.

Schmidt, W. H., Cogan, L., \& Houang, R. (2011). The role of opportunity to learn in teacher preparation: An international context. Journal of Teacher Education, 62(2), 138-153. doi.org/10.1177/0022487110391987 
Sherer, S. (2012). Playing with pedagogy: The role of games in teaching and learning mathematics. In M. McAteer (Ed.), Improving primary mathematics teaching and learning. Maidenhead, Berkshire: Open University Press.

Shores, M. L., Shannon, D. M., \& Smith, T. G. (2010). Individual learner variables and their effect on mathematics achievement as students advance from fifth to sixth grade. Journal of Research in Childhood Education, 24(3), 187-194. doi.org/10.1080/02568543.2010.487393

Sirin, S. R. (2005). Socioeconomic status and academic achievement: A meta-analytic review of research. Review of Educational Research, 75(3), 417-453. doi.org/10.3102/00346543075003417

Skemp, R. R. (2006). Relational understanding and instrumental understanding. Mathematics Teaching in the Middle School, 12(2), 88-95.

Skinner, B. (1953). Science and human behavior. New York: Macmillan.

Sørensen, A., \& Hallinan, M. (1977). A reconceptualization of school effects. Sociology of Education, 50(4), 273-289. doi.org/10.2307/2112500

Sorhagen, N. S. (2013). Early teacher expectations disproportionately affect poor children's high school performance. Journal of Educational Psychology, 105(2), 465-477. doi.org/10.1037/a0031754

Statistics New Zealand. (2013). Skill levels of New Zealand jobs Retrieved from http://www.stats.govt.nz/browse_for_stats/income-andwork/employment_and_unemployment/skills-employed-people.aspx

Statistics New Zealand. (2014). Household economic survey (income): Year ended June 2014. Retrieved from http://www.stats.govt.nz/browse_for_stats/people_and_communities/Households /HouseholdEconomicSurvey_HOTPYeJun14.aspx

Stephanou, G. (2012). Students' school performance in language and mathematics: Effects of hope on attributions, emotions and performance expectations. International Journal of Psychological Studies, 4(2), 93-119. doi.org/10.5539/ijps.v4n2p93

Strauss, A., \& Corbin, J. (1998). Basic qualitative research: Techniques and procedures for developing grounded theory (2nd ed.). Thousand Oaks, CA: Sage.

Stylianides, A. J., \& Stylianides, G. J. (2010). Mathematics for teaching: A form of applied mathematics. Teaching and Teacher Education, 26(2), 161-172. doi.org/10.1016/j.tate.2009.03.022 
Stylianides, A. J., \& Stylianides, G. J. (2011). A type of parental involvement with an isomorphic effect on urban children's mathematics, reading, science, and social studies achievement at kindergarten entry. Urban Education, 46(3), 408-425. doi.org/10.1177/0042085910377605

Suárez-Álvarez, J., Fernández-Alonso, R., \& Muñiz, J. (2014). Self-concept, motivation, expectations, and socioeconomic level as predictors of academic performance in mathematics. Learning and Individual Differences, 30, 118-123.

Sullivan, P. (2011). Teaching mathematics: Using research-informed strategies.

Retrieved from http://research.acer.edu.au/cgi/viewcontent.cgi?article=1022\&context=aer

Sullivan, P., Mousley, J., \& Zevenbergen, R. (2006). Developing guidleines for teachers helping students experiencing difficulty in learning mathematics. Paper presented at the Mathematics Education Research Group of Australasia 29th Conference, Canberra, ACT.

Susi, L. (2011). 5 reasons why math worksheets don't work. Retrieved from http://www.conceptuamath.com/blog/5-reasons-why-math-worksheetsdon $\%$ E2\%80\%99t-work.html

Suter, W. N. (2006). Introduction to educational research: A critical thinking approach. Thousand Oaks, CA: SAGE.

Swan, M. (2005). Standards Unit - Improving learning in mathematics: Challenges and strategies. Nottingham, UK: Department for Education and Skills, University of Nottingham. Retrieved from https://www.ncetm.org.uk/public/files/224/improving_learning_in_mathematicsi. pdf

Thorvaldsen, S., Vavik, L., \& Salomon, G. (2012). The use of ICT tools in mathematics: A case-control study of best practice in 9th grade classrooms. Scandinavian Journal of Educational Research, 56(2), 213-228.

doi.org/10.1080/00313831.2011.581684

Tiberius, R. (1990). Small group teaching: A trouble-shooting guide. Toronto, Ontario: OISE Press.

Timperley, H., Wilson, A., Barrar, H., \& Fung, I. (2007). Teacher professional learning and development: Best evidence synthesis iteration (BES). Wellington: Ministry of Education. 
Thompson, A. G. (1984). The relationship of teachers' conceptions of mathematics and mathematics teaching to instructional practice. Educational Studies in Mathematics, 15(2), 105-127. doi.org/10.1007/BF00305892

Torres, Z. N., \& Moran, R. A. (2014). Race, SES, and mathematics achievement conflicts: How policy and political climate affect academic achievement. ZDM Mathematics Education, 46(7), 987-998. doi.org/10.1007/s11858-014-0640-9

Townsend, V. (2012). ICT and mathematics. In M. McAteer (Ed.), Improving primary mathematics teaching and learning. Maidenhead, Berkshire: Open University Press.

Trautwein, U. (2007). The homework-achievement relation reconsideration:

Differentiating homework time, homework frequency, and homework effort. Learning and Instruction, 17, 372-388. doi.org/10.1016/j.learninstruc.2007.02.009

Valtonen, T., Kukkonen, J., Kontkanen, S., Sormunen, K., Dillon, P., \& Sointu, E. (2015). The impact of authentic learning experiences with ICT on pre-service teachers' intentions to use ICT for teaching and learning. Computers and Education, 81, 49-58. doi.org/10.1016/j.compedu.2014.09.008

Van de Walle, J., \& Lovin, L. (2006). Teaching student-centered mathematics: Grades 5-8 (Vol. 3). Boston: Pearson Allyn \& Bacon.

Van Ewijk, R., \& Sleegers, P. (2010). The effect of peer socioeconomic status on student achievement: A meta-analysis. Educational Research Review, 5(2), 134150. doi.org/10.1016/j.edurev.2010.02.001

Van Lier, L. (2001). Constraints and resources in classroom talk: Issues of equality and symmetry. In C. Candlin \& N. Mercer (Eds.), English language teaching in its social context. London: Open University.

Vygotsky, L. S. (1978). Mind in society: The development of higher psychological processes. Cambridge: Harvard University Press.

Walberg, H. J. (1988). Synthesis of research in time and learning. Educational Leadership, 45(6), 76-85.

Walberg, H. J., Niemiec, R. P., \& Frederick, W. C. (1994). Productive curriculum time. Peabody Journal of Education, 69(3), 86-100. doi.org/10.1080/01619569409538779 
Warshauer, H. K. (2015). Productive struggle in middle school mathematics classrooms. Journal of Mathematics Teacher Education, 18(4), 375-400. doi.org/10.1007/s10857-014-9286-3

Weiss, C. C., Carolan, B. V., \& Baker-Smith, E. (2010). Big school, small school: (Re)testing assumptions about high school size, school engagement and mathematics achievement. Journal of Youth and Adolescence, 39(2), 163-176. doi.org/10.1007/s10964-009-9402-3

White, K. R. (1982). The relationship between socioeconomic status and academic achievement. Psychological Bulletin, 91(3), 461-481. doi.org/10.1037/00332909.91.3.461

Wiliam, D. (2011). Professor Dylan Wiliam at The Schools Network Annual Conference. Retrieved from https://www.youtube.com/watch?v=wKLo15A801I Williams, G. (2002). Identifying tasks that promote creative thinking in mathematics: A tool. Paper presented at the Mathematical Education Research Group of Australasia Conference, Sydney: MERGA.

Wilson, P. S., Cooney, T. J., \& Stinson, D. W. (2005). What constitutes good mathematics teaching and how it develops: Nine high school teachers' perspectives. Journal of Mathematics Teacher Education, 8(2), 83-111. doi.org/10.1007/s10857-005-4796-7

Winter, J. (2010). Home-school knowledge exchange. In I. Thompson (Ed.), Issues in teaching numeracy in primary schools (2nd ed.). Berkshire, England: Open University Press.

Woods, D. (1996). Teacher cognition in language teaching: Beliefs, decision-making and classroom practice. Cambridge, UK: Cambridge University Press.

Woolley, M. E., Strutchens, M., Gilbert, M. C., \& Martin, W. G. (2010). Mathematics success of black middle school students: Direct and indirect effects of teacher expectations and reform practices. Negro Educational Review, 61(1-4), 4159,123-124.

Wragg, E. C. (1994). An introduction to classroom observation. New York: Routledge. Wyels, C. (2015). Engaging students via in-class worksheets. Retrieved from http://www.maa.org/programs/faculty-and-departments/curriculum-departmentguidelines-recommendations/innovative-teaching-exchange/in-class-worksheets 
Wylie, C. (1999). Eight years old \& competent: The third stage of the competent children project: A summary of the main findings. Wellington: New Zealand Council for Educational Research.

Wylie, C. (2001a). Ten years old \& competent: The fourth stage of the competent children project: A summary of the main findings. Wellington: New Zealand Council for Educational Research.

Wylie, C. (2001b). Competent children: Findings and issues from the first 7 years. Paper presented at the Ministry of Social Policy Seminar, Wellington.

Wylie, C. (2013). Schools and inequality. In M. Rashbrooke (Ed.), Inequality: A New Zealand crisis. Wellington: Bridget Williams Books.

Wylie, C., \& Thompson, J. (1998). Competent children at 6: Families, early education, and schools. Wellington: New Zealand Council for Educational Research.

Yin, R. K. (2003). Case study research: Design and methods (3rd ed.). London: Sage.

Zevenbergen, R., Dole, S., \& Wright, R. J. (2004). Teaching mathematics in primary schools. Crows Nest, NSW: Allen \& Unwin.

Zhao, N., Valcke, M., Desoete, A., Zhu, C., Sang, G., \& Verhaeghe, J. (2012). A holistic model to infer mathematics performance: The interrelated impact of student, family and school context variables. Scandinavian Journal of Educational Research, 58(1), 1-20. doi.org/10.1080/00313831.2012.696210 


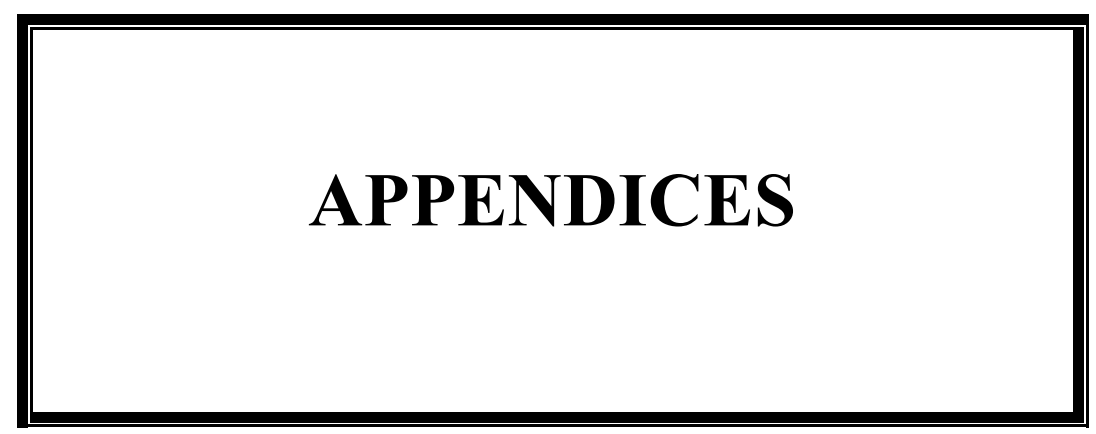


Appendix A Influences on Student Achievement / Data Gathering Tools

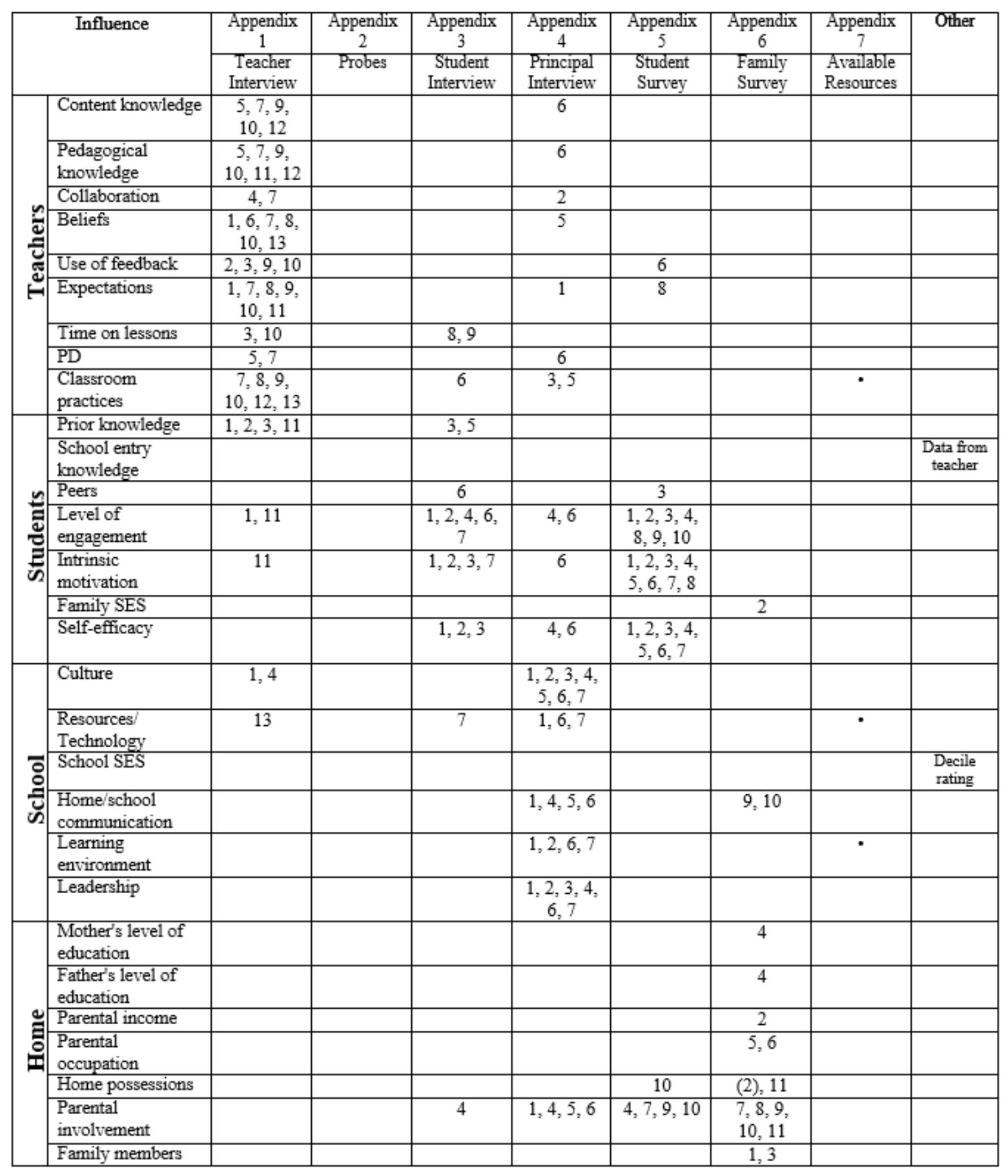




\section{Appendix B Principal Interview}

Semi-Structured (Guthrie, 2010) Principal Interview

1. Can you tell me what is being done to increase student achievement in your school?

Probe: What do you promote that increases student achievement?

2. What is the school currently focussing on, in terms of professional development, to improve student achievement?

\section{Research indicates that when teachers and students feel that they are part of the school community, student achievement increases.}

3. How are you developing this sense of community for teachers?

Probe: How are you building a sense of direction so that everyone is working towards the same goals?

4. How are you developing this sense of community for students?

5. How do you encourage and develop teacher collaboration?

Probes: Do your teachers plan together?

Are teachers given time to discuss the needs of individual students?

Do teachers share their successes?

Are teachers given time to watch each other and share best practice?

6. What are the main channels that you have established for communication between home and school?

Probes: How often do you hold parent/teacher interviews?

Do parents have regular interaction with classroom teachers about their child/ren's progress?

How is this structured?

Do you hold regular events for the community to learn about teaching and learning at school, e.g. maths parents evening?

Do you hold regular events to find out the community's opinions and needs, e.g. hui?

7. What strategies do you have in place to help build mathematics achievement?

Probe: What strategies are in place to develop the pedagogical knowledge of the teachers?

8. What school wide initiatives are you school currently involved in that might have an impact on students' mathematics achievement?

Probe: Are you involved in programmes like ALiM/MST, Learning with Digital Technologies?

9. How are you developing the use of technology in mathematics teaching and learning? 


\section{Appendix C Teacher Interview}

Semi-Structured (Guthrie, 2010) Teacher Interview based on (Hattie, 2002b). This interview should be conducted within 24 hours of the final lesson observation.

1. What is the biggest influence over the way you teach?

2. Could you tell me what mathematics achievement data you collect from your students? Probe: Why have you chosen to gather that data?

3. How do you use the mathematics assessment data that you gather?

Probes: Do you think that there is any other data that would be useful? Why?

Why have you decided to use that data in that way?

Why have you decided not to use that data?

4. How do you collaborate with other teachers about mathematics?

Probes: Do you plan together?

Do you discuss individual students' needs?

Do you observe each other's lessons?

How do you moderate assessment data?

5. What mathematics professional development have you done in the last 12 months?

Probe: What professional development needs, either school wide or personal, would you like to see addressed?

6. Could you tell me a bit about how you believe maths should be taught?

Probe: What do you think about using:

$$
\begin{array}{ll}
\text { - } & \text { Student discourse/teacher dialogue? } \\
\text { - } & \text { Problem solving/calculation strategies? } \\
\text { - } & \text { Mixed/ability groupings? } \\
\text { - } & \text { Whole class/group teaching? } \\
\text { - } & \text { Materials/Equipment? }
\end{array}
$$

\section{Note: Remind the teacher of the last lesson (have video available if necessary).}

7. Thinking back to the last lesson I observed you teach, what influenced your lesson planning?

8. Still thinking about the last lesson I observed you teach, would you rate it as successful? Why or why not?

9. Was there anything in that lesson that you would do differently if you were to repeat it?

10. Again, thinking about the last lesson I observed, what were the most important decisions you made during the lessons?

11. I noticed that students were using a range of technologies during (some of) the lessons I observed. How are you using ICT to improve student achievement?

Probe: I noticed that students weren't using any technology during the lessons I observed? Could you tell me what you think about using ICT in maths?

12. Could you tell me about the expectations you had for [student's name] during the last lesson I observed?

13. What do you want to teach the last group/individual I observed you teach next? Why? 


\section{Appendix D Student Interview}

Semi-Structured (Guthrie, 2010) based on Absolum (2006).

1. What do you enjoy doing in maths?

2. What don't you enjoy doing in maths?

3. What do you want to get better at in maths?

4. What maths do you do at home?

5. Tell me some things you have learned in maths this year.

6. Do you prefer to work by yourself, with a partner and/or in groups or a mix of all of these? Why? When?

7. Are there any maths activities or equipment that you enjoy working with?

8. How often do you do maths?

9. How long do maths lessons last? 


\section{Appendix E Family Survey}

Family Survey based on Marks (2014)

\section{Family Survey}

Welcome to the survey for parents/caregivers

Thank you for participating in my research into maths achievement and taking the time to complete this survey. Your feedback is confidential and neither you nor your child will be named.

This questionnaire can be completed either online or on this form. If you would prefer to complete this survey online, please go to https://www.surveymonkey.com/r/ before Friday 31 July. If you use this form please return it, completed, to your child's teacher before Friday 31 July.

* 1. Please enter the number provided in the box below into the equivalent box in the online survey. If you are completing this survey on the paper form, please go to Question 2.

The number in the box above will be used to link your responses to the data collected in school from your child, who will use the same number. This means that I do not know your name, or that of your child, and helps to ensure that all data collected remains confidential. 


\section{Your Household}

*2. How many people live in your household?

* What is the approximate total annual household income?

Below $\$ 25,000$

$\$ 25,001-\$ 45,000$

$\$ 45,001-\$ 65,000$

$\$ 65,001-\$ 85,000$

$\$ 85,001-\$ 105,000$

$\$ 105,001-\$ 125,000$

$\$ 125,001-\$ 145,000$

$\$ 145,001-\$ 165,000$

More than $\$ 165,000$

Prefer not to say 


\section{Family Survey}

\section{Parent/Caregiver 1}

*4. Are you male or female?

Male

Female

* 5 . What is your highest level of qualification?

No formal qualifications

NCEA Level 1, or equivalent, e.g. School Certificate

NCEA Level 2, or equivalent, e.g. UE

NCEA 3, or equivalent, e.g. University Bursary

NCEA Level 4, or equivalent, e.g. National Certificate

Diploma, or equivalent

Bachelor Degree, Graduate Diploma/Certificate

Postgraduate Diploma, Certificate, Honours Degree, or higher

Other (please specify) 


\section{Parent/Caregiver 1}

*6. Do you have more than one job?

Yes

No

${ }^{*} 7$. What is your main job?

No paid employment

Stay at home parent

Machine operator, hospitality, assistant, labourer

Tradesperson, clerk, office, sales or service staff

Business manager or professional

Senior management or qualified professional

Other (please specify) 
Family Survey

\section{Parent/Caregiver 1}

Please answer the following questions thinking only about your child in Teacher's class.

* 8 . On average, how much time do you spend on school work with your child each week?
No time
Up to 1 hour
Up to 2 hours
Up to 3 hours
Up to 4 hours
Up to 5 hours
More than 5 hours

* 9. There are many maths activities that can be done with children at home, for example cooking together, looking at sports' scores and statistics, playing board games such as Monopoly, counting and looking at numbers, or doing maths homework together.

How often do you do maths activities at home with your child?
Never
Sometimes
Once a fortnight
Once a week
3 or 4 times a week
Everyday 


\section{Family Survey}

\section{Parent/Caregiver 1}

Please answer the following questions thinking only about your child in Teacher's class.

* 10. If your child's school has a newsletter, do you read every issue?

Yes

No

Not Applicable

*11. About how often do you have contact with your child's school, excluding reading the newsletter? Never

Twice a year, usually at parent interviews

Once a term

Once a month

Once a fortnight

Once or twice a week

Every day 
Important: If there is only one parent or caregiver in your household, please go straight to Question 20.

\section{Parent/Caregiver 2}

12. Are you male or female?
Male
Female

13. What is your highest level of qualification?

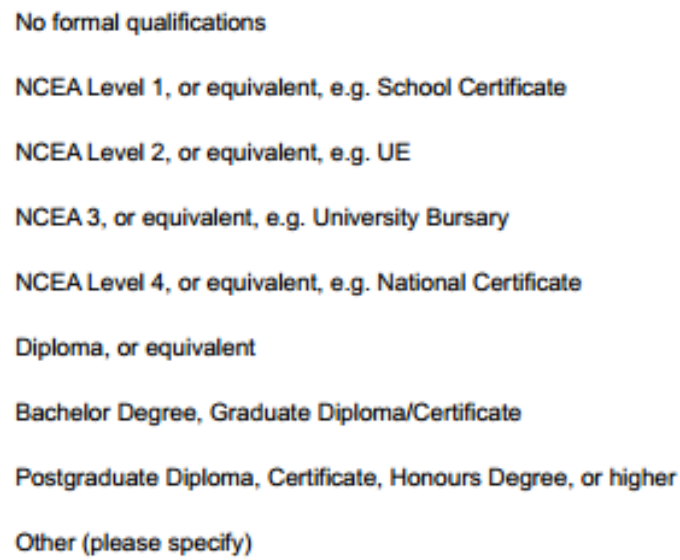




\section{Parent/Caregiver 2}

14. Do you have more than one job?
Yes

No

15. What is your main job?

No paid employment

Stay at home parent

Machine operator, hospitality, assistant, labourer

Tradesperson, clerk, office, sales or service staff

Business manager or professional

Senior management or qualified professional

Other (please specify) 


\section{Parent/Caregiver 2}

Please answer the following questions thinking only about your child in Teacher's class.

16. On average, how much time do you spend on school work with your child each week?
No time
Up to 1 hour
Up to 2 hours
Up to 3 hours
Up to 4 hours
Up to 5 hours
More than 5 hours

17. There are many maths activities that can be done with children at home, for example cooking together, looking at sports' scores and statistics, playing board games such as Monopoly, counting and looking at numbers, or doing maths homework together.

How often do you do maths activities at home with your child?
Never
Sometimes
Once a fortnight
Once a week
3 or 4 times a week
Everyday 


\section{Parent/Caregiver 2}

Please answer the following questions thinking only about your child in Teacher's class.

18. If your child's school has a newsletter, do you read every issue?
Yes
No
Not Applicable

19. About how often do you have contact with your child's school, excluding reading the newsletter?

Never

Twice a year, usually at parent interviews

Once a term

Once a month

Once a fortnight

Once or twice a week

Every day 
Family Survey

\section{Your Household}

* 20. Which of the following do you have at home that your child can use to help them with maths (tick all that apply).
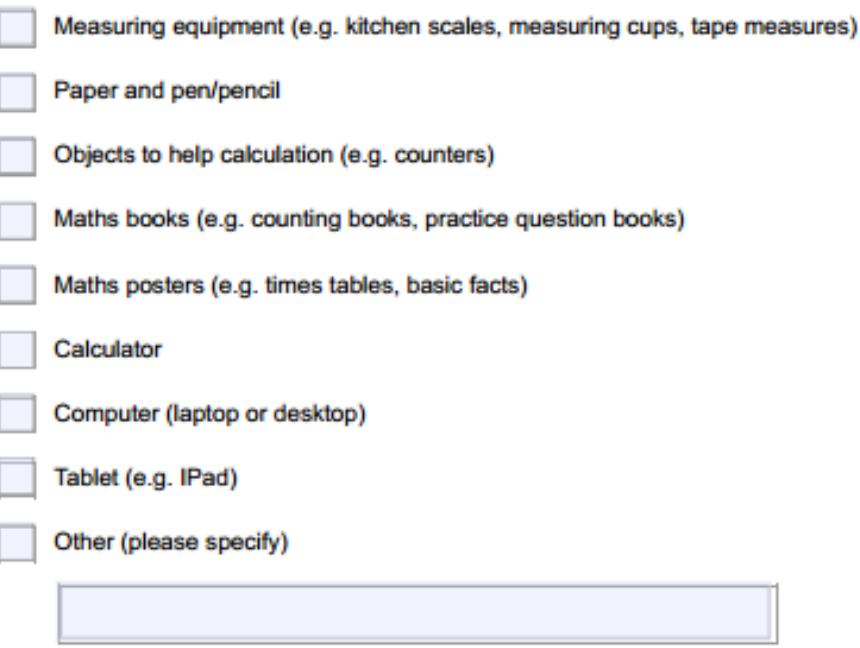

Thank you for completing the survey. 


\section{Appendix F Student Survey}

Middle and Senior Student Attitudinal Survey based on Ministry of Education (2015)

Circle the number that you think is most like you, or mark 'Don't Know'

1. I like coming to school.

\begin{tabular}{|c|c|c|c|c|c|}
\hline $\begin{array}{l}\text { Strongly } \\
\text { Disagree }\end{array}$ & & & & $\begin{array}{l}\text { Strongly } \\
\text { Agree }\end{array}$ & $\begin{array}{l}\text { Don't } \\
\text { Know }\end{array}$ \\
\hline 1 & 2 & 3 & 4 & 5 & \\
\hline
\end{tabular}

2. I enjoy doing maths by myself.

\begin{tabular}{|c|c|c|c|c|c|}
\hline $\begin{array}{l}\text { Strongly } \\
\text { Disagree }\end{array}$ & & & & $\begin{array}{l}\text { Strongly } \\
\text { Agree }\end{array}$ & $\begin{array}{l}\text { Don't } \\
\text { Know }\end{array}$ \\
\hline 1 & 2 & 3 & 4 & 5 & \\
\hline
\end{tabular}

3. I enjoy doing maths in a group.

\begin{tabular}{llll|l}
\cline { 4 - 4 } $\begin{array}{l}\text { Strongly } \\
\text { Disagree }\end{array}$ & & & Strongly & Don’t \\
1 & 2 & 3 & & Know \\
\cline { 4 - 5 } 1 & & 4 & 5 & \\
\hline
\end{tabular}

4. I enjoy doing maths at home.

\begin{tabular}{|c|c|c|c|c|c|}
\hline $\begin{array}{l}\text { Strongly } \\
\text { Disagree }\end{array}$ & & & & $\begin{array}{l}\text { Strongly } \\
\text { Agree }\end{array}$ & $\begin{array}{l}\text { Don't } \\
\text { Know }\end{array}$ \\
\hline 1 & 2 & 3 & 4 & 5 & \\
\hline
\end{tabular}

5. I am good at maths.

\begin{tabular}{|c|c|c|c|c|c|}
\hline $\begin{array}{l}\text { Strongly } \\
\text { Disagree }\end{array}$ & & & & $\begin{array}{l}\text { Strongly } \\
\text { Agree }\end{array}$ & $\begin{array}{l}\text { Don't } \\
\text { Know }\end{array}$ \\
\hline 1 & 2 & 3 & 4 & 5 & \\
\hline
\end{tabular}

6. My teacher thinks I'm good at maths.

\begin{tabular}{|c|c|c|c|c|c|}
\hline $\begin{array}{l}\text { Strongly } \\
\text { Disagree }\end{array}$ & & & & $\begin{array}{l}\text { Strongly } \\
\text { Agree }\end{array}$ & \begin{tabular}{|l} 
Don't \\
Know
\end{tabular} \\
\hline 1 & 2 & 3 & 4 & 5 & \\
\hline
\end{tabular}


7. My parents think I'm good at maths.

\begin{tabular}{|c|c|c|c|c|c|}
\hline \multirow{2}{*}{$\begin{array}{l}\text { Strongly } \\
\text { Disagree } \\
1\end{array}$} & \multirow[b]{2}{*}{2} & \multirow[b]{2}{*}{3} & & \multirow{2}{*}{$\begin{array}{l}\text { Strongly } \\
\text { Agree } \\
5\end{array}$} & $\begin{array}{l}\text { Don't } \\
\text { Know }\end{array}$ \\
\hline & & & 4 & & \\
\hline
\end{tabular}

8. I think it is important to learn maths.

\begin{tabular}{|c|c|c|c|c|c|}
\hline $\begin{array}{l}\text { Strongly } \\
\text { Disagree }\end{array}$ & & & & $\begin{array}{l}\text { Strongly } \\
\text { Agree }\end{array}$ & $\begin{array}{l}\text { Don't } \\
\text { Know }\end{array}$ \\
\hline 1 & 2 & 3 & 4 & 5 & \\
\hline
\end{tabular}

9. My parents often help me with maths at home.

\begin{tabular}{llllll}
\cline { 3 - 4 } Strongly & & & Strongly & Don't \\
Disagree & & & Agree & Know \\
1 & 2 & 3 & 4 & 5 & \\
\hline
\end{tabular}

10. We play board games, card games and maths games, like Mathletics, Studyladder, and Monopoly, at home.

\begin{tabular}{|c|c|c|c|c|c|}
\hline $\begin{array}{l}\text { Strongly } \\
\text { Disagree }\end{array}$ & & & & $\begin{array}{l}\text { Strongly } \\
\text { Agree }\end{array}$ & $\begin{array}{l}\text { Don't } \\
\text { Know }\end{array}$ \\
\hline 1 & 2 & 3 & 4 & 5 & \\
\hline
\end{tabular}

Thank you for taking the time to complete this questionnaire. 
Junior Student Attitudinal Survey based on Ministry of Education (2015)

Circle the number that you think is most like you, or mark 'Don't Know'.

1. I like coming to school.

\begin{tabular}{|c|c|c|c|c|c|}
\hline & & & & & $\begin{array}{l}\text { Don't } \\
\text { Know }\end{array}$ \\
\hline 1 & 2 & 3 & 4 & 5 & \\
\hline
\end{tabular}

2. I enjoy doing maths by myself.

\begin{tabular}{|c|c|c|c|c|c|}
\hline & & & & & $\begin{array}{l}\text { Don't } \\
\text { Know }\end{array}$ \\
\hline 1 & 2 & 3 & 4 & 5 & \\
\hline
\end{tabular}

3. I enjoy doing maths in a group.

\begin{tabular}{|c|c|c|c|c|c|}
\hline & & & & & $\begin{array}{l}\text { Don't } \\
\text { Know }\end{array}$ \\
\hline 1 & 2 & 3 & 4 & 5 & \\
\hline
\end{tabular}

4. I enjoy doing maths at home.

\begin{tabular}{|c|c|c|c|c|c|}
\hline & & & & & $\begin{array}{l}\text { Don't } \\
\text { Know }\end{array}$ \\
\hline 1 & 2 & 3 & 4 & 5 & \\
\hline
\end{tabular}

5. I am good at maths.

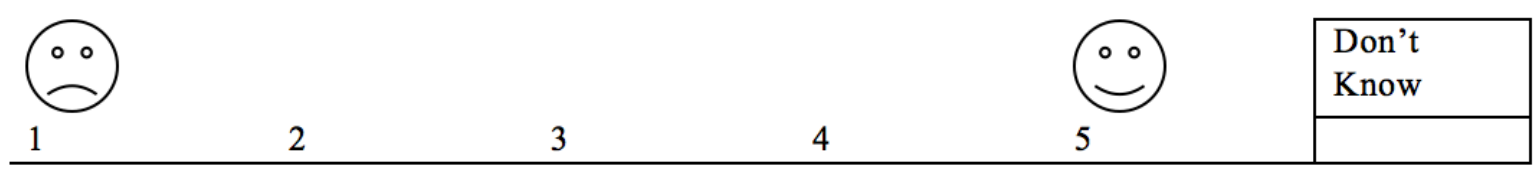

6. My teacher thinks I'm good at maths.

\begin{tabular}{lllll|l|}
$\circ$ & & & & & $\begin{array}{l}\text { Don't } \\
\text { Know }\end{array}$ \\
1 & 2 & 3 & & & \\
\hline
\end{tabular}


7. My parents think I'm good at maths.

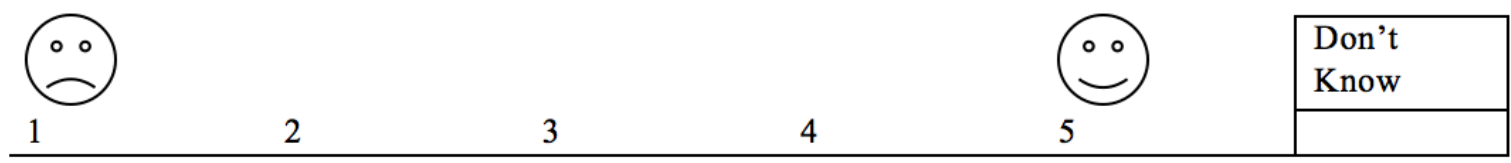

8. I think it is important to learn maths.

\begin{tabular}{|c|c|c|c|c|c|}
\hline & & & & & $\begin{array}{l}\text { Don't } \\
\text { Know }\end{array}$ \\
\hline 1 & 2 & 3 & 4 & 5 & \\
\hline
\end{tabular}

9. My parents often help me with maths at home.

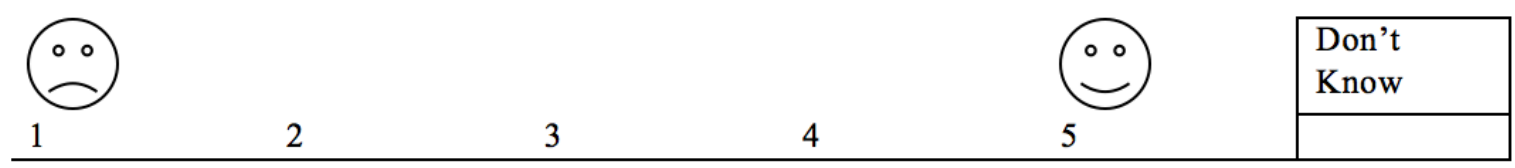

10. We play board games, card games and maths games, like Mathletics, Studyladder, snakes and ladders, and snap, at home.

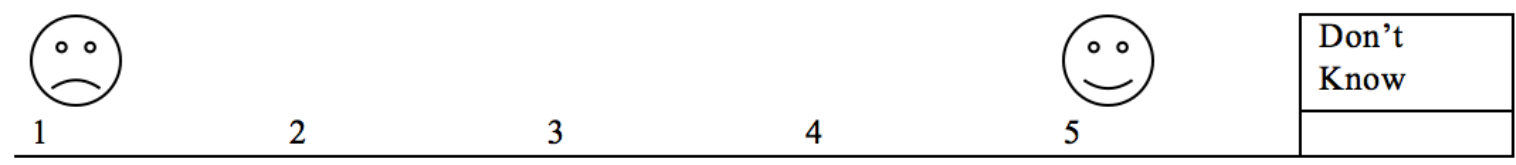

Thank you for taking the time to complete this questionnaire. 


\section{Appendix G Physical Artefacts Checklist}

Classroom Resource Availability Survey based on MoE (2008a).

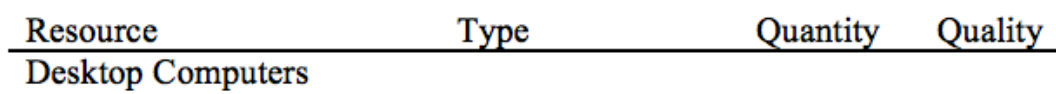

Laptop Computers

Tablets

\begin{tabular}{l} 
Whiteboard: \\
Teacher \\
Student \\
Group \\
\hline Mathematics Equipment: \\
Teacher \\
Student \\
Group \\
\hline Teacher Aide for \\
Mathematics \\
\\
Task Board
\end{tabular}

Task Board

Planning

Assessment Tools

Text Books, including FIO

Mathematics Displays

Other 


\section{Appendix H Master List of Codes Used Throughout the Research}

\begin{tabular}{l} 
Code \\
\hline Use of allocated time \\
$\mathrm{T} \rightarrow \mathrm{C}$ \\
$\mathrm{T} \rightarrow \mathrm{G}$ \\
$\mathrm{T} \rightarrow \mathrm{S}$ \\
$\mathrm{S} \rightarrow \mathrm{T}$ \\
$1-1$ \\
$\mathrm{NM}$ \\
$\mathrm{SMG}$
\end{tabular}

\section{Meaning}

The teacher interacting with the whole class.

The teacher interacting with the whole group.

The teacher interacting with one student.

One student interacting with the teacher|

A one to one interaction between teacher and student.

No mathematics taking place.

\begin{tabular}{|c|c|}
\hline SMG & $\begin{array}{l}\text { Students interacting with mathematics in a group whilst the teacher } \\
\text { observes them. }\end{array}$ \\
\hline Off & Students, or teacher, off task. \\
\hline Int. & An interruption to the lesson (internal or external). \\
\hline BM & $\begin{array}{l}\text { A behaviour management incident where the remainder of the } \\
\text { students stopped interacting with mathematics. }\end{array}$ \\
\hline BMS & $\begin{array}{l}\text { A behaviour management incident where the remainder of the } \\
\text { students continued interacting with mathematics. }\end{array}$ \\
\hline $\begin{array}{l}\text { Trans } \\
\text { Tidy }\end{array}$ & $\begin{array}{l}\text { The time taken to transition between groups or activities. } \\
\text { The time used to tidy the classroom during or after the } \\
\text { mathematics lesson. }\end{array}$ \\
\hline
\end{tabular}

Interactions between teachers, students and the mathematical tasks

$\mathrm{T} \rightarrow \mathrm{C}$

The teacher interacting with the whole class.

$\mathrm{T} \rightarrow \mathrm{G}$

The teacher interacting with the whole group.

$\mathrm{T} \rightarrow \mathrm{S}$

The teacher interacting with one student.

$\mathrm{S} \rightarrow \mathrm{T}$

One student interacting with the teacher.

NM

No mathematics taking place.

SMG

Students interacting with mathematics in a group whilst the teacher observes them.

NI Not interacting with mathematics.

I Interacting with mathematics.

WCI Whole class interacting with mathematics.

\begin{tabular}{|c|c|}
\hline Interruption & \\
\hline Late & A student arriving late \\
\hline Message & A message being brou \\
\hline $\mathrm{EF}$ & $\begin{array}{l}\text { A student who finishe } \\
\text { session or lesson. }\end{array}$ \\
\hline ICT & A problem based in IC \\
\hline Explain & $\begin{array}{l}\text { The teacher giving a } \mathrm{f} \\
\text { group or class. }\end{array}$ \\
\hline Conversations & Student talking about \\
\hline Bathroom & A student asking to $\mathrm{g}$ \\
\hline Personal & $\begin{array}{l}\text { A student interrupting } \\
\text { shoe laces tying. }\end{array}$ \\
\hline Unknown & $\begin{array}{l}\text { The reason for the int } \\
\text { teacher. }\end{array}$ \\
\hline Equipment & $\begin{array}{l}\text { The teacher or stuc } \\
\text { mathematics equipmer }\end{array}$ \\
\hline Sections of the & ratics lesson \\
\hline S & Starter. \\
\hline WC & Whole class teachin \\
\hline
\end{tabular}


$\begin{array}{ll}\text { PS } & \text { Problem solving. } \\ \text { GW } & \text { Group work. } \\ \text { P } & \text { Plenary. }\end{array}$

Types of mathematics tasks given to students

W Worksheet.

Complete The requirement for the worksheet to be completed.

OTQ

Oral questions asked by the teacher during group or class time.

WTQ

Questions written by the teacher, either on a whiteboard, or in a book, for student to answer.

ICT The use of ICT for the teaching of mathematics.

MG The use of mathematics games for the teaching of mathematics.

Ways in which students interacted with the given mathematics tasks

WM

TWM

Students interacting with mathematics by writing.

OM

Students observing the teacher write mathematics.

DM

Students interacting with mathematics orally.

1-1 Students interacting with their teacher and the mathematics task on a one to one basis, whether written or oral.

Level of challenge presented by the mathematics

Inaccessible knowledge, i.e. knowledge that is beyond the reach of
a student.
Accessible knowledge, i.e. knowledge that can be achieved
through scaffolding.
Existing knowledge, i.e. what the student already knows and can
do.
Other mathematics, i.e. the original question asked, or
explanations.
Other non-mathematics, i.e. off task events, or behaviour
management.




\section{Appendix I Types of Mathematics Activities and Interactions}

\begin{tabular}{|c|c|c|c|c|c|}
\hline $\begin{array}{l}\text { Lesson } \\
\text { Section }\end{array}$ & & $\begin{array}{l}\text { Time } \\
\text { (minutes) }\end{array}$ & Activity & Interaction & Number of tasks \\
\hline \multicolumn{6}{|c|}{ Patty (11 students) } \\
\hline $\mathrm{S}$ & WC & 43 & OTQx4, WTQx1 & $\mathrm{OM} \times 3, \mathrm{WMx} 1$ & 62 \\
\hline WC & & 36 & $\mathrm{~W} \times 2$ & WMx1 & Complete \\
\hline \multirow[t]{3}{*}{ GW1 } & $\mathrm{A}$ & & Wx2, OTQx1, WTQx1 & WMx3 & $7,2 \times$ Complete \\
\hline & $\mathrm{B}$ & 40 & Wx1, ICTx2, MGx1 & OMx1, WMx1, DMx2 & Complete \\
\hline & $\mathrm{C}$ & & Wx1, OTQx1, WTQx2 & WMx2, TWMx1 & 23 \\
\hline \multirow[t]{3}{*}{ GW2 } & $\mathrm{A}$ & & $\mathrm{W} \times 1, \mathrm{ICT} 2$ & WMx1, DMx2 & Complete \\
\hline & $\bar{B}$ & 44 & OTQx2, WTQx2, ICTx1 & $\begin{array}{l}\text { WMx1, } \\
\text { DMx1 }\end{array}$ & 23 \\
\hline & $\mathrm{C}$ & & MGx3 & $\mathrm{OMx} 3$ & N/A \\
\hline \multicolumn{6}{|c|}{ Wanda (14 students) } \\
\hline \multirow{4}{*}{$\frac{\mathrm{S}}{\mathrm{GW} 1}$} & WC & 43 & OTQX4 & OMx2 OM1-1x2 & 13 \\
\hline & A & 56 & OTQx4 & $\begin{array}{l}\text { OMx1, OM } 1-1 \times 3 \\
\text { TWM 1-1x1 }\end{array}$ & 22 \\
\hline & $\mathrm{B}$ & & MGx4 & $\mathrm{OMx} 4$ & N/A \\
\hline & $\mathrm{C}$ & & MGx4 & $\mathrm{OMx} 4$ & N/A \\
\hline \multirow[t]{3}{*}{ GW2 } & $\mathrm{A}$ & & MGx4 & $\mathrm{OMx} 4$ & N/A \\
\hline & $\mathrm{B}$ & 66 & OTQx4 & OM 1-1 x4 & 20 \\
\hline & $\mathrm{C}$ & & MGx4 & $\mathrm{OMx} 4$ & N/A \\
\hline \multirow[t]{3}{*}{ GW3 } & $\mathrm{A}$ & & MGx4 & $\mathrm{OMx} 4$ & N/A \\
\hline & $\mathrm{B}$ & 50 & MGx4 & OMx4 & N/A \\
\hline & $\mathrm{C}$ & & OTQx3 & OM 1-1x3 & 20 \\
\hline \multicolumn{6}{|c|}{ Peter (30 students) } \\
\hline \multirow[t]{4}{*}{ GW1 } & A & & WTQx3, ICTx1 & WMx3, DMx1 & 30 \\
\hline & $\mathrm{B}$ & 92 & Wx2, WTQx2, ICTx1 & WMx4, DMx1 & $2 \times$ Complete, 72 \\
\hline & $\mathrm{C}$ & & WTQx2, ICTx2 & WMx2, DMx2 & 26 \\
\hline & $\mathrm{D}$ & & Wx2, WTQx2, MGx1 & WMx4, OMx1 & $2 \mathrm{xComplete,} 22$ \\
\hline \multirow[t]{4}{*}{ GW2 } & $\bar{A}$ & & Wx2, WTQx3 & WMx4 & $2 \mathrm{xComplete,} 23$ \\
\hline & $\mathrm{B}$ & 67 & WTQx2, MGx1, ICTx1 & $\mathrm{OMx} 1, \mathrm{WM} \times 2, \mathrm{DMx} 1$ & 59 \\
\hline & $\mathrm{C}$ & & Wx2, WTQx2 & WMx4 & $2 \times$ Complete, 72 \\
\hline & $\mathrm{D}$ & & WTQx2, ICTx1, MGx1 & $\mathrm{OMx} 1, \mathrm{WM} 2, \mathrm{DMx} 1$ & 23 \\
\hline \multicolumn{6}{|c|}{ Whitney (14 students) } \\
\hline $\mathrm{GW}$ & WC & 20 & MGx4 & $\mathrm{OMx} 4$ & 4 \\
\hline PS & WC & 58 & WTQx2, OTQx4 & OM 1-1x4 & 12 \\
\hline \multirow[t]{2}{*}{ GW1 } & $\mathrm{A}$ & 38 & OTQx4 & OM 1-1x4 & 24 \\
\hline & $\mathrm{B}$ & & OTQx1, WTQx4, ICTx4 & OMx1, WMx4, DMx4 & 41 \\
\hline \multirow[t]{2}{*}{ GW2 } & $\mathrm{A}$ & 45 & OTQx4 & OMx4, TWM 1-1x4 & 26 \\
\hline & $\mathrm{B}$ & & OTQx1, WTQx4, ICTx4 & $\mathrm{OMx} 1, \mathrm{WM} \times 4, \mathrm{DMx} 4$ & 30 \\
\hline $\mathrm{WC}$ & & 32 & OTQx1, WTQx4, ICTx4 & $\mathrm{OMx} 1, \mathrm{WMx} 4, \mathrm{DM} 4$ & N/A \\
\hline$P$ & WC & 12 & OTQx1 & OMx1 OM1-1x1 & 2 \\
\hline \multicolumn{6}{|c|}{ Paula (24 students) } \\
\hline$S$ & $\mathrm{WC}$ & 20 & WTQX3 & WMx3 & 23 \\
\hline $\mathrm{S}$ & WC & 50 & WTQx4 & $\mathrm{OMx} 4$ & 88 \\
\hline $\mathrm{WC}$ & & 81 & Wx1 WTQx2 & WMx2 & 48, Complete \\
\hline \multirow[t]{6}{*}{$\mathrm{GW}$} & $\mathrm{A}$ & & Wx2, WTQx1, ICTx1 & WMx2, DMx1 & $2 \mathrm{xComplete}$ \\
\hline & $\mathrm{B}$ & & Wx2, WTQx1, ICTx1 & WMx2, DMx1 & $4,2 \times$ Complete \\
\hline & $\mathrm{C}$ & & Wx2, WTQx1, OTQx1, ICTx1 & $\mathrm{OMx} 1, \mathrm{WM} 2, \mathrm{DMx} 1$ & $12,2 \times$ Complete \\
\hline & $\mathrm{D}$ & 65 & Wx2, WTQx1, OTQx1, ICTx1 & $\mathrm{OMx} 1, \mathrm{WM} 2, \mathrm{DMx} 1$ & $8,2 \times$ Complete \\
\hline & $\mathrm{E}$ & & Wx1, WTQx1, OTQx1, ICTx1 & OMx1, WMx1, DMx1 & 5 , Complete \\
\hline & $\mathrm{F}$ & & Wx2, WTQx1, OTQx1, ICTx1 & OMx1, WMx1, DMx1 & $5,2 \times$ Complete \\
\hline$\overline{\mathrm{P}}$ & $\overline{\mathrm{WC}}$ & 2 & Wx1 & OMx1 & N/A \\
\hline
\end{tabular}


Weston (19 students)

\begin{tabular}{|c|c|c|c|c|c|}
\hline $\mathrm{S}$ & WC & 41 & Wx1, OTQx3 & WMx1, OM 1-1x3 & 88 \\
\hline GW1 & A & \multirow{3}{*}{82} & Wx2, OTQx1, WTQx1 & WMx4 & $10,2 \times$ Complete \\
\hline & $\mathrm{B}$ & & Wx1, OTQx1, WTQx1, ICTx1 & WMx3, DMx1 & 14, Complete \\
\hline & $\mathrm{C}$ & & OTQx2, WTQx1, ICTx1, MGx1 & WMx3, DMx1, OMx1 & 18 \\
\hline GW2 & $\bar{A}$ & \multirow{3}{*}{117} & Wx1, OTQx2, ICTx1 & WMx3, DMx1 & 9, Complete \\
\hline & $\bar{B}$ & & Wx1, OTQx1, ICTx1, MGx2 & WMx2, DMx1, OMx2 & 6, Complete \\
\hline & $\bar{C}$ & & OTQx1, WTQx2, ICTx1 & WMx3, DMx1 & 33 \\
\hline
\end{tabular}




\section{Appendix J Family Survey Codes}

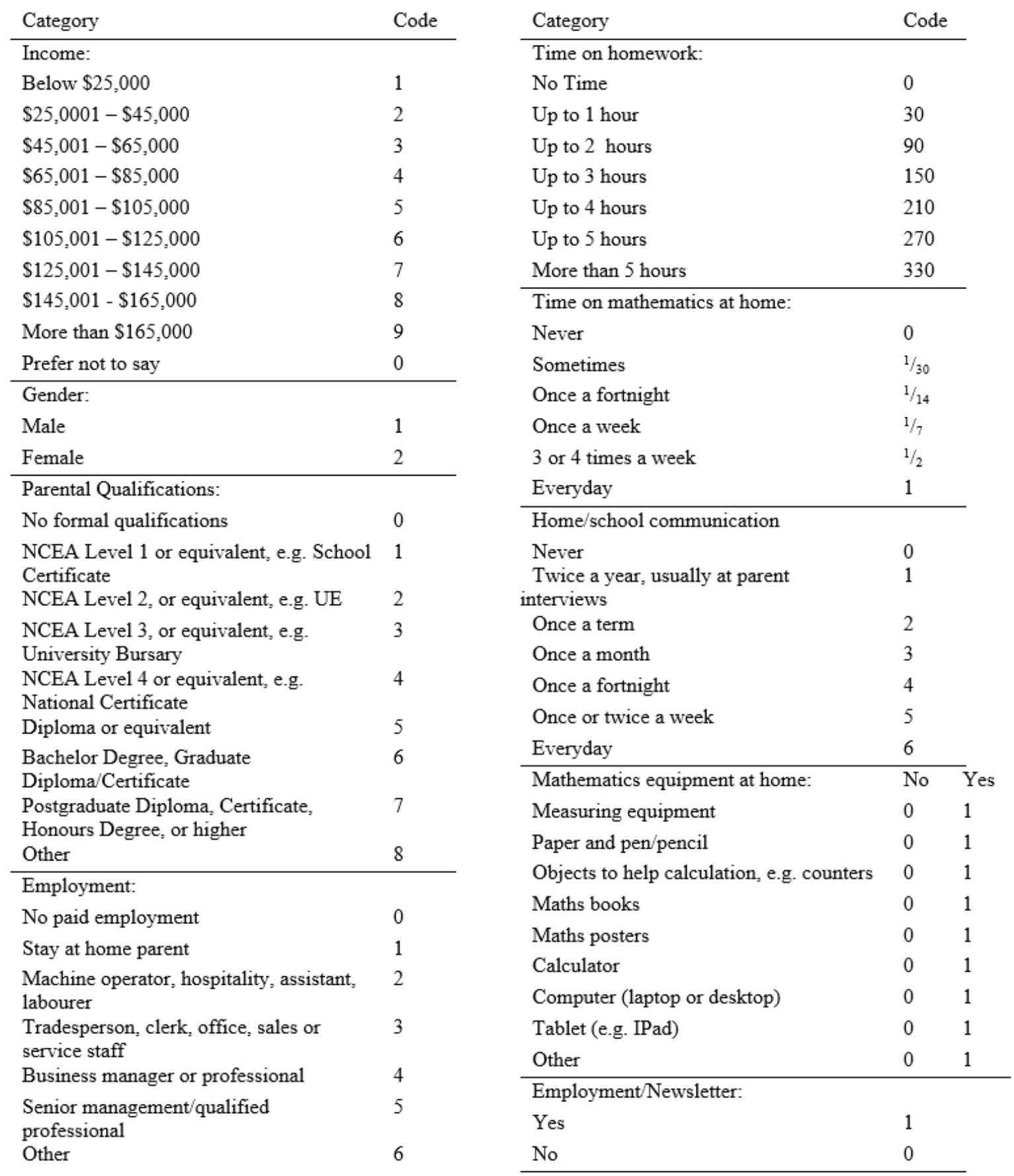




\title{
Appendix K Example of an Ethics Information Sheet
}

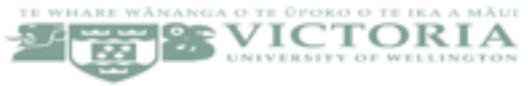 \\ Teacher Information Sheet \\ The Influence of Socioeconomic Status on Mathematics Achievement in Two New \\ Zealand Primary Schools
}

My name is Jenni Harrison and my background is as a primary school teacher and lead teacher for mathematics. I am currently a student at Victoria University of Wellington, Faculty of Education, studying for a Master's of Education. My thesis is on The Influence of Socioeconomic Status on Mathematics Achievement in Two New Zealand Primary Schools. The underlying purposes of this research are to both identify key factors that may be influencing mathematics achievement in an individual school and to develop tools to support schools to identify these factors in their own context. To do this I intend looking at the similarities and differences between two primary schools, one low decile and the other high decile. I am hoping that by identifying key factors that enable or constrain mathematics achievement, schools will be better placed to improve students' mathematics achievement. The data gathered during this research will be used confidentially to write my thesis, and the results of the data analysis will be used for conferences, and in journal articles. This Master's research study will be supervised by Dr Michael Drake and Dr Sandi McCutcheon.

The purpose of this letter is to seek permission from you for participation in my Master's research. Participation will involve:

- Four mathematics lessons that you teach being videoed, over a period of five weeks in June and July.

- Providing school entry mathematics achievement data and the latest National Standards mathematics achievement data for participating students in your class whose caregivers agree to release this data.

- Being interviewed individually, lasting up to 45 minutes.

- Allowing about 15 minutes of class time, immediately after one of the observed lessons, for me to administer a confidential attitudinal survey to students with signed consent forms.

- Working with me to identify and invite three students, with a range of abilities, in your class that would be appropriate for me to interview for approximately 30 minutes.

- Assisting with the distribution of information sheets and consent forms to students and caregivers.

Information collected from these sources will be used to help me identify key factors that may be influencing students' mathematics achievement in your school. Video and audio recordings will only be seen and heard by myself and my supervisors. Achievement data will be used as part of the data analysis and will not be reported in any way that identifies individual teachers or students. If desired, any transcriptions from the lesson observations or the interview will be given back to you for an accuracy check and confirmation, before being used in the data analysis. 
If you agree to participate in this research you can:

- Withdraw yourself from this study before August 2015;

- Ask any questions about the research at any time during your participation;

- Be given access to the summary of findings when the study is completed.

To give or withhold consent please read, sign and return the attached consent form to me. Once you have agreed to this research taking place in your classroom, consent will be sought from students and their caregivers/parents. Only those students that give consent (by returning the consent form signed by both themselves and their caregivers) will be video recorded during the lesson observations. If you withdraw from the study, any data collected from you will not be used and will be destroyed. Any analysis of the data gathered will be done by myself.

This research has been approved by the Victoria University of Wellington Human Ethics Committee. All data collected for this research will be kept confidential, with access limited to myself and my supervisors. You and your students will not be identified by your real names and no data gathered will be in a way that allows the participants to be identified. Two years after the end of the research, all paper copies of the data will be destroyed, with audiotapes, videotapes and computer files wiped.

If you have any ethical concerns about the research please contact Associate Professor Susan Corbett, Convener of the Victoria University of Wellington Human Ethics Committee susan.corbett@vuw.ac.nz

The results of the research will be used to improve the teaching and learning of mathematics in New Zealand schools. A summary sheet of the results of this research will be provided to all participants who desire it.

If you have any further questions, please feel free to contact me on 044636892 or by email Elizabeth.Harrison@vuw.ac.nz or my supervisors:

Dr Michael Drake

Email: michael.drake@vuw.ac.nz

Phone: 044639668

Dr Sandi McCutcheon

Email: sandi.mccutcheon(avuw.ac.nz

Phone: 044639647

Yours faithfully

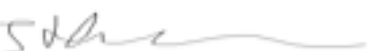

Jenni Harrison 


\section{Appendix L Example of an Ethics Consent Form}

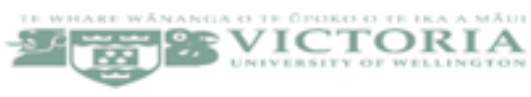

Consent Form for Teachers

\section{The Influence of Socioeconomic Status on Mathematics Achievement in Two New Zealand Primary \\ Schools}

- I understand that participation in this research is voluntary.

- I have been provided with adequate information about the nature and purpose of this research.

- I have understood the information about the research project and had the opportunity to ask questions and seek further information and clarification. My questions have been answered to my satisfaction.

- As part of this research, I agree to participating in 4 video recorded lessons, and taking part in an audio recorded individual interview.

- As part of this research, I agree to work with the researcher to collect ethics forms, to discuss with the researcher when interviews and surveys may disrupt the class the least, and discuss which students may be appropriate to interview.

- I understand that data gathered during this research will be used confidentially to write a thesis, and the results of the data analysis will be used for conferences, and in journal articles.

- I understand that all data collected for this research will be kept confidential, with access limited to the researcher and supervisors.

- I understand that the school, the teachers, the students, and their families will not be identified by their real names. No participant will be named and no data gathered will be reported in such a way that the participants can be identified.

- I understand that the data collected will be kept secure and access to the data will be limited to the researcher and supervisors. Two years after the end of the research, any data collected will be destroyed by shredding, or by deleting any video, audio, and computer files.

- I understand that, should I choose to participate, I have the right to withdraw from this research at any point before August 2015 by telling the researcher or thesis supervisor. No reason for withdrawal from the research needs to be given. If for any reason I decide to withdraw from the research, any data collected from or about me will be destroyed and not used in the project.

A summary sheet on the results of this research will be provided to me if I tick the box on the consent form (below).

I consent to being involved in this research study. Yes/No

Teacher's Name:

Teacher's Signature:

I would like written feedback on the outcomes of this research.

Email address to which the research findings should be sent.

Please keep this form and I will collect it. 
Appendix M Stage 5 Mathematics Poster (MoE, 2008a)

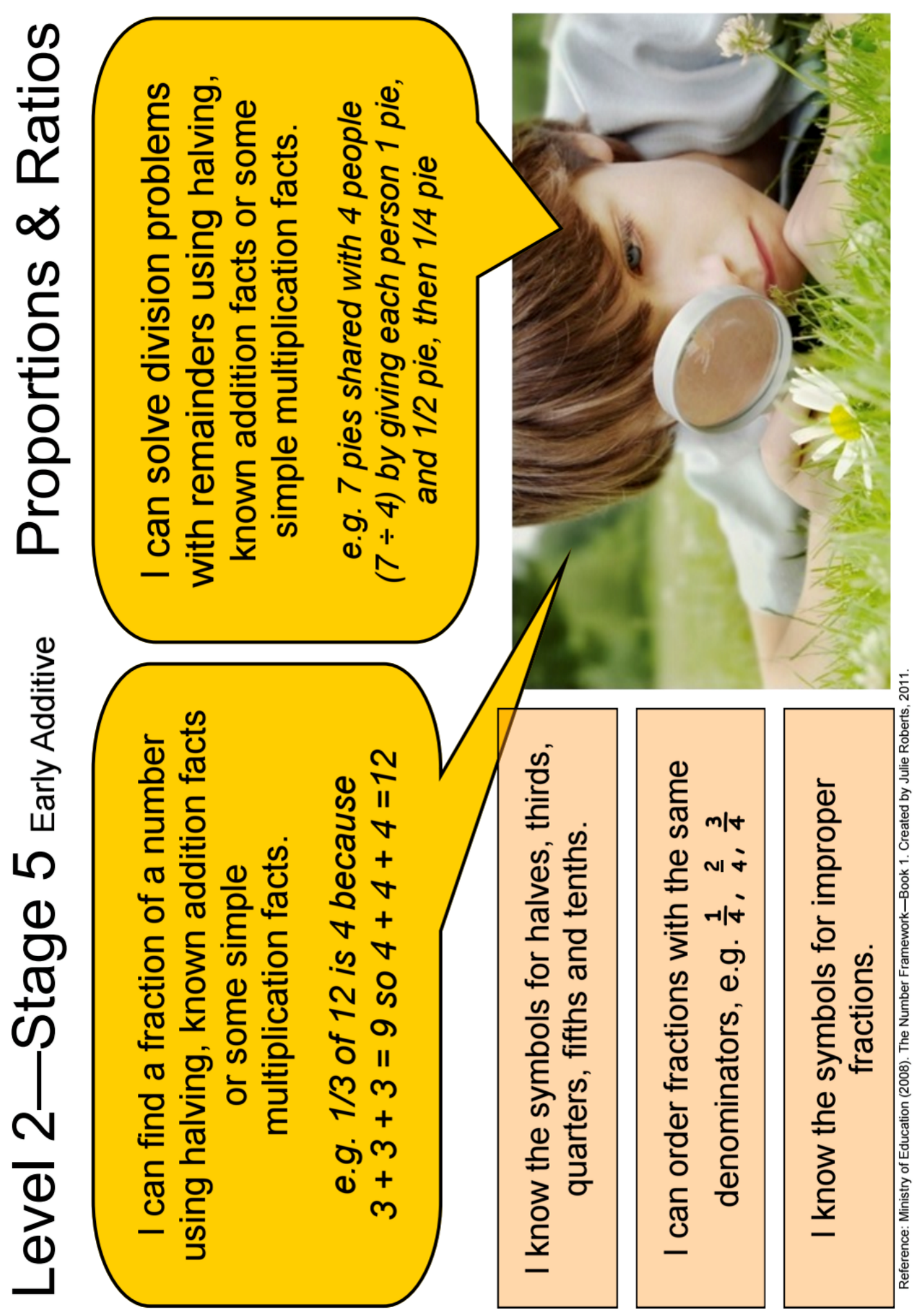




\section{Glossary of Acronyms}

\begin{tabular}{ll} 
Acronym & Full Terminology \\
\hline ALiM & Accelerated learning in mathematics \\
CMI & Complete mathematical interactions \\
DM & Digital mathematics \\
ERO & Educational Review Office \\
FIO & Figure It Out \\
GMI & Group mathematical interaction \\
ICT & Information communication technology \\
IMI & Intermittent mathematical interactions \\
IRF & Initiation-response-feedback \\
MG & Mathematics games \\
MoE & Ministry of Education \\
MST & Mathematics support teacher \\
NCEA & National Certificate of Educational Achievement \\
NEMP & National Education Monitoring Project \\
NMI & No mathematical interactions \\
NumPA & Numeracy Project assessment \\
NZCER & New Zealand Council for Educational Research \\
OM & Student oral mathematics \\
OTJ & Overall teacher judgement \\
OTQ & Oral teacher questions \\
PAT & Progressive achievement test \\
PLD & Professional learning and development \\
SES & Socioeconomic status \\
SMI & Single mathematical interactions \\
TIMSS & Trends in International Mathematics and Science Study \\
TWM & Teacher written mathematics \\
USA & United States of America \\
W & Worksheet \\
WM & Written mathematics \\
WTQ & Written teacher questions \\
ZPD & Zone of proximal development \\
& \\
\hline
\end{tabular}

